PNL-2749

UC-20e

\title{
Safety Analysis Report for the Neutron Multiplier Facility, 329 Building
}

H. G. Rieck

September 1978

Prepared for the U.S. Department of Energy under Contract EY-76-C-06-1830

\section{Pacific Northwest Laboratory}

Operated for the U.S. Department of Energy by

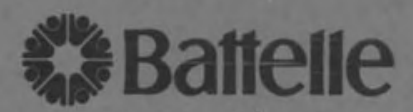


This report was prepared as an account of work sponsored by the United States Government. Neither the United States nor the Department of Energy, nor any of their employees, nor any of their contractors, subcontractors, or their employees, makes any warranty, express or implied, or assumes any legai liaoility or responsibility for the accuracy, completeness or usefulness of any iniormation, apparatus, product or process cisclosed, or represents that its use would not infringe privateiy owned rights.

The views, opinions and conclusions contained in this report are those of the contractor and do not necessariily represent those of the United Staies Government or the United States Department of Energy.

\author{
PACIFIC NORTHWEST LABORATORY \\ operated by \\ BATTELLE \\ for the \\ UNITED STATES DEPARTMENT OF ENERGY \\ Under Contract EY-75-C-106-1830
}

\author{
Printed in the United States of America \\ Available from \\ National Technical Information Service \\ United States Department of Commerce \\ 5235 Port Royal Road \\ Springfield, Virginia 22151
}

Price: Printed Copy 5

$\therefore$ Microfiche 53.00

\begin{tabular}{cr} 
*Pages & \multicolumn{1}{c}{$\begin{array}{c}\text { NTIS } \\
\text { Seiling Price }\end{array}$} \\
$001-025$ & $\$ 4.00$ \\
$026-050$ & $\$ 4.50$ \\
$051-075$ & $\$ 5.25$ \\
$076-100$ & $\$ 6.00$ \\
$101-125$ & $\$ 6.50$ \\
$126-150$ & $\$ 7.25$ \\
$151-175$ & $\$ 8.00$ \\
$176-200$ & $\$ 9.00$ \\
$201-225$ & $\$ 9.25$ \\
$226-250$ & $\$ 9.50$ \\
$251-275$ & $\$ 10.75$ \\
$276-300$ & $\$ 11.00$
\end{tabular}




\section{4}

SAFETY ANALYSIS REPORT

FOR THE NEUTRON MULTIPLIER

FACILITY, 329 BUILDING

H. G. Rieck

September 1978

Prepared for

the U.S. Department of Energy

Under Contract EY-76-C-06-1830

Pacific Northwest Laboratory

Richland, Washington 99352 
$\because$

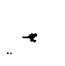

$\ldots$

. 


\section{CONTENTS}

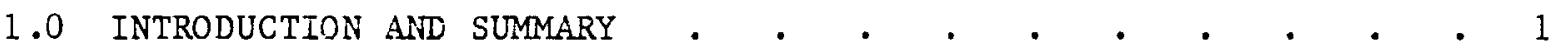

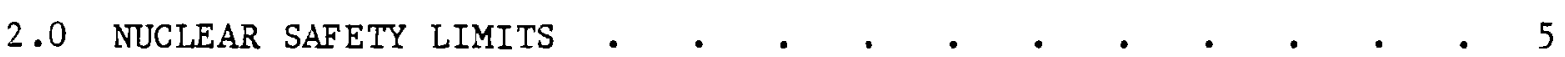

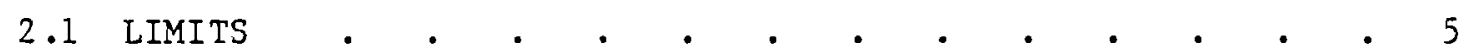

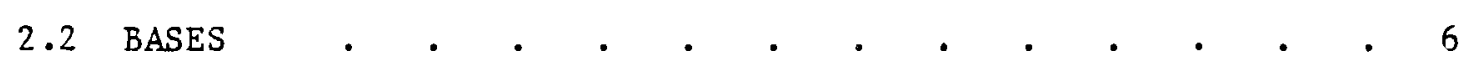

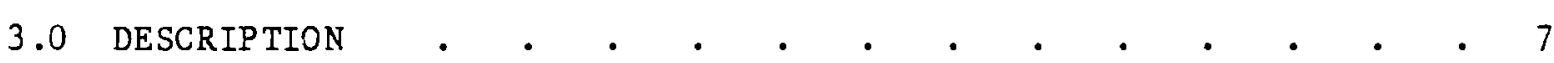

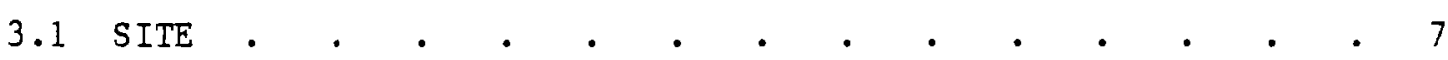

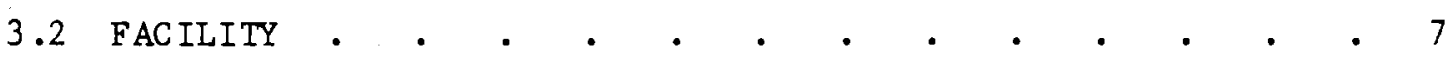

4.0 ORGANIZATION AND ADMINISTRATIVE CONTROLS . • • • • • • . . 23

4.1 ORGANIZATION AND ASSIGNMENT OF NUCLEAR SAFETY

RESPONSIBILITY $\quad \cdot \quad \cdot \quad \cdot \quad \cdot \quad \cdot \quad \cdot \quad \cdot \quad \cdot \quad \cdot \quad \cdot \quad \cdot 23$

4.2 ADMINISTRATIVE CONTROLS.$\quad \cdot \quad \cdot \quad \cdot \quad \cdot \quad \cdot \quad \cdot \quad \cdot \quad \cdot 23$

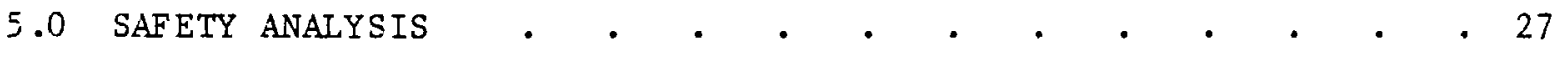

5.1 CRITICALITY CONTROL OF CONTINGENCIES • • • • • • • $\quad$ • 27

5.2 RADIATION POTENTIAL AND CONTROL • • • • • • • • 37

5.3 CONTINGENCIES FROM OPERATION • • • • • • • • • • 42

5.4 CONTINGENCIES FROM ENVIRONMENTAL CONDITIONS • • • . 44

5.5 CONSEQUENCES CF A CRITICALITY ACCIDENT . • • • • • . 48

5.6 PLANS FOR EVENTUAL SHUTDOWN AND DISPOSAL OF NMF • • . 66

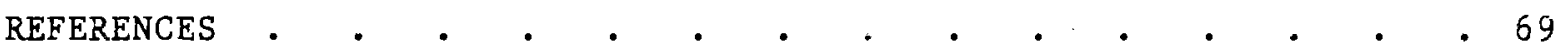

APPENDIX A - ${ }^{41}$ AT PRODUCTION . . . . . . . . . . . . . . A-1

APPENDIX B - CALCULATION OF ${ }^{24}$ Na ACTIVITY IN POOL WATER • • • • B-1

APPENDIX C - ESTIMATIOM OF HEAT OUTPUT FROM NMA • . . . . . .

APPENDIX D - CAICULATION OF REACTIVITY CLANGE IN NMA • • • • D-1

APPENDIX E - EVALUATION OF ${ }^{252}$ Cf SOURCE TRANSFER METHODS • • • E-1

APPENDIX F - RELEASE EXPOSURES FROM A NEUTRON MULTIPLIER FACILITY

CRITICALITY INCIDENT • • • • • • • • • F-1 

3-1 Neutron Multiplier Facility • • • • • • • • • • • 8

3-2 Floor Plan - Neutron Multiplier Facility . . . . . . . . . . 9

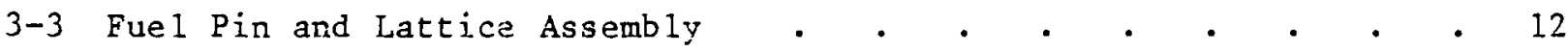

3-4 Lattice and Cover Plate Details . . . . . . . . . . . . 13

3-5 Neutron Multiplier System . • • • • • • . • • . . . 14

3-6 Support Structure and Plates . . . . . . . . . . . . . . 15

3-7 Fuel Rod (or fuel pin) . . . . . . . . . . . . . 17

3-8 ${ }^{252}$ Cf Sources and Holder . . . . . . . . . . . . . . 18

3-9 Source Drive Details . . . . . . . . . . . . . . . 19

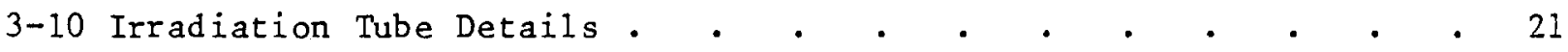

5-1 Temperature Change Effect on Neutron Multiplier Criticality . . 29

5-2 Center Void Effect on Neutron Multiplier Criticality . . . . . 30

5-3 Inhalation Dose Prediction, Rem - Noble Gases (assumes 100\% release of Noble Gases) Stable Meteorological Conditions . . . 51

5-4 Inhalation Dose Prediction, Rem - Noble Gases (assumes 100\% release of noble gases) Moderately Stable Meteorological Conditions

5-5 External Dose Prediction, Rem - Noble Gases (assumes 100\% release of Noble Gases) Stable Meteorological Conditions . . . 53

5-6 External Dose Prediction, Rem - Noble Gases (assumes 100\% release of Noble Gases) Moderately Stable Meteorological Conditions . . . . . . . . . . . . . . . . 54

5-7 Inhalation Dose Prediction, Rem - Soluble $\mathrm{I}_{2}$ (assumes $10 \%$
release of $\mathrm{I}_{2}$ ) Stable Meteorological Conditions . . . . . . 55

5-8 Inhalation Dose Prediction, Rem - Soluble $I_{2}$ (assumes $10 \%$ release of $\mathrm{I}_{2}$ ) Moderately Stable Meteorological Conditions . . 56

5-9 Inhalation Dose Prediction, Rem - Insoluble $\mathrm{I}_{2}$ (assumes $10 \%$
release of $\mathrm{I}_{2}$ ) Stable Meteorological Conditions) . . . . . 57

5-10 Inhalation Dose Prediction, Rem - Insoluble $I_{2}$ (assumes 10\% release of $\mathrm{I}_{2}$ ) Moderately Stable Meteorological Conditions • $\quad 58$

5-11 Inhalation Dose Prediction, Rem - Soluble Volatile Fission Products (assumes 1\% release of Volatile Fission Products) Stable Meteorological Conditions . . . . . . . . . . 59

5-12 Inhalation Dose Prediction, Rem - Soluble Volatile Fission Products (assumes $1 \%$ release of Volatile Fission Product) Moderately Stable Meteorological Conditions 
5-13 Inhalation Dose Prediction, Rem - Insoluble Volatile Fission Products (assumes 1\% release of Volatile Fission Products)

Stable Meteorological Conditions . . . . . . .

5-14 Inhalation Dose Prediction, Rem - Insoluble Volatile Fission

Products (assumes 1\% release of Volatile Fission Products)

Moderately Stable Meteorological Conditions . . . . . . 62

5-15 Total External Dose Prediction, Rem, Stable Meteorological Conditions

5-16 Total External Dose Prediction, Rem, Moderately Stable Meteorological Conditions.

D-7 Fuel Rod Loading Effect on Neutron Multiplication Factor, (k $k_{\text {ff }}$ ) D-7

E-1 Exposure Rate Estimate from a $20 \mathrm{mg}^{252}$ Cf Source Versus Distance E-1

\section{TABLES}

5-1 Effect of Material in Center Tube . . . . . . . . 32

5-2 Effect of Outside Lattice Void Tubes and Material . . . . . 32

5-3 Effect of Operating Changes on $k_{\text {eff }} \quad \cdot \quad \cdot \quad \cdot \quad \cdot \quad \cdot \quad \cdot \quad \cdot 33$

5-4 Energy Release from Prompt Critical Excursions for Various Systems for Various Systems • • . . . . . 50 
SAFETY ANALYSIS REPORT FOR THE NEUTRON

MULTIPLIER FACILITY, 329 EUILDING

H. G. Rieck

Battelle-Northwest

August, 1978

\subsection{INTRODUCTION AND SUMMARY}

Neutron multiplication is a process wherain the flux of a neutron source such as ${ }^{252} \mathrm{Cf}$ is enhanced by fission reactions that occur in a subcritical assemblage of fissile material. The multiplication factor of the device depends upon the consequences of neutron reactions with matter and is independent of the initial number of neutrons present. Safe utilization of such a device demands that the fissile material assemblage be maintained in a subcritical state throughout all normal and credibly abnormal conditions. Examples of things that can alter the multiplication factor (and degree of subcriticality) are temperature fluctuations, changes in moderator material such as voiding or composition, addition of fissile materials, and change in assembly configuration.

The Neutron Multiplier Facility (NMF) utilizes a multiplier- ${ }^{252} \mathrm{Cf}$ assembly to produce neutrons for activation analysis of organic and inorganic environmental samples and for on-line mass spectrometry analysis of fission products which diffuse from a stationary fissile target ( $\leqq 4 \mathrm{~g}$ fissile material) located in the Neutron Multiplier. The NMF annex to the 329 Building provides close proximity to related counting equipment, and delay between sample irradiation and counting is minimized.

The Neutron Multiplier (NM) is a subcritical assembly of enriched uranium (93.2 wt\% ${ }^{235} \mathrm{U}$ )-aluminum fuel rods having a neutron multiplication factor $\left(k_{e f f}\right) \leq 0.993$. A thermal neutron flux of about $10^{10} \mathrm{n} / \mathrm{cm}^{2} \mathrm{~cm}-\mathrm{sec}$ is 
produced from a $100 \mathrm{mg}{ }^{252} \mathrm{Cf}$ source. As a result of the following design features and operational procedures, the $N M$ is maintained in a subcritical state.

- The fuel rod arrangement was designed from experimental measurements to optimize $k_{\text {eff }}$ such that the assembly will remain subcritical under abnormal temperature fluctuations or water density changes (flooding or voiding).

- The NM is located at the bottom of a 20-ft deep pool of water. The water limits physical access to the NM and provides necessary radiation shielding.

- Physical constraints prevent unauthorized rearrangement of the fuel rods. The primary constraint is an aluminum cover plate fitted over the top of the lattice plate, securing the fuel rods in place. This cover plate is attached to the holding plate by locking nuts that can only be removed by a special tool made for this purpose. The tool will be kept and controlled by the Manager, Safety and Nuclear Materials Management.

- The maximum amount of fissile material allowed in the facility in excess of the NM fuel loading is $4 \mathrm{~g}$ in the form of irradiation samples. Extra fuel rods for the NM shall be stored in the 303-C fissionable material storage facility under the control of Safety and Nuclear Materials Management pesonnel.

- Irradiation samples that may cause an increase in $k_{\text {eff }}$ of the NM wil1 be regulated by approved Criticality Safety Specifications.

- Physical security of the facility will be maintained by roof and door penetration and motion detectors that alarm at the 300 Area patrol headquarters. The steel grating which covers the top of the NM pool is equipped with an intrusion alarm that also signals at the patrol headquarters.

- Initial fuel loading and any subsequent modification to the fuel loading will be regulated by a Criticality Safety Specification. Fuel loadings and modifications shall be conducted under the direct supervision of the Manager, Critical Mass Laboratory, or his authorized delegate. 
- Any maintenance on the TM assembly shall be reviewed and approved by the Manager, Safety and Nuclear Materials Management. Maintenance requiring rearrangement of the fuel loading shall be conducted under the direct supervision of the Manager, Critical Mass Laboratory, or his authorized delegate.

- Operations of the facility shall be limited to personnel qualified to handle fissionable material in the NM facility. Qualification requirements shall be in accordance with the training requirements given in Procedure No. 7, Criticality Safety Procedures, BNWL-MA-25.

A high degree of radiation safety is maintained by the following design features and administrative controls:

- Shielding by the pool water and other external shields or barriers is adequate for personnel to remain in accessible pool room areas during NM operation.

- Physical restrictions or external shielding are used to limit personnel exposure when voided center tube experiments are in progress.

- The fuel rods and ${ }^{252} \mathrm{Cf}$ sources are adequately encapsulated to prevent contamination spread.

- All irradiated sampie and ${ }^{252}$ Cf source handling is performed under an approved Radiation Work Procedure.

It is concluded that the NMF will operate without creating an unacceptable risk to the public or to the operating personnel. 


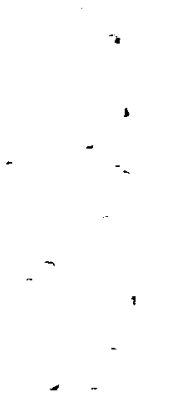




\subsection{NUCLEAR SAFETY LIMITS}

The Nuclear Safety Limits stated in this section are binding. Material presented elsewhere is intended to be descriptive of, or justirication for, the Nuclear Safety Limits. Other restrictions given in this report are examples of those set forth in Criticality Safety Specifications and Radiation Work Procedures, presented for description purposes, and subject to change within the boundaries of the limits stated here. Any change in operations or equipment that introduces an unreviewed safety question, or significantly increases the probability or consequences of an accident discussed herein, shall require an addendum to the Safety Analysis Report.

The operation of the $\mathrm{NM}$ and handling of fissionable material in the NM facility shall be controlled by Criticality Safety Specifications. Criticality Safety Specifications covering the operation, fuel loadings and modifications, and fuel handling in the NM facility, shall be revieved and approved by the Manager, Critical Mass Laboratory. This review and approval replaces that normally performed by the Criticality Safaty and Shielding Analysis Section.

\subsection{IIMITS}

1) Fissionable material within the NM facility is limited to the NM Fuel loading, sealed sources to drive the NM, and a maximum of $4 \mathrm{~g}$ fissile material in excess of the fuel loading in the form of irradiation samples.

2) The NM shall be limited to a maximum $k_{\text {eff }}$ of 0.993 .

3) The amount of beryllium shall be limited to $5 \mathrm{~g}$ and $D_{2} 0$ shall not be permitted within the facility.

4) The total amount of carbon (in the form of organics or otherwise) loaded into the NM shall be limited to $715 \mathrm{~g}$.

5) Fuel loadings and modifications shall be conducted under the direct supervision of the Manager, Critical Mass Laboratory, or his authorized de legate.

6) The total amount of ${ }^{252} \mathrm{Cf}$ in the driver source shall be linited to 100 miligrams. 


\subsection{BASES}

1) Limit 非 1 limits the amount of fissionable material in the NMF to that determined experimentaliy to cause no greater hazard than that assumed for the Final Safety Analysis Report.

2) Limit $\# 2$ is the maximum $k_{\text {eff }}$ of the fuel loading determined experimentally under credible conditions of samples, irradiation tubes and moderator-reflector conditions.

3) Beryllium and $\mathrm{D}_{2} \mathrm{O}$ are more effective moderators than water or carbon.

4) When carbon is loaded into irradiation tubes, the center tube has the maximum effect on $k_{\text {eff }}$ where $715 \mathrm{~g}$ increases $k_{\text {eff }} 0.0024$.

5) Since the mode of operation for the $N M$ is slightly subcritical, any fuel loading or modification requires the direct supervision of an individual highly knowledgeable and experienced with critical and near critical systems.

6) Radiation potentials evaluated for this SAR are based upon 100 milligrams of ${ }^{252} \mathrm{Cf}$ as the driver source 


\subsection{DESCRIPTION}

\section{$3.1 \underline{\text { SITE }}$}

The NM is housed in an annex attached to the 329 Building near the southeast corner. The 329 Building is located in the 300 Area of the Hanford Reservation. A 300 Area site description is given in BNWL-CC-1693. A view of the facility is shown in Figure $3-1$.

\subsection{FACILITY}

The NMF is a 26-ft long $x$ 20-ft wide $x$ 16-ft high one-room structure attached to the 329 Building. The $N M$ is installed near the bottom of a 5-ft diameter $x$ 20-ft deep water filled pool which is located in the southeast corner of the floor area. The $N M$ support equipment includes a neutron source drive assembly, a water treatment system (circulating pump, filter, ion exchange, and auxiliary controls), an electric hoist, a standard and laminar flow hood, and standard laboratory benches. Supporting services in the facility include air conditioning, ventilation system with HEPA filter, heat, light, sanitary water, electric power, penetration alarms, and fire protection. A floor plan is shown in Figure 3-2.

\subsubsection{Building}

The NMF is constructed of insulated metal siding that provides a dustproof interior. Equipment access to the room is provided from the loading dock through a 12-ft high double door at the southeast corner of the roomi. Main access to the NMF is through an entry door from the 329 Building at the southwest corner. A 4-ft square hatch is located in the ceiling over the pool to facilitate transfer of the ${ }^{252} \mathrm{Cf}$ sources into and from the facility. dIl outside accesses are weather-stripped to provide adequate dust proofing. Ventilation is a "once-through" system with a single stage HEPA filter in the exhaust. Security of the room is provided by penetration and motion detectors with alarms at 300 Area patrol headquarters. The doors, roof hatch and poo $I$ cover are equipped with penetration switches. Two motion detectcrs provide surveillance over $75 \%$ of the room volume. 


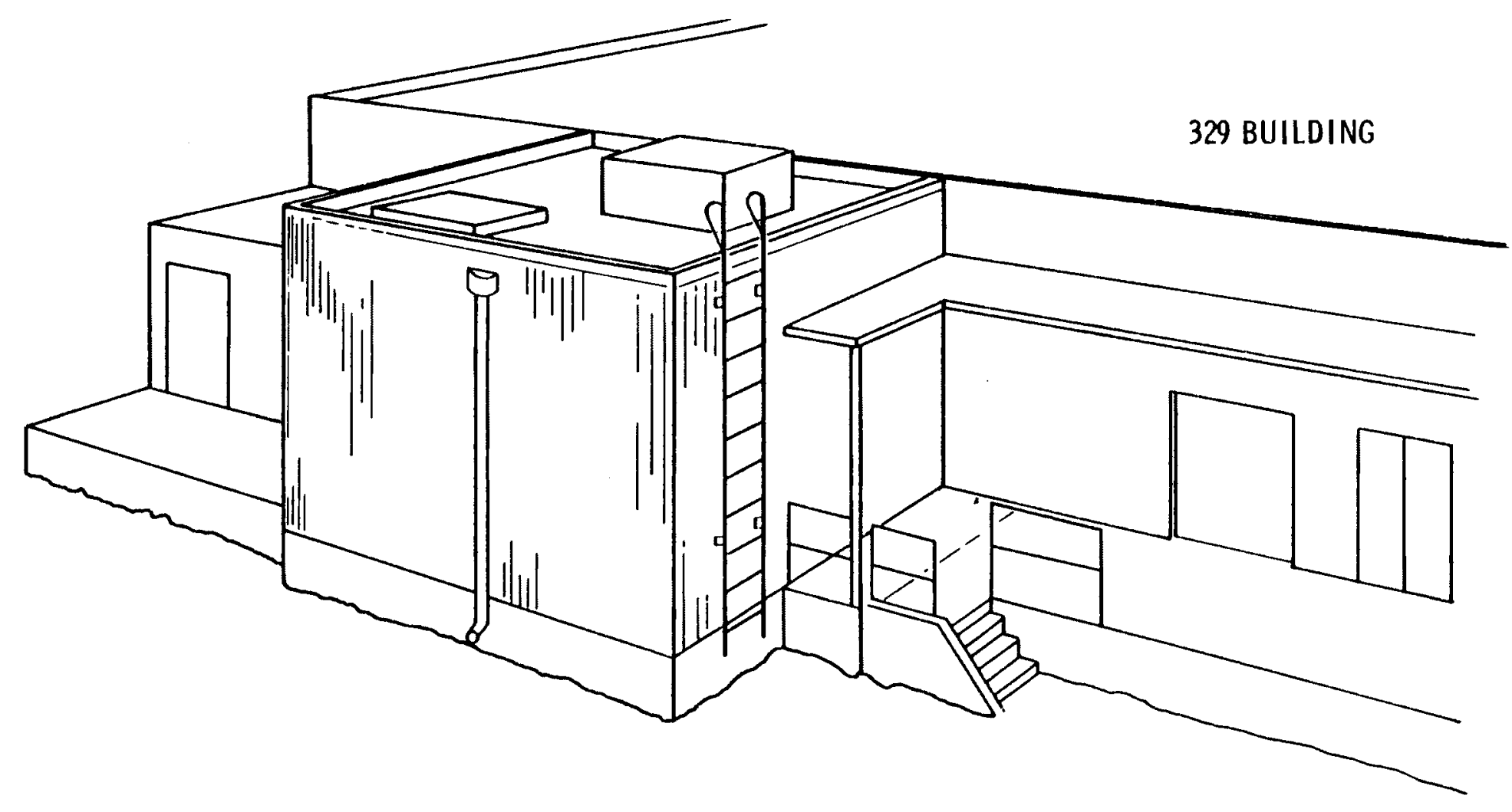

FIGURE 3-1. Neutron Multiplier Facility 


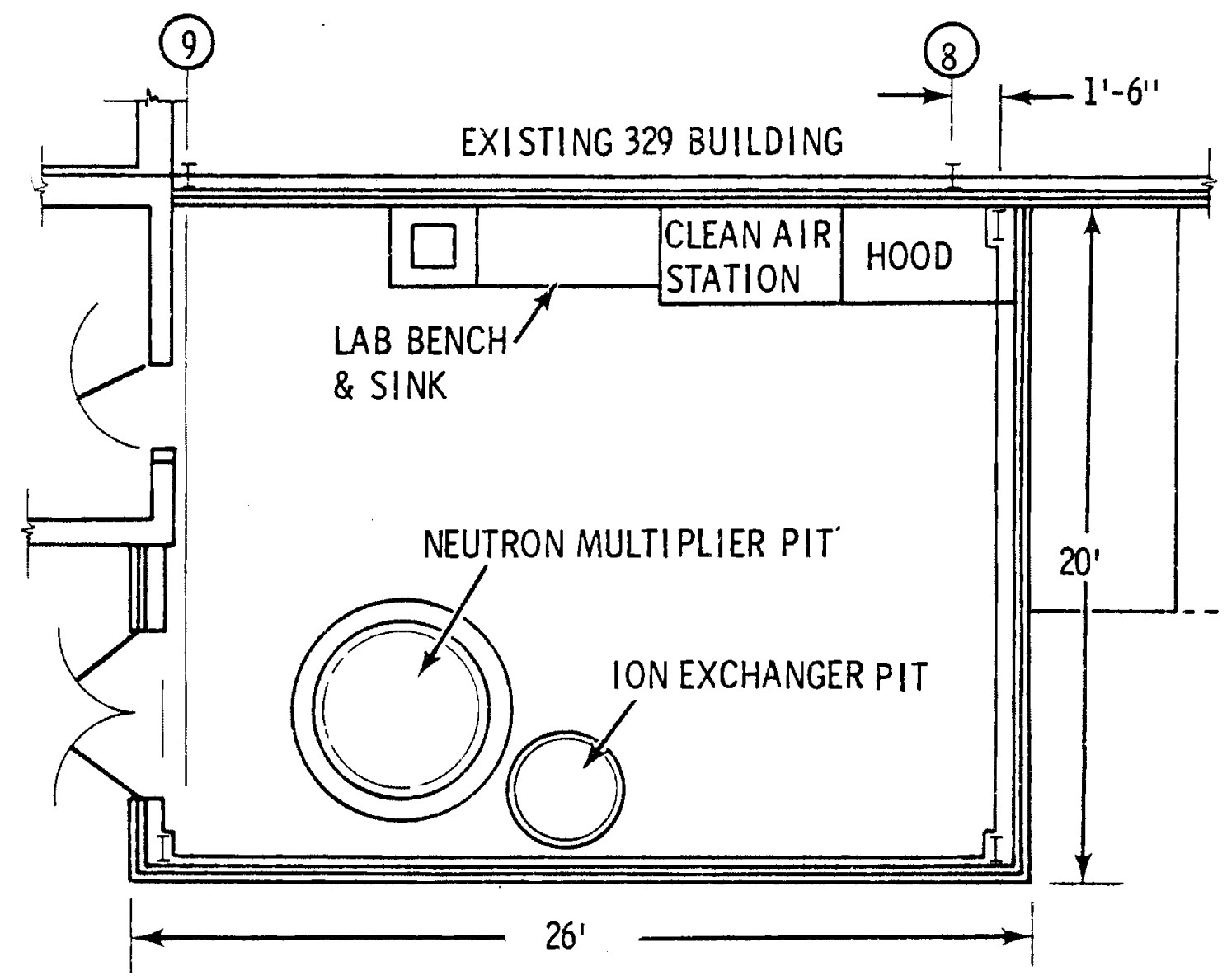

FIGURE 3-2. Floor Plan--Neutron Multiplier Facility 


\section{2 .2 Pool}

The wall of the pool is a 9-in. thick layer of 300 psi reinforced concrete poured inside a 6-1/2 ft diameter circular liner plate. The liner plate is attached to the surrounding soil column with a grouting procedure. The construction provides resistance to earthquake motions with peak horizontal accelerations of $8.05 \mathrm{ft} / \mathrm{sec}^{2}$, and simultaneous peak vertical accelerations of $5.37 \mathrm{ft} / \mathrm{sec}^{2}$. A 6-in. high curb around the top of the pool will prevent entry of floor surface water into the pool. The interior surfaces of the pool are coated with plastic sealer to prevent leaching of concrete into the pool water. A four-section 500 psf steel grating covers the top of the pool and is equipped with a penetration switch.

\section{2 .3 Pool Water System}

A $50 \mathrm{gpm}$ pump circulates the water from the pool through a particulate filter and an ion exchange resin bed. Inlet to the pump is 18 in. below the pool surface and the discharge is 9 in. above the bottom of the pool. Flow, temperature, and conductivity sensors monitor the system operation and water quality. No drain connections are provided in the pool construction; therefore, the pool water is isolated from all sewer systems. Water cannot be drained from the pool except through an accidental breach of the pool wall or by use of a portable pumping system. Water level in the pool is maintained by a manually operated valve in series with a float valve. When the manual valve is periodically opened, the float valve controls the level of the pool water.

\subsubsection{Neutron Multiplier System}

The system is a water shielded annular assembly of fuel rods, a ${ }^{252} \mathrm{Cf}$ source(s), and an array of sample irradiation tubes. The fuel assembly is rigidly supported on a structure which is attached to the pool floor. The ${ }^{252} \mathrm{Cf}$ source is attached to a source drive arm located below the fuel assembly. The NM is turned "on" by remotely raising the source into the fuel assembly, where neutrons from ${ }^{252} \mathrm{Cf}$ interact with the fuel. A neutron proportional counter filled with ${ }^{3} \mathrm{He}$ is located in a polyvinyl chloride thimble on the side of the pool and monitors the proper operation of the NMA. The multiplier is turned "off" by lowering the source out of the fuel assembly. Irradiations may be done in one 2-in. diameter aluminum tube in the 
center, four 2-in. diameter, or two 4-in. diameter aluminum tubes located on the outer periphery of the fuel region.

\subsubsection{Fuel Assembly}

The fuel region is the shape of an annular hexagon 9-3/4 in. across the external sides, 3-3/4 in. across the internal sides, and $23 \mathrm{in}$. long. The ${ }^{235} \mathrm{U}(93.2 w t \%)$ fuel rods are held in fixed configuration by top and bottom 1attice plates. Holes are drilled in a hexagonal pattern of 0.600 in. centers through the top plate and partially through the bottom plate to hold the fuel rods in the fixed configuration. The holes in the top plate are 0.5 in. diameter to provide for an aluminum sleeve around the fuel rod. This sleeve will allow easy removal of the fuel rods in event that corrosion occurs. The two lattice plates are held 22-5/8 in. apart by three aluminum angle structural members in a welded construction. Eyes in the top end of the structural members provide means for raising or lowering the loaded ruel assembly. An aluminum cover plate fits over the top lattice plate and holds the fuel rods in place. The lattice assembly is shown in Figures $3-3$ and 3-4.

The lattice assembly with fuel rods is positioned in a support structure which is attached to the floor of the pool. A bottom or mounting plate is bolted to a tubular aluminum framework which is bolted to the pool floor. The upper or holding plate is attached to the bottom plate with three tie rods which are attached by locknuts on the bottom plate and by specially designed locknuts on the top plate. The fuel-lattice assembly is secured in position by three element retainers and locking nuts attached to the holding plate. The locknuts can only be removed by a special tool for this purpose. The source drive and irradiation tubes are attached to the mounting and/or holding plate with bolts and suitable brackets. The holding and mounting plates are shown in Figures $3-5$ and 3-6.

The fuel rods are $93.2 \%{ }^{235} \mathrm{U}$ enriched uranium-aluminum alloy ( 28 wt\% U) canned in 0.040-in. wall 1100 aluminum seamless tubing with welded top and bottom closure. The fuel element is $0.3 \mathrm{in}$. diameter and $20.6 \mathrm{in.}$ 1ong. Each rod contains 22.224 grams of ${ }^{235} \mathrm{U}$. A drawing of a fuel rod is shown in Figure $3-i$. The neat generated by the fission reaction in the NMA is estimated to be $103 \mathrm{~W}$. This calculation is shown in Appendix C. 


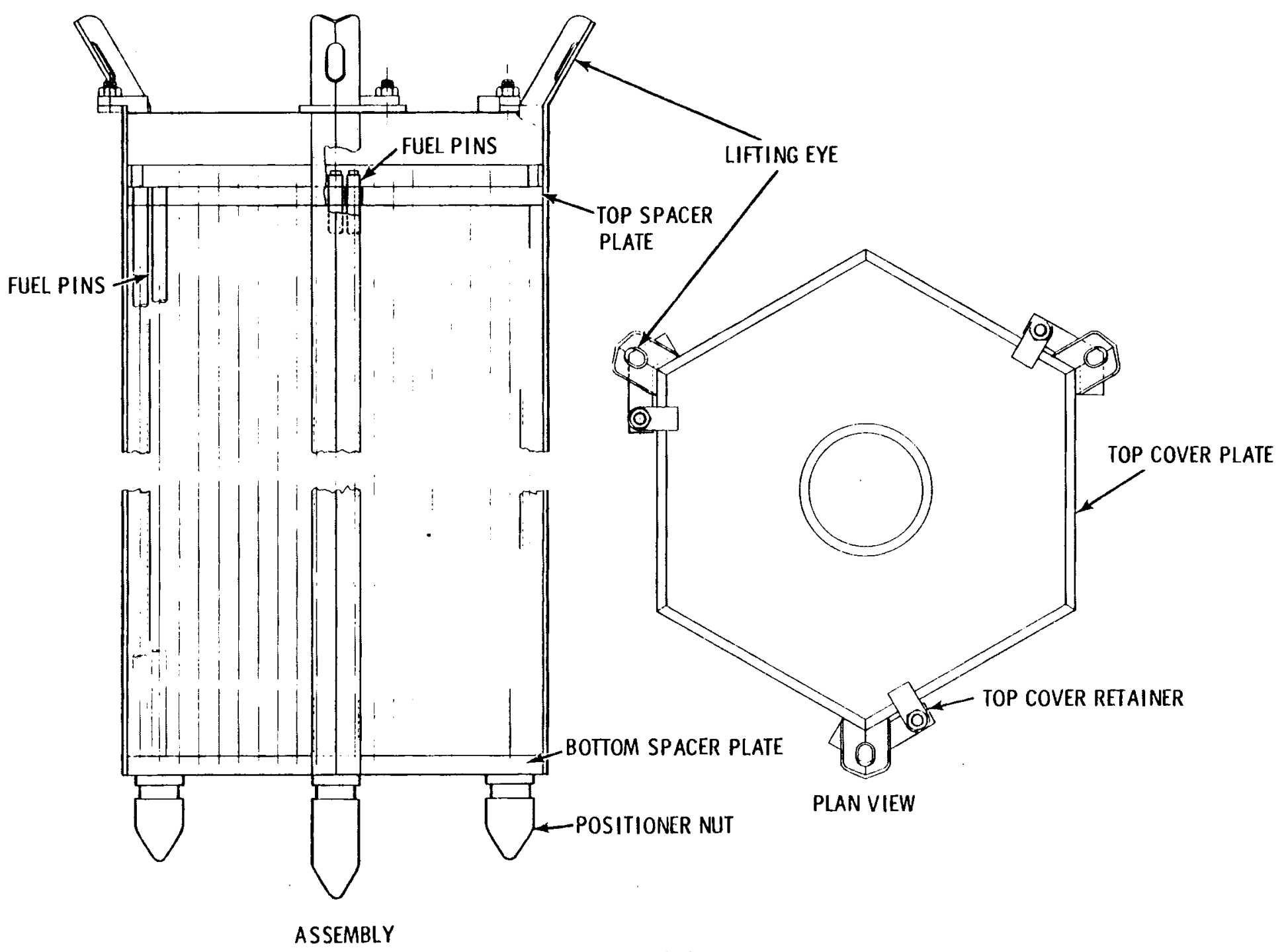

FIGURE 3-3. Fue1 Pin Lattice Assembly 

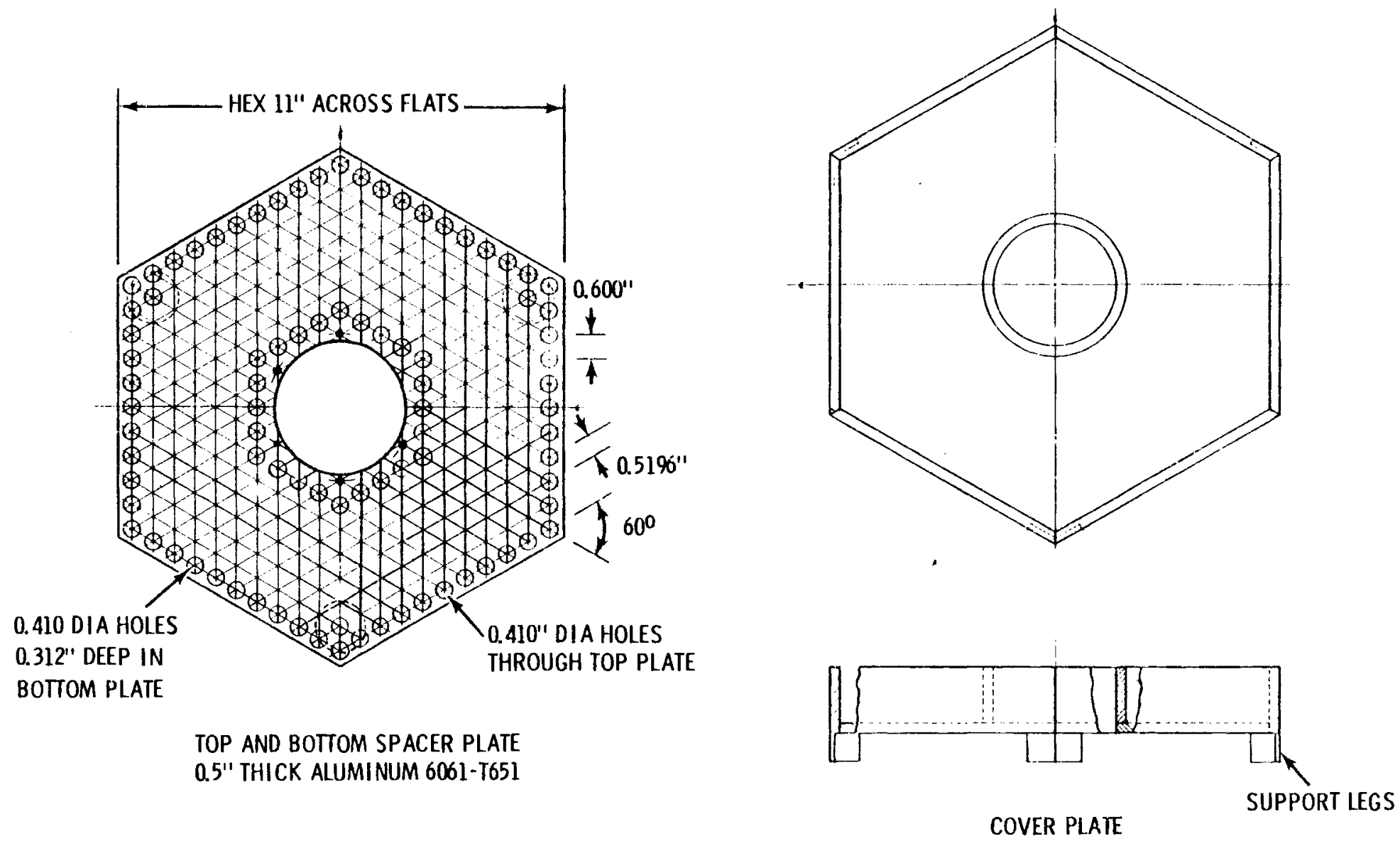

FIGURE 3-4. Lattice and Cover Plate Details 


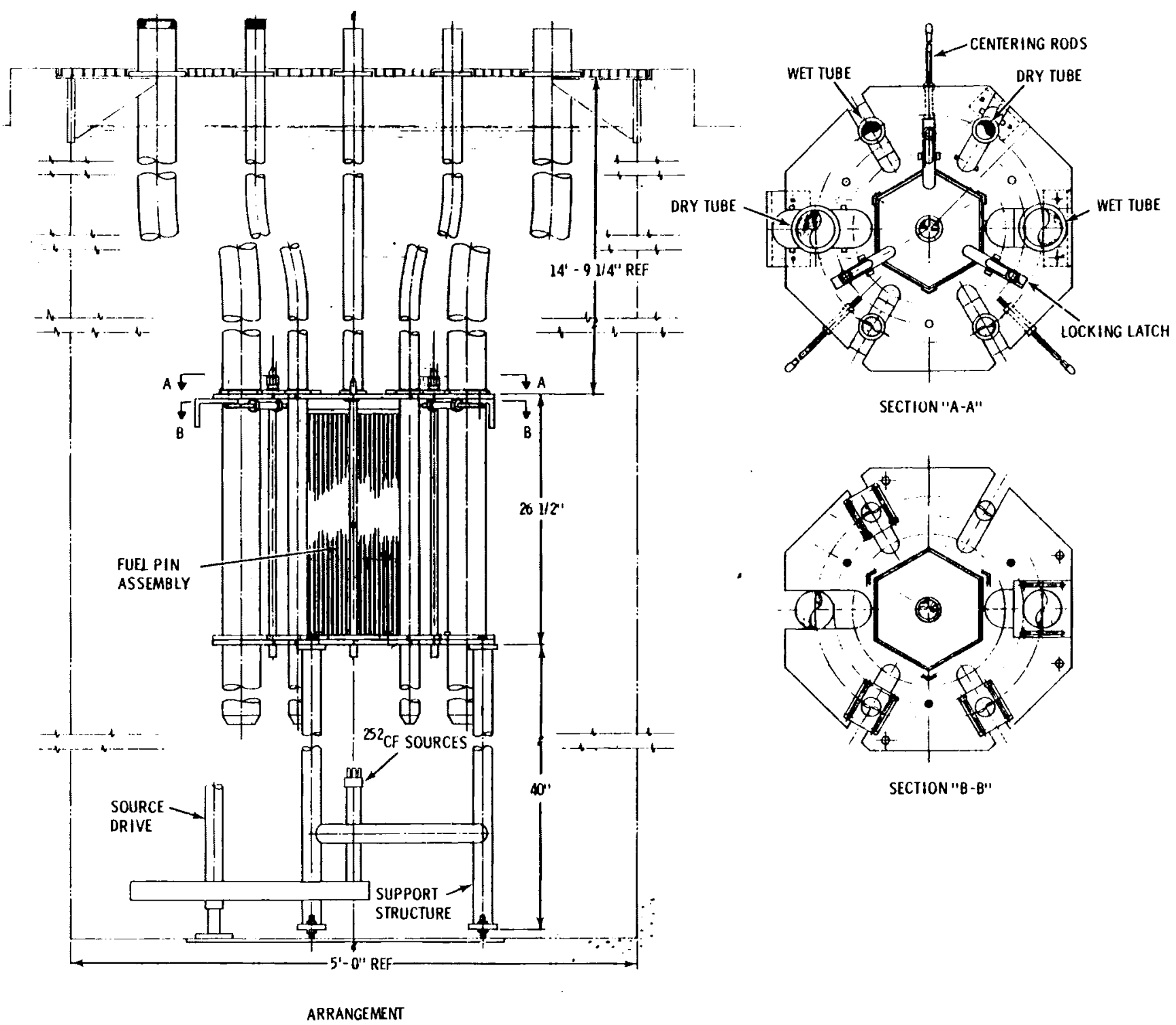

FIGURE 3-5. Neutron Multiplier System 


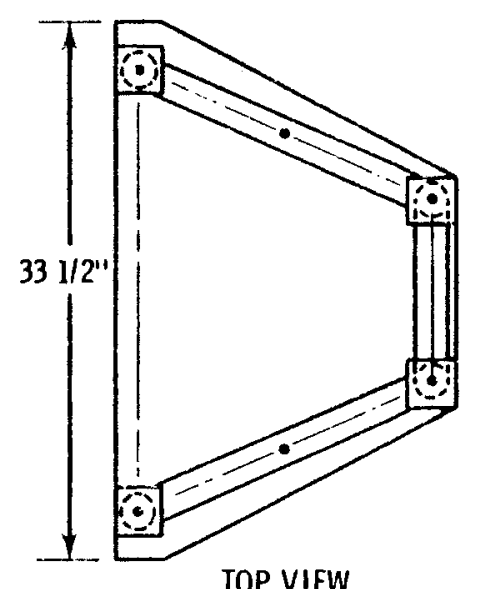

TOP VIEW

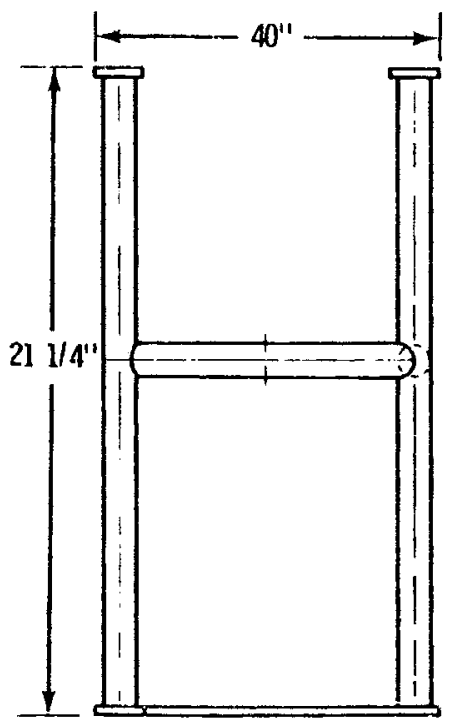

SUPPORT FRAME

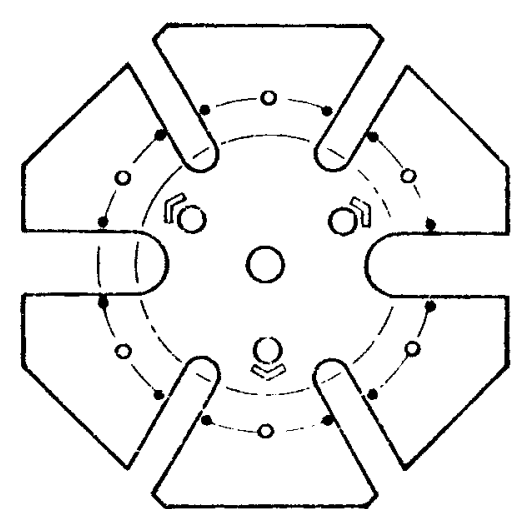

MOUNTING PIATE

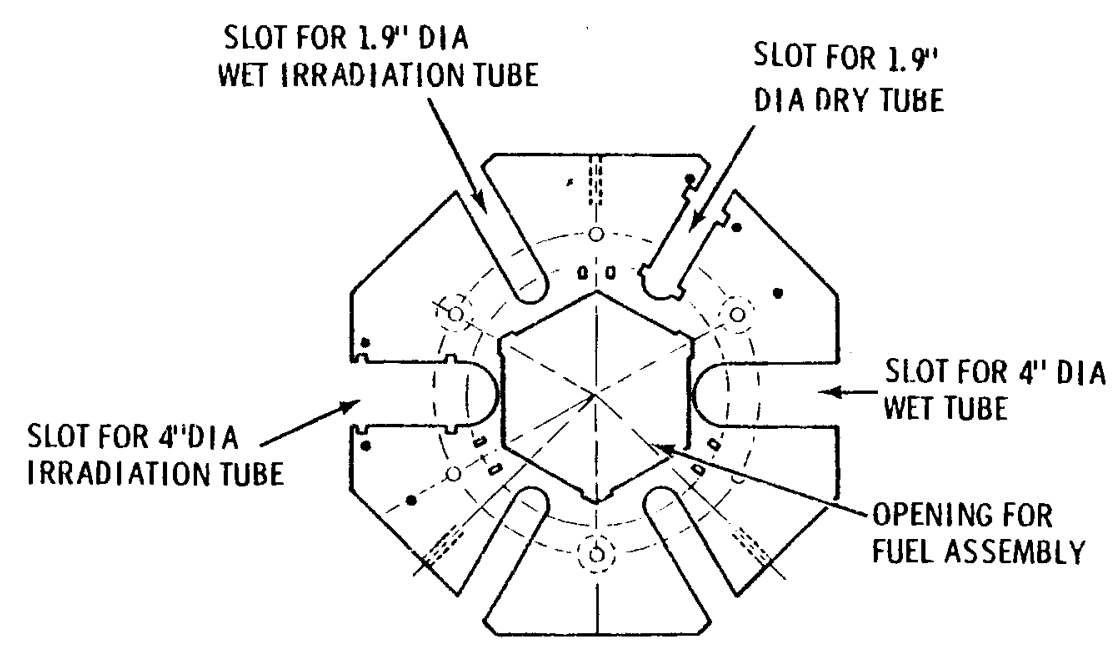

HOL.DING PLATE

FIGURE 3-6. Support Structure and Plates 


\section{$3.2 .4 .2 \quad{ }^{252}$ Cf Source}

The neutron sources which "activate" the neutron multiplier are $100 \mathrm{mg}$ of ${ }^{252} \mathrm{Cf}$. Neutrons are produced by spontaneous fission. Six sources (100 mg total or less) are attached to the holder which is installed in the source drive arm. The sources are doubly encapsulated in $304 \mathrm{~L}$ stainless steel containers. The total weight of steel is $0.438 \mathrm{lb}$. The total source yield is $2.34 \times 10^{11}$ neutrons/sec, and the heat output is $3.9 \mathrm{~W}$. The ${ }^{252} \mathrm{Cf}$ source holder is shown in Figure 3-8.

The ${ }^{252} \mathrm{Cf}$ is moved into and out of the fuel region by a source positioning mechanism. An electric motor-driven screw assembly above the pool surface is attached to a long rod which extends down into the pool below the fuel assembly. An arm extends horizontally from the bottom of the rod to the center line of the fuel assembly; then vertically 15-in. The sources are attached to the vertical section of the arm and are held on the centerline of the fuel assembly by a mechanical guide. The source drive is shown in Figure 3-9.

Limit switches on the screw assembly stop the source travel at the lower or "off" location and at the upper or "on" location. A clutch in the motor drive provides for slippage in case resistance to movement is encountered. Speed of travel is $10 \mathrm{in./min.}$

Source loading is done by lowering the positioner to the pool floor and manually rotating the arm from under the fuel assembly. Bypass of the lower limit switch is required. The source drive can be manually operated with a hand wheel.

\subsubsection{Irradiation Tubes}

An aluminum tube 2-in. outside diameter and $0.035-i n$. wall thickness extends from 5 in. above the steel grating down the fuel assembly center line to the bottom of the fuel assembly. The tube bottom is open and a perforated aluminum disk is welded in place about $1 / 4 \mathrm{in}$. above the horizontal center line of the fuel region. This allows placement of the source in the position of maximum effectiveness. 


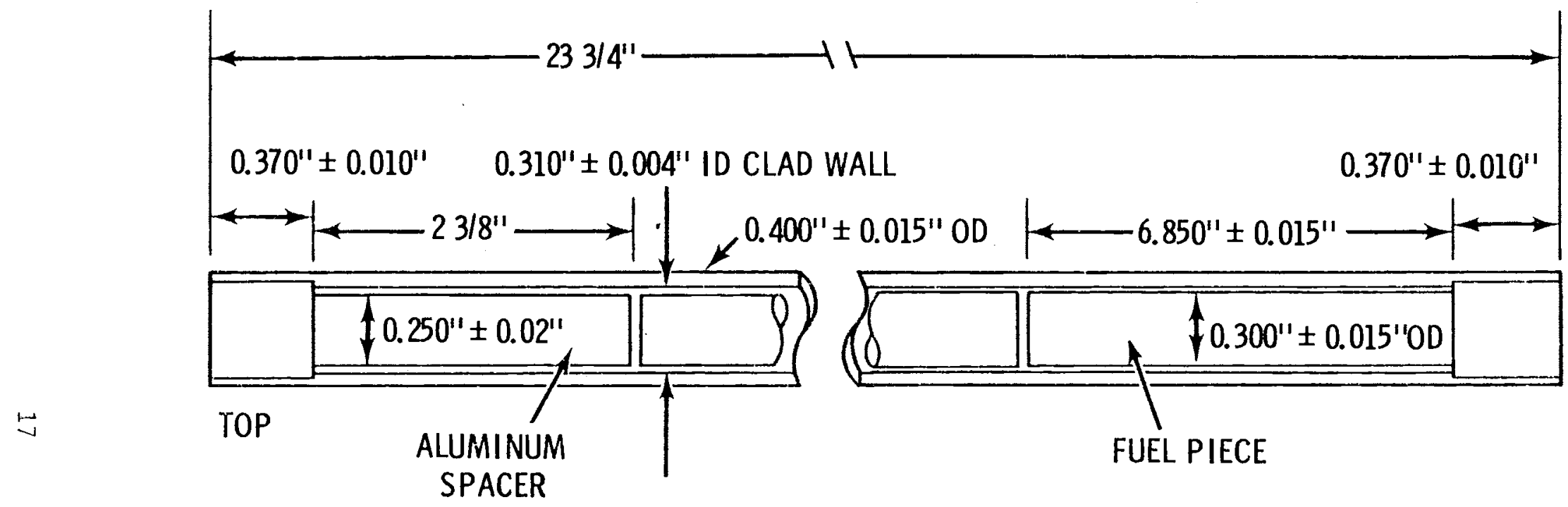

CLAD MATERIAL: ALUMINUM, 1100

LOAD MATERIAL: $28 \mathrm{w} / \mathrm{O}$ U IN AI, $93.2 \mathrm{w/0} \mathrm{o}^{235} \mathrm{U}$ IN U, $1 \mathrm{gm} \mathrm{U}(93.2) / \mathrm{cm}^{3}$. 3 FUEL PIECES PER ROD. $22.224 \mathrm{gm}^{235} \mathrm{U}$ PER ROD 

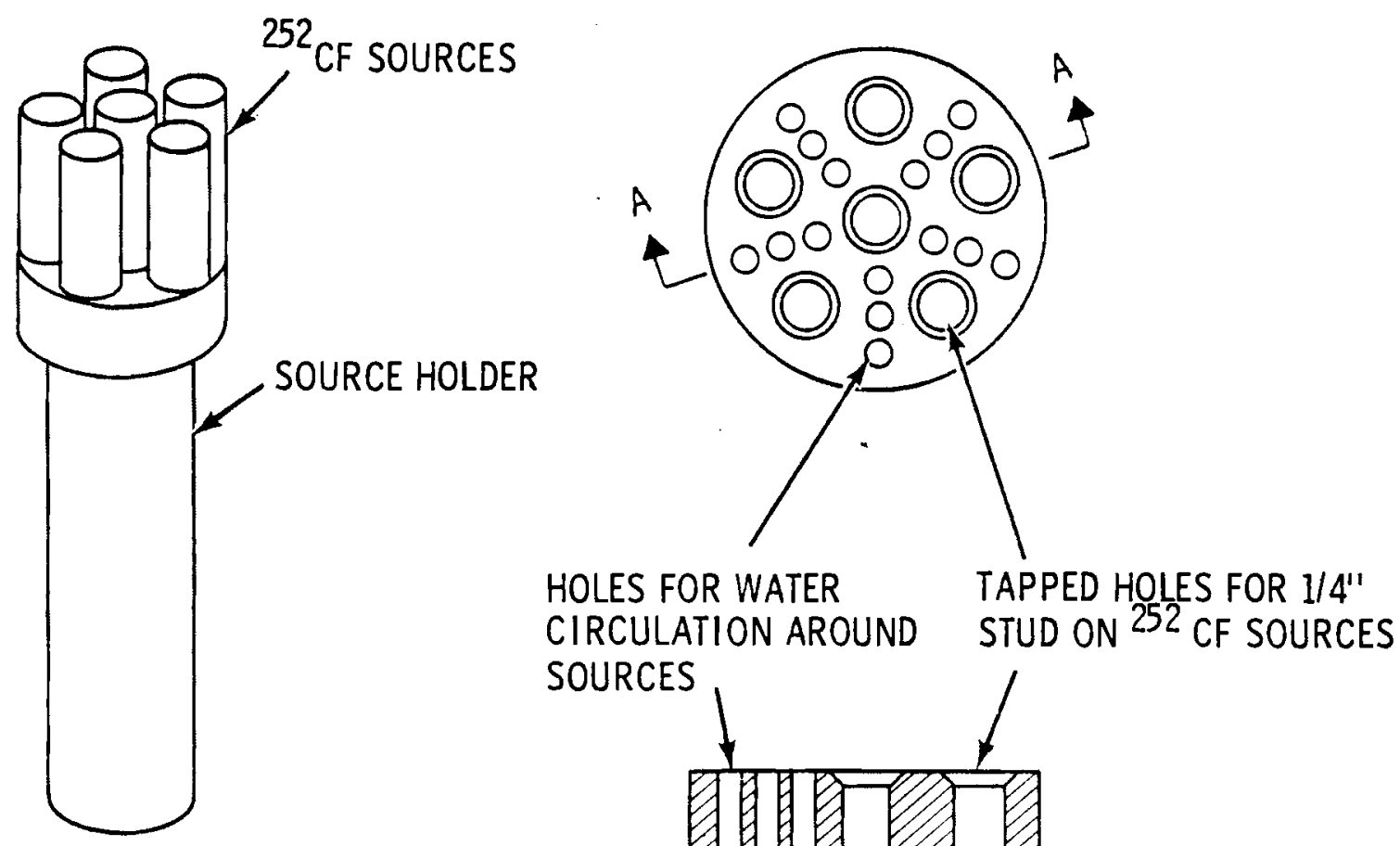
SOURCES

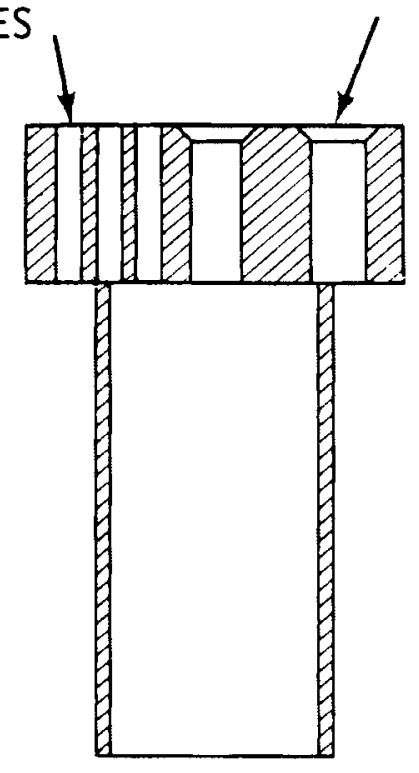

\section{SECTION A-A}

FIGURE 3-8. ${ }^{252} \mathrm{Cf}$ Sources and Holder 


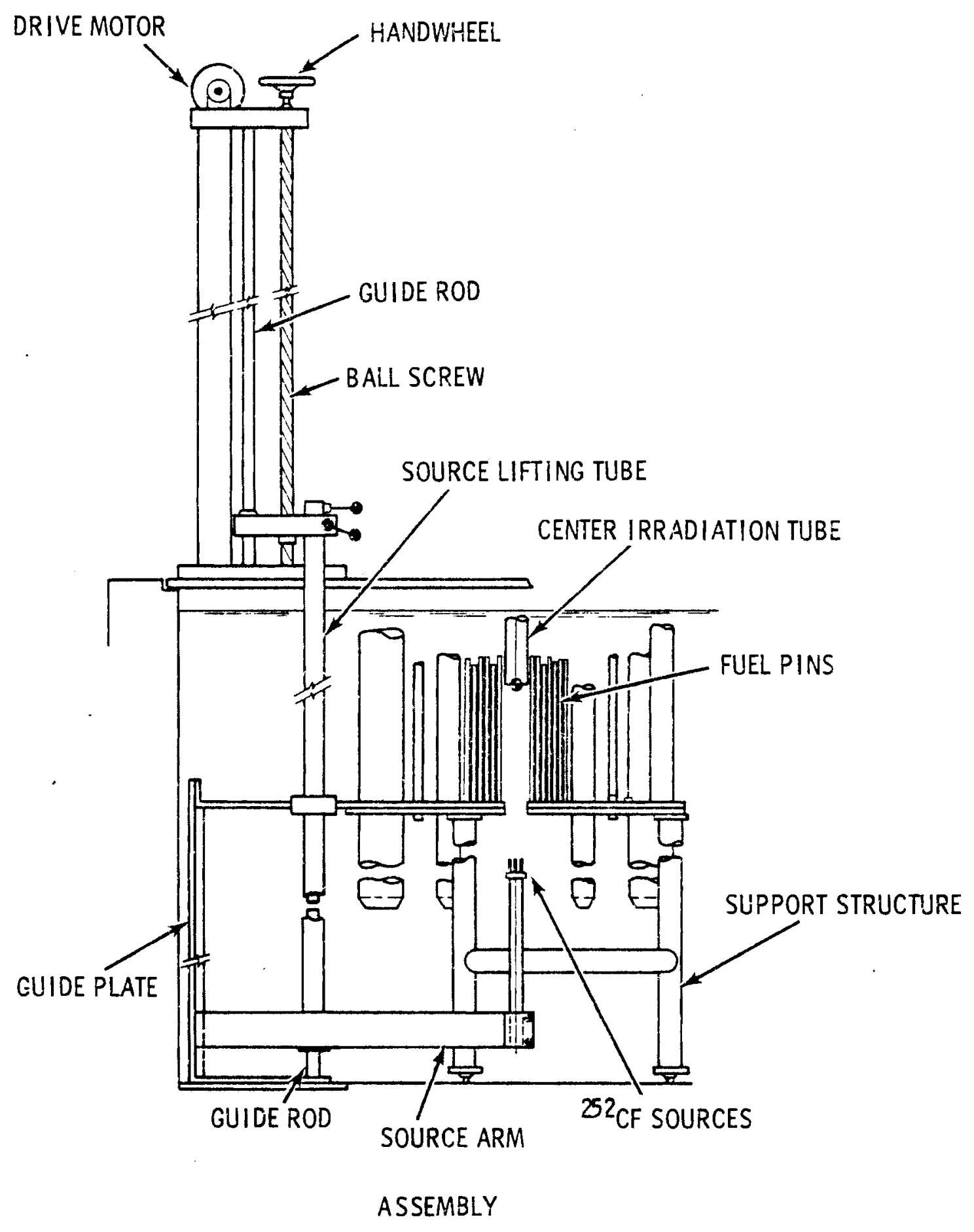

FIGURE 3-9. Source Drive Details 
Two dry tubes are located around the periphery of the fuel assembly. One tube is 2-in. outside diameter and the other is 4-in. outside diameter. Wall thickness is $0.035 \mathrm{in}$. These tubes have bends that provide a 9 in. offset between top and bottom to limit radiation beams. Lead shot in the bottom of the dry tubes provides neutral buoyancy. Slots in the top of the holding plate are provided so that the dry tubes can be moved away from the fuel assembly when not in use. The tubes extend from 5 in. above the grating down below the bottom or mounting plate.

One 4-in. diameter and three 2-in. diameter aluminum wet tubes are located around the periphery of the fuel assembly. These tubes are held in place by clamps bolted to the bottom or mounting plate. These tubes have an opening in the bottom and are not intended to be moved from position. The irradiation tubes are shown in Figure 3-10.

A 2-in. outside diameter dry tube may be substituted for the wet center tube when pneumatic sample transfer or on-line mass spectrometer irradiation experiments are conducted. 

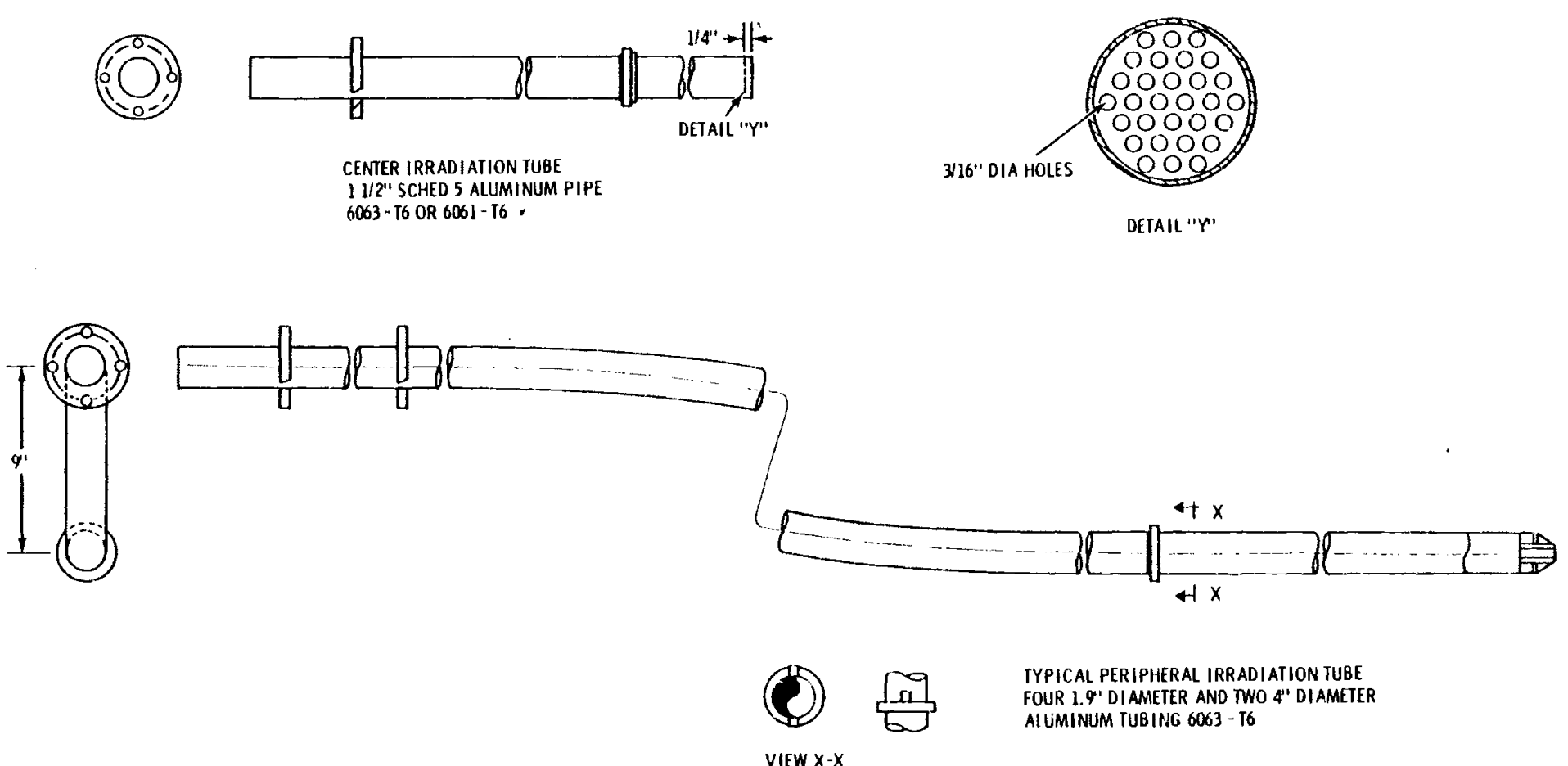

FIGURE 3-10. Irradiation Tube Details 


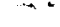

.

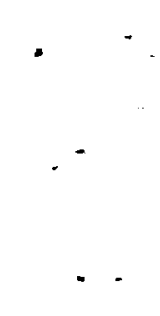




\subsection{ORGANIZATION AND ADMINISTRATIVE CONTROLS}

Nuclear safety was a predominant factor in the design and fabrication of the neutron multiplier system. The nuclear parameters of the fabricated assembly were established by an extensive and complete testing phase in the Critical Mass Laboratory. Certain operating restrictions evolved during the testing phase and responsible administrative controls insure that these requirements are met.

\subsection{ORGANIZATION AND ASSIGNMENT OF NUCLEAR SAFETY RESPONSIBILITY}

The Physical Sciences Department, Battelle Northwest, is responsible for the nuclear safety of the NMF. A Facility Supervisor who reports to the Manager of Physical Sciences Department is responsible for the operation of the facility. His responsibilities (referenced in Criticality Safety Procedures, $B N W L-M A-25)$ include personnel training, security, radiation, nuclear and industrial safety, and proper operation of the facility.

\subsection{ADMINISTRATIVE CONTROLS}

Administrative controls prescribed for the operation and use of the NMF insure a high degree of safety to personnel, equipment, and the public. These administrative controls are formulated in accordance with the BNW Management Guide and Criticality Safety Procedures, BNWL-MA-25. The controls are considered effective requirements that will provide a safe operation based upon the nuclear parameters determined by mock-up experiments at the Criticai Mass Laboratory.

\subsubsection{Nuclear Safety Procedures}

Safety in the startup and operation of the NMF is insured by the following operational requirements:

- The loading of the neutron multiplier assembly (NMA) in the water pool and subsequent startup is in compliance with an approved Criticality Safety Specification. Any fuel loading or modification shall be under the direct supervision of the Manager, Critical Mass Laboratory, or his authorized delegate. 
- Operation of the facility and conduct of experiments shall be by qualified personnel as specified in the training program guidelines (Procedure No. 7, Criticality Safety Procedures, BNWL-MA-25).

- All experiments and operations conducted in the NMF are in compliance with the Criticality Safety Specification and the Final Safety Analysis Report.

- A high degree of physical security for the NMF is maintained.

- Periodic inspections and testing of the $N M$ and supporting equipment is done to verify normal operation and discover and identify any abnormal conditions.

\subsubsection{Mandatory Nuclear Safety Specifications}

The Criticality Safety Specifications for the NMF conform with the requirements specified in Criticality Safety Procedures, BNWL-MA-25, for a Non-Reactor Nuclear Facility. An exception to these requirements is that the Manager, Critical Mass Laboratory shall review and approve Criticality Safety Procedures for the NM facility in place of that normally conducted by the Criticality Safety and Shielding Analysis Section.

\subsubsection{Criticality Safety Audits}

All procedures that affect the Criticality Safety of the NMF are periodically audited by prescribed operating and Nuclear safety personnel to insure compliance with the requirements of the Criticality Safety Specification and the Final Safety Analysis Report. The audit program will comply with the requirements specified in Criticality Safety Procedures, BNWL-MA-25.

\subsubsection{Training Program}

The training program for personnel who are involved with the operation and use of the NMF complies with the requirements of Procedure No. 7, Criticality Safety Procedures, BNWL-MA-25.

\subsubsection{Labeling and Posting}

The labeling and posting program in the NMF complies with the procedures prescribed in Criticality Safety Procedures, BNWL-MA-25. 


\subsubsection{Radiation Generating Devices}

The Neutron Multiplier is a radiation generating achine and where applicable meets the requirements of Radiation Protection Procedures, BNWL-MA-6.

\subsubsection{Emergency Procedures}

Emergency procedures will be prepared prior to the operation of the facility. 


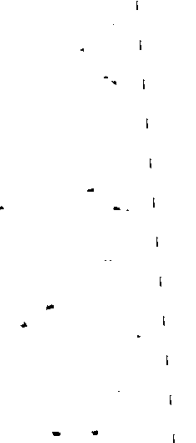




\subsection{SAFETY ANALYSIS}

The analysis of environmental samples frequently requires the measurement of very low concentrations of the element of interest. The lower limit of detection depends upon the reutron flux available when the aralysis is done by neutron activation techniques. The operating parameters of the NM must therefore provide the maximun neutron flux commensurate with absolute criticality sarety.

\subsection{CRITICALITY POTENTIAL AND CONTROL}

Foliowing a calculational design, a detailed, fueled mockup of the neutron muitiplier was extensively tested at the Critical Mass Facility. Operating parameters were experimentally optimized and the safaty of the assembly was verified. ( 1 ) The NM uses the same lattice plates and fuel rods that were testad in the mockup.

\subsection{Fissionable Material Description}

The fissile material in the neutron multiplier is approximately $5.5 \mathrm{~kg}$ of ${ }^{235} \mathrm{U}$ contained in about 252 fuel rods 0.4-in. diameter and 23.75-in. long. The fue 1 is a 28 wt\% uranium ( $93.2 \%{ }^{235}$ U enriched) - aluminum alloy.

\subsubsection{Criticality Potential}

The NM is arranged in an annular hexagon configuration of fuel rods and moderator that can result in a maximum credible $k_{\text {eff }}$ of 0.993 . Criticality could be caused by one or more of the following actions:

- an additional specified amount of fissile material is inserted within the assembly

- the water is replaced by a material that increases the reactivity of the NM, or if

- a specified number of fuel rods are removed from the midsection of the annular fuel rod assembly.

\subsubsection{Criticality Controls and Limits}

Criticality controi of the neutron multiplier is accomplished by arranging a specified number of fuel rods in a fixed configuration in water at a 
near optimum moderation. The specified number is experimentally determined under conditions of maxinum sample interactions. Engineered safety features are incorporated in the NM design and administrative controls are established to insure that these criticaity controls are met.

The final mass and configuration of the fissile fuel region was determined experimentally at the Critical Mass Laboratory for slightly undermoderated conditions. This corresponds to 1) flooded external irradiation tubes, 2) moderator temperature at the highest temperature coefficient of reactivity, and 3 ) voided central volume equal to the maximum voiding coefficient of reactivity.

\subsubsection{NM Characteristics}

The fuel region of the NM is an array of fuel rods arranged in a configuration that is slightly undermoderated and consequently if selected fuel rods are removed from the midsection of the annular assembly, reactivity will increase. If a removed fuel rod is transferred into its center test location, reactivity will increase. If any other change in fuel rod location is made, the reactivity will decrease. The fuel region is annular in shape with an interior water moderated region known as a "flux trap".

\subsubsection{Temperature Effects}

The effects of surrounding water temperature fluctuations on the reactivity of the NMA was determined experimentally at the Critical Mass Laboratory. The results of these critical approach measurements are shown in Figure 5-1. The critical number of rods decreases with increase in temperature initially but reverses at about $48^{\circ} \mathrm{C}$. This decrease in the critical number of rods (2.62) corresponds to an increase in $k_{\text {eff }}$ of 0.0021 . These tests verify that no ambient temperature can cause the assembly to become critical.

\subsubsection{Voiding Effects}

When the flux trap region is voided, the reactivity of the NM increases. The effects of voiding were measured at the Critical Mass Laboratory and the results are shown in Figure 5-2. As the flux trap is voided, the critical nunber of rods decreases until $30 \%$ roiding is reached. At this point the voiding effect reverses and increased voiding causes an increase in the critical number of rods. The maximum effect at 30\% voiding corresponds to a 


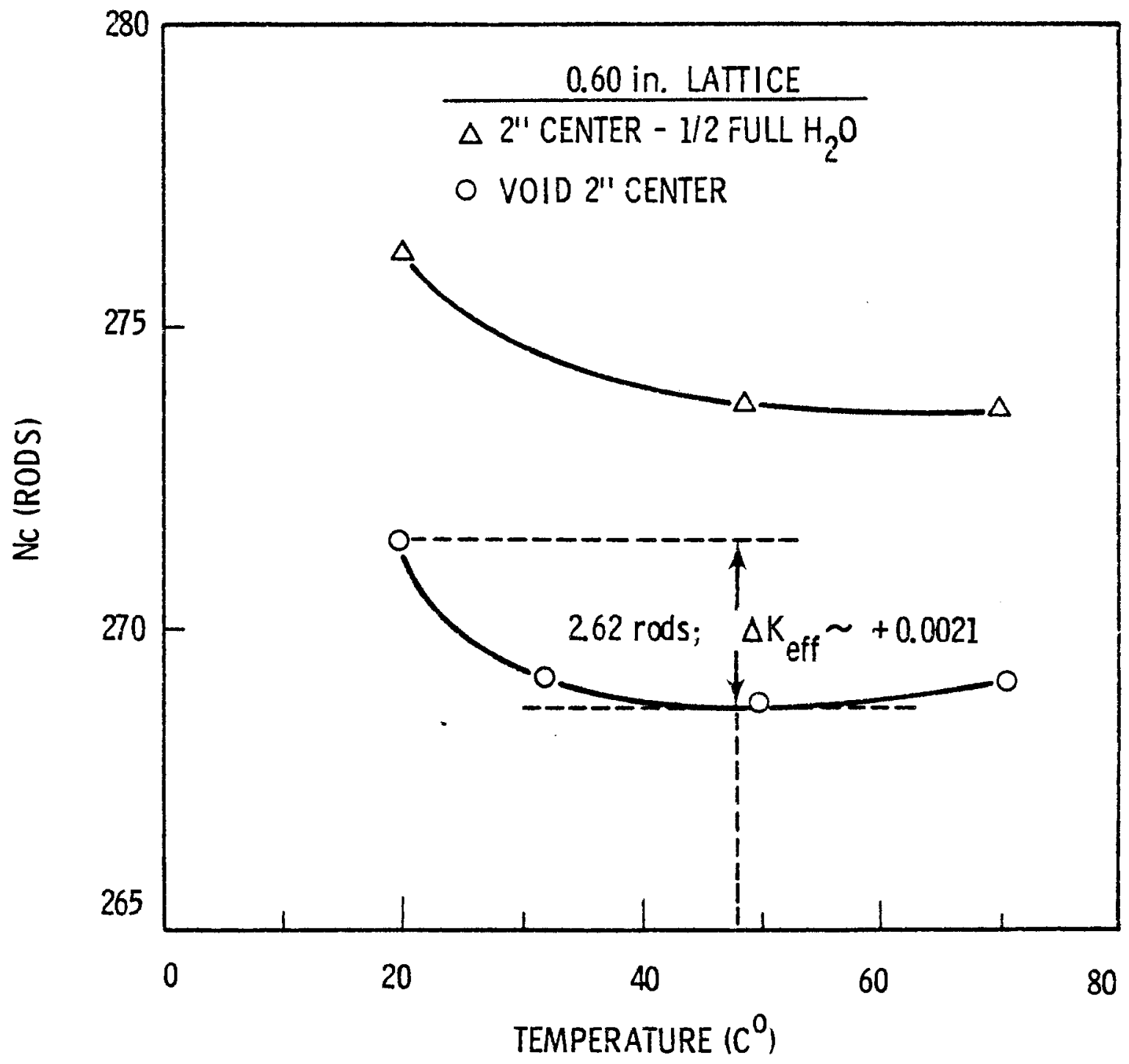

FIGURE 5-1. Temperature Change Effect on Neutron Multiplier Criticality 


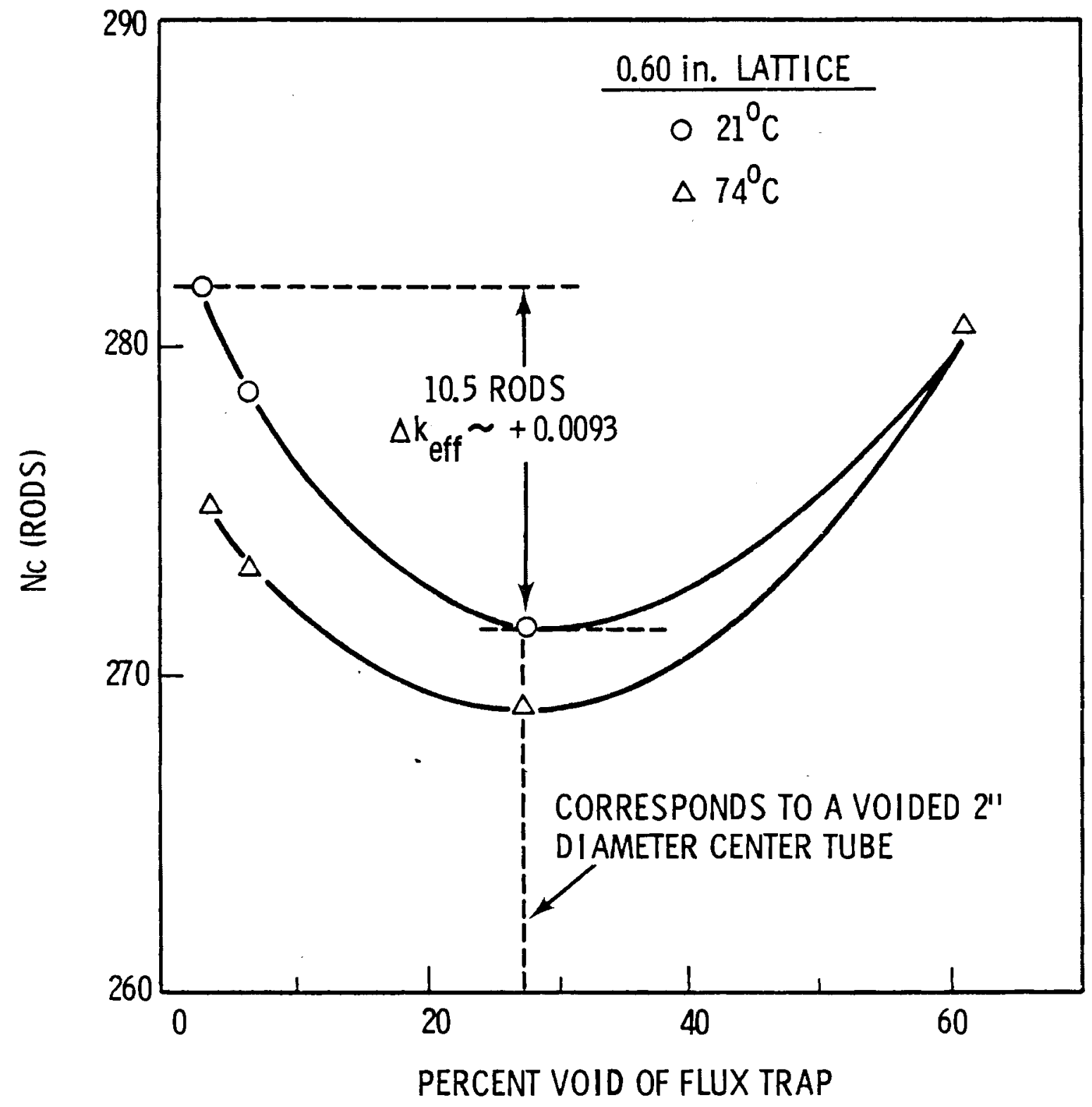

FIGURE 5-2. Center Void Effect on Neutron Multiplier Criticality 
decrease of 10.5 rods or an increase in theff of 0.0093 . These tests verify that voiding of the center flux trap region cannot cause the assembly to become critical.

Voiding effects external to the fuel lattice vere measured at the Critical Mass Laboratory. Voiding was found to have a considerabie negative effect on criticality; the critical number of rods increased 2.4 rods for a 2-in. diameter and 6 for a 5-in. diameter void external to the assembly. This corresponds to a decrease in $k_{\text {eff }}$ of 0.0022 for the 2 in. void and 0.0053 for the 5 in. void.

\subsubsection{Sample Effects on Reactivity}

The change in reactivity caused by various materials in the irradiation position of the NMA was determined at the Critical Mass Laboratory. The changes in $k_{\text {eff }}$ are shown in Table 5-l for various materials tested in the center tube. The changes in $k_{\text {eff }}$ for various materials tested in the external tiabes is shown in Table 5-2.

Since the addition of graphite to the irradiation tubes increases the reactivity above that for water, the presence of graphite and other low absorption scatterers in the racility is regulated by administrative control. The insertion of $1 / 3$ of a fuel rod or about $7.4 \mathrm{~g}$ of ${ }^{235} \mathrm{U}$ increases the $k_{\text {eff }} 0.0038$ and consequently the $4 \mathrm{~g}$ limit imposed by the Criticality Safety Specification and administrative control is a very conservative limit.

If the NMA is assumed to be in a typical operating mode with external test tube in positions of least reactivity, the consequences of credible changes in the operation are shown in Table 5-3. Data is presented for two fuel loadings; one is the initial fuel loading of 252 fuel rods, and the other is the maximum possible loading of 258 fuel rods. The initial fuel loading is approximately 252 fuel rods having a maximum credible operating $k_{\text {eff }}$ of 0.9872. The fuel loading could be increased, however, to about 258 fuel rods maintaining a maximum credible $k_{\text {eff }}$ of 0.9924 ; less than the allowable value of 0.993 .

The pneumatic sample transfer operation is a means for rapidly inserting or withdrawing a neutron capturing sample from the MM. Insertion reduces the value of $k_{\text {erf }}$. Withdrawal of the sample increases $k_{\text {eff }}$ to the preinsertion 
TABLE 5-1. Effect of Material in Center Tube*

(Center Tube 1/2-Filied with $\mathrm{H}_{2} \mathrm{O}$ )

\begin{tabular}{|c|c|c|}
\hline Material & Position & $\mathrm{k}_{\text {eff*x }}$ \\
\hline Water & Flooded Center Tube & -0.0050 \\
\hline $\begin{array}{l}1 / 3 \text { Fuel Rod } 235 \mathrm{U}) \\
(\sim 7.4 \mathrm{~g}\end{array}$ & In Void - Above Center & +0.0038 \\
\hline I Fuel Rod & Centered Vertically & $+0.0100 x-x$ \\
\hline Graphite $(1-3 / 4$ in. OD) & In Void in Top Half & +0.0028 \\
\hline Source Mockup (200 g SS) & In Water in Bottom Half & -0.0017 \\
\hline Bismuth (1.34-in. Tube) & In Void in Top Half & +0.0007 \\
\hline Mineral Oil (1.34-in. Tube) & In Void in Top Half & -0.0022 \\
\hline $\begin{array}{c}\text { Boric Acid }(6 \mathrm{~g} / \mathrm{l}) \text {, Filled } \\
2-i n \text {. Void Tube }\end{array}$ & Centered Vertically & $-0.0258 \div \div$ \\
\hline
\end{tabular}

* See Appendix D for calculations.

** Based upon $k_{\text {fff }}=0.9799$ with 252 fuel rods on a 0.6 " lattice spacing. $* * *$ Center tube completely void of water.

TABLE 5-2. Effect of Outside Lattice Void Tubes and Material*

\begin{tabular}{|c|c|c|}
\hline Diameter & Placement Description & $k_{e f f * *}$ \\
\hline 2 in. & Void (flush to lattice plate) $* x * x$ & -0.0022 \\
\hline 5 in. & Void (flush to lattice plate) & -0.0053 \\
\hline 2 in. & $\begin{array}{l}\text { 1.75-in. D Graphite Rod in Void } \\
\text { (flush to lattice plate) }\end{array}$ & +0.0032 \\
\hline 2 in. & $\begin{array}{l}\text { Graphite Rod in Void Compared to Water } \\
\text { (flush to lattice plate) }\end{array}$ & +0.0010 \\
\hline 2 in. & $\begin{array}{l}\text { 1.75-in. D Tube Mineral Oil in Void } \\
\text { (flush to lattice plate) }\end{array}$ & -0.0009 \\
\hline
\end{tabular}


TABLE 5-2. (contd)

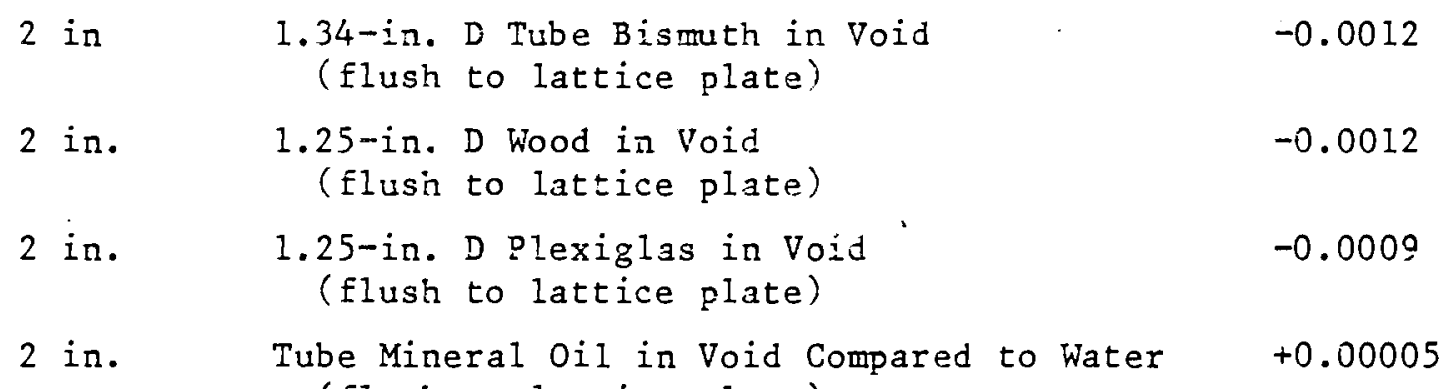
(flush to lattice plate)

* See Appendix $D$ for calculations.

$* *$ Based upon $k_{\text {eff }}=0.9799$ with 252 fuel rods on $a .6$ " lattice spacing. $* * *$ Center tube completely void of water

TABLE 5-3. Effect of Operating Changes on $k_{\text {eff }}$

Initial Operating Conditions

1. 2 in. and 4 in. external irradiation tubes voided.

2. Top $1 / 2$ of center irradiation tube voided. $*$

3. Ambient temperature of $21^{\circ} \mathrm{C}$.

4. No irradiation sample in center tube.

\begin{tabular}{|c|c|c|c|}
\hline Action Taken & $\Delta k_{\text {eff }}$ & 252 rods & 258 rods \\
\hline Initial Operating Mode & & 0.9717 & 0.9769 \\
\hline Source Removal & +0.0017 & 0.9734 & 0.9786 \\
\hline Move 2 in. tube away & +0.0022 & 0.9756 & 0.9808 \\
\hline Move 4 in. tube away & +0.0043 & 0.9799 & 0.9851 \\
\hline Insert graphite $(715 \mathrm{~g})$ & +0.0032 & 0.9831 & 0.9883 \\
\hline Increase temp to $48^{\circ} \mathrm{C}$ & +0.0021 & 0.9852 & 0.9904 \\
\hline Insert $4 \mathrm{~g}$ fissile sample & +0.0020 & $0.9872 * *$ & 0.9924 \\
\hline
\end{tabular}

* Complete flooding of center tube decreases k ff by 0.0050 . **Maximum $k_{\text {eff }}$ under credible operating conditions. 
value. The $N M$ is a subcritical water moderation system having neutron lifetimes on the order of a few milliseconds. The sample withdrawal is approximately 50 milliseconds and should, therefore, not result in a flux increase greater than the equilibrium value obtained by a slow withdrawal of the sample. Rabbit operations have been used in critical reactor experiments $\left(k_{\text {eff }} \geq 1.0\right)$ for many years and have not presented any unforeseen safety problems.

\section{1 .3 .5 Rod Removal Effect on Reactivity}

In order to obtain a negative temperature effect on reactivity, the lattice configuration of the NMA was designed to be undermoderated. This characteristic can be explained as follows. In an undermoderated lattice, the pathlengths in the moderator are not sufficient to completely thermalize the fast neutrons. This reduces the number of fission producing neutron reactions within the fuel. If the temperature of the lattice is increased, these path lengths become less effective in moderating fast neutrons: 1) the hydrogen atom concentration per unit volume decreases (because of density decrease) and 2) equilibrium neutron spectrum with the hydrogen moderator is at a higher temperature. The assembly becomes further undermoderated and $k_{e f f}$ decreases. If a single fuel rod is removed from within a cluster of fuel rods, water replaces the rod and the path length in water is significantly increased. The additional thermal neutrons produced increase the probability of fission, resulting in a higher $k_{\text {eff }}$. In experiments conducted at the Critical Mass Laboratory, the removal of a rod from within the lattice increased $k_{\text {eff }}$ by 0.00048 . Removal of adjacent fuel rods in the 0.6 in. lattice leads to an overmoderating situation that reduces the value of $k_{\text {eff }}$ and maintains subcriticality. Criticality could not result except by removal of specific fuel rods from their location within the lattice. If the operating conditions of the NMA correspond to those for 258 fuel rods in Table $5-3$, the removal of 16 specifically selected fuel rods could cause criticality.

\subsubsection{Normal Operating Conditions}

The neutron multiplier has two normal states, "on" and "off". During

sample irradiation the neutron multiplier will be "on" (i.e., the ${ }^{252} \mathrm{Cf}$ 
source will be at the symmetrical center of the neutron multiplior). When no irradiation is in progress the neutron multiplier is nomally "off" (i.e., the ${ }^{252} \mathrm{Cf}$ source is in the lowered position below the neutron multiplier). Since many samples require long irradiation intervals, the multiplier if "on" most of the time.

The center tube is a wet tube except in cases of mass spectrometer or pneumatic sample transfer experiments. Three 2-in. and one 4-in. diameter external tubes are wet tubes and are in a fixed location. One 2-in. diameter and one 4-in. diameter external tube are dry and both are moved out of the irradiation position when they are not being used for irradiations. These tubes are not moved during sample irradiation or with samples in the tubes.

Samples are only irradiated in the sample irradiation tubes that are located in their design positions. A sample may be inserted and/or removed with the neutron multiplier either "on" or "off". There is no restricticn on the number of samples that may be irradiated at any one time. There is a restriction, however, or the composition of the samples. The amount of fissile material which can be irradiated in the NMA is $4 \mathrm{~g}$. A gamma moritor with a portable probe is located near the pool and is utilized to indicate excessive radiation exposure to personnel during sample removal and subsequent handling. When radiation levels exceed values set by Radiation Work Procedures, audible and visual alarms are energized.

A neutron proportional counter is positioned adjacent to the pool wall near the same level of the NMA in a submerged polyvinyl chloride (PVC) thimble. The PVC thimble and detector cause no significant effect on reactivity because of their distance from the NMA. This detector serves to monitor the operation of the NMA, and is used primarily to calibrate the flux levels at the irradiation tubes. The neutron detector also indicates the "on" and "off" state of the NMA.

The mass spectrometer experiment, which may be periodically performed, involves irradiation of $4 \mathrm{~g}$ of ${ }^{235} \mathrm{U}$. In this experiment, the ${ }^{235} \mathrm{U}$ metal sample is located in an evacuated (2-in. diameter) drift tube which replaces 
the normal central irradiation tube. The experiment is designed to obtain on-line mass spectrometry information on fission products.

Normal operating conditions include a 20-ft depth of water in the pool. The water level is maintained by a manually operated valve in series with a float controlled valve fill system. Pooi water circulation through the filter and ion exchange column will be at a rate required to maintain water quality. Water quality is monitored by a standard conductivity probe.

\subsubsection{Engineered Safety Feature}

Certain safety features have been incorporated into the design of the NM to help insure that the criticality controls and limits are met during the operation. Rearrangement of the fuel rods in the NMA can cause criticality; therefore; design features must control this possibility. Accessibility to the NM is an important factor to consider in evaluating the possibility of fuel region alteration. A major barrier against direct access to the NMA is provided by the 15-ft water column over the unit. When the lattice-fuel assembly is in place in the pool, three element retainers and special nuts lock the assembly and cover plate to the holding plate of the support structure. The assembly or cover plate cannot be removed without use of a special tool to remove the locking nuts. The special tool will be kept and controlled by the Manager, Safety and Nuclear Materials Management. The lattice plate locking assembly improves the procedural control for preventing an unplanned lattice loading change. When the cover plate is in place, the fuel rods are covered and cannot be removed or altered. The cover plate also protects the fuel rods from damage by objects falling into the pool. A steel grate equipped with an intrusion detector is located over the top of the pool and serves to further 1 imit access to the NMA. The intrusion detector alarm is located at 300 Area patrol headquarters and is energized on all off shift hours.

The only moving part of the $N M$ is the motor driven source positioner mechanism. In case of misalignment or jamming, a slip clutch in the motor drive assembly will prevent damage from being done to the source, lattice plates, or fuel rods. 
Irradiations are done in one central and six external tubes extending from the pool surface to the $\mathrm{IM}$. The 2-in. diameter center tube is flooded except in cases of pneumatic sample transfer or mass spectrometer experiments. The external tubes are flooded except for one 2-in. and one 4-in. diameter tube. The dry tubes will be moved adjacent to the fuel assembly during sample irradiations and are held in this position by slots in the top plate. The wet tubes are held in position by plates bolted in a fixed location on the bottom plate. The irradiation tubes can therefore cause no displacement or damage to the fuel rods in the assembly.

Criticality cannot be caused by changes in position, flooding or voiding of any combination of tubes because the maximum number of fuel rods allowable to maintain subcriticality was experimentally determined for slightly under moderated conditions with flooded external tubes and a partially voided center tube.

\subsection{RADIATION POTENTIAL AND CONTROL}

Operating personnel can receive radiation exposures from several sources during routine operation of the NMA. Although the water column above the NMA provides adequate shielding to neutrons and gama radiation from the fission reaction and ${ }^{252}$ Cf sources, dry irradiation tubes are potential sources for personnel exposures. Manipulation of the ${ }^{252} \mathrm{Cf}$ sources and handling irradiated samples are also potential exposure sources. The radiation hazard potential of each source is evaluated and control measures are identified.

\subsubsection{Radiation from Neutron Multiplier}

The maximum heat output of the neutron multiplier is estimated to be 103 watts. The maximum thermal neutron flux in the central irradiation tube is on the order of $10^{10} \mathrm{n} / \mathrm{cm}^{2}-\mathrm{sec}$. The $15-\mathrm{ft}$ water colum above the fuel region of the neutron multiplier acts as an excellent radiation shield. From comparison with Bulk Shielding Reactor Experimental data (2) on radiation attenuation in water, it is estimated that with the sample irradiation tubes removed or flooded, the radiation level at the top of the pool due to neutron multiplier operation is less than $0.01 \mathrm{mR} / \mathrm{hr}$. The radiation is essentially all gamma rays. 


\subsubsection{Radiation from Irradiation Tubes}

The two external dry irradiation tubes are constructed with an offset to prevent direct radiation streaming. The radiation field in the top section of the tubes reported in The Preliminary Safety Analysis Report for the BNW Neutron Multiplier Facility, (3) $3 N W L-B-341$, is $10 \mathrm{mR} / \mathrm{hr}$. This value is based on conservative assumptions. The field is a highly collimated gamma radiation.

Except for special experiments involving irradiation of a $4 \mathrm{~g}$ uranium sample at the bottom of an evacuated drift tube, or for pneumatic sample transfer irradiations, the central irradiation tube is water-filled. Anticipated radiation levels above a dry central irradiation tube were reported in $B N W L-B-341$ to be $150 \mathrm{mrem} / \mathrm{hr}$. This radiation field is primarily due to thermal neutrons and is a highly collimated 2-in. diameter beam directly above the tube. Access to the roof area will be controlled with radiation zones established by Radiation Work Procedures.

\subsubsection{2 ${ }^{41}$ Ar Production - External Irradiation Tubes}

When the external dry irradiation tubes are used for sample irradiations or if the center tube is used for pneumatic sample transfer irradiations, ${ }^{41} \mathrm{Ar}$ is produced by interaction of neutrons with the natural argon in air. In the worst case situation, if both dry external tubes are used for irradiations, the maximum ${ }^{41} \mathrm{Ar}$ activity produced at saturation is approximately $80 \mathrm{\mu Ci}$. The maximum permissible concentration in air is $2 \times 10^{-6} \mathrm{\mu Ci} / \mathrm{cc}$ for a 40-hr week. (8) This concentration would be obtained by diluting the ${ }^{41} \mathrm{Ar}$ in $4 \times 10^{7} \mathrm{cc}$ of air or $1471 \mathrm{ft}^{3}$. Transfer of the entire amount of ${ }^{41}$ Ar from the irradiation tubes could only be accomplished by a specially designed effort such as displacement of the entire air volume of the external dry tubes at one time. A possible way for this to occur is by a simultaneous failure of these external tubes allowing the air volume to be displaced with pool water. A metal failure or a mechanical breaching of the tube walls to cause this to happen is unlikely and engineered features prevent accidental submergence of the tubes during operation. Operating procedures will minimize the ${ }^{41} \mathrm{Ar}$ problem. When dry external tubes are not being used, they will be 
moved away from the irradiation position and flux in the external tubes will be reduced to zero. Then the tubes are in the irradiate position the active volume is partially displaced by the sample. If large sealed containers are used for long irradiation of samples, Radiation Work Procedures require these containers to be opened in the hood if there is a potential hazard from ${ }^{41}$ Ar.

\section{$5.2 .1 .3{ }^{41}$ Ar Production - Pneumatic Sample Transfer System}

When the pneumatic sample transfer system is installed in the center tube location and air is used as the transfer gas, ${ }^{41} \mathrm{Ar}$ will be formed. The maximum credible ${ }^{41}$ Ar release is from the first pneumatic transfer cycle following a long period with the NM "on". For example, if the NM is "on" for an overnight irradiation of samples in the external tubes, the first pneumatic transfer cycle will move the saturated ${ }^{41} \mathrm{Ar}$ out of the center tube. The maximum credible amount is $8 \mathrm{LCi}$. The exhaust of the pneumatic sample transfer system is vented to the hood. Release for the worst case sicuation of $8 \mathrm{\mu Ci}$ is into a $1900 \mathrm{CFM}$ air stream. Turbulence from air flow through the duct will provide good mixing and therefore adequate dilution to insure that the limit of $2 \times 10^{-6} \mu \mathrm{Ci} / c c$ air ${ }^{(8)}$ will not be exceeded at the building exhaust. A volume of $143 \mathrm{CF}$ air or $24.5 \mathrm{sec}$ of flow will accomplish this required dilution. Calculations of the ${ }^{4 !}$ Ar productions are shown in Appendix A.

\subsubsection{Radiation from Sample Manipulation}

Personnel radiation exposure is a potential hazard that can result during removal of irradiated samples from the NM and from the isotope collections at the detector location of the on-line mass spectrometer experiments. Control of this hazard is accomplished by use of approved Radiation Work Procedures and appropriate radiation monitoring. Shielding and remote handling techniques are utilized to control exposures to personnel so that the limit of 1 $\mathrm{rem} / \mathrm{yr}$ is not exceeded. A gamma monitor located in the vicinity of the poo1 provides visual and audible alarm in case of high radiation fields.

In on-line mass spectrometer and pneumatic sample transfer system experiments, radiation exposure from the voided center tube is a potential hazard. Control of this hazard is accomplished by shielding and by physical 
restraint. Access to the roof above the pool will be controlled by established Radiation Work Procedures. In the on-line mass spectrometer experiment, radiation exposure is possible from the mixed radiations from the isotopes at the collector or detector location on the mass spectrometer. Similar experiments being conducted at Washington State University indicate that radiation levels at the collector may approach $20 \mathrm{mR} / \mathrm{hr}$, and lead shielding is adequate protection from this source. Operating experience will dictate the final requirements for adequate radiation protection to personnel.

Samples will be prepared for activation in the neutron multiplier by appropriate encapsulation to prevent spread of contamination. It is imperative that a low level of contamination be maintained to avoid adversely affecting low-level counting operations conducted in the 329 Building. Encapsulation techniques which have been developed for successful use in other irradiation facilities will be adapted for use in the NMF.

5.2.3 Radiation from ${ }^{252}$ Cf Source Manipulation

Six ${ }^{252}$ Cf sources will be delivered to the NMF in two separate shipments of three sources each. Shipment will be made in a large transportation cask mounted on a trailer. Following arrival, the sources will be physically transferred out of the transport cask into the NM pool. This phase of the operation will present a radiation exposure hazard to personnel involved in the source transfer. Exposure to the neutron field will be minimized by use of shielding or by operating at a distance which affords the necessary reduction in exposure level consistent with the required dexterity and maneuverability to accomplish the transfer rapidly and without malfunction.

Three methods of source transfer are evaluated in Appendix E: 1) manipulator, 2) track and trolley, and 3) auxiliary transfer cask systems. Although source transfers could be accomplished by all three methods, the track and trolley method will provide the least radiation exposure to personnel. Using this system, the six sources can be transferred with an estimated maximum exposure accumulation of $50 \mathrm{mrem}(n+Y)$. An additional advantage of this system is that it uses the manipulator that accompanies the 
shipment. This manipulator is specifically designed for the transfer operation. The possibility of accidental release of a source by this manipulator has been evaluated and found acceptably low.

The disadvantage of the manipulator transfer system is the higher exposure levels encountered in the operation. Using this method, the six sources could be transferred with an estimated maximum exposure accumulation of 450 mrem $(n+\gamma)$.

A transfer cask would reduce exposure levels to 1/3; however, this level would not permit close approach to the cask. Remote moving would be required. The cransfer would be further complicated by additional source handling; i.e., transfer from transport cask to transfer cask and from transfer cask to the NM pool.

No exposure hazards are encountered during assembly or disassembly of the sources into the source holder since this operation is done under water. Manipulators are used in this operation to remove the shipping adapter from each source and to attach the source into the source holder. A long-handled manipulator will be used to lower the source holder into the source drive assembly.

\subsubsection{Radiation from Ion Exchange Unit}

During normal operation of the NMA, the ion exchange unit will remove ${ }^{24} \mathrm{Na}$ which is in the pool water as a result of aluminum corrosion of the fuel rod cladding. The ${ }^{24} \mathrm{Na}$ is formed by the $(\mathrm{n}, \alpha)$ reaction of fast neutrons on ${ }^{27} \mathrm{Al}$. At equilibrium operating conditions, the NMA contributes about $0.1 \mu \mathrm{Ci}$ of ${ }^{24} \mathrm{Na}$. The gamma radiation from this source is less than $0.1 \mathrm{mR} / \mathrm{hr}$. Calculation of ${ }^{24} \mathrm{Na}$ production is shown in Appendix $\mathrm{B}$.

A fuel rod cladding or source container failure could cause a potential radiation hazard from the ion exchange unit. Buildup of long-lived isotopes on the resin bed from such a failure could cause much higher exposure levels than resilt from normal operation. The unit is located in a pit below floor level and is covered by a steel grate that will support lead shielding over the resin bed. Isead shialding an also be stackes around the unit below the steel grate if desired. 
Scandard operating procedures require coutine periodic measurements of the radiation exposure rate from the ion exchange unit. Increases in the exposure rate will indicate that a failure is in progress.

\subsection{CONTINGENCIES FROM OFERATION}

Operating procedures for the NMA are established to provide a safe, reliable system for sample irradiation. Careless, accidental or intentional disregard for these procedures can cause abnormal conditions in the NMF which are hazardous to personnel conducting irradiation experiments. Unnecessary radiation exposure to personnel is the most likely consequences of these abnormal conditions.

\subsubsection{Fissile Material in Excess of Allowable Quantity}

The possibility of accidental or intentional introduction of an additional amount of fissile material to the NM must be considered in the safety analysis. The Nuclear Safety Limits for the NII facility restrict the amount of fissile material in the facility to be the fuel loading of the neutron muleiplier, sealed sources to drive the $\mathrm{NM}$, and an additional $4 \mathrm{~g}$ of fissile material. NMF operating procedures require verification of the fissile material content of all samples prior to entry to the facility. The facility manager shall approve the introduction of any fissile material into the facility.

\subsubsection{Improper Irradiation Sample Handling}

The most credible abnormal occurrence in the NMF is improper handling of an irradiated sample which causes an unplanned radiation exposure to personnel. The chemical makeup of the many environmental samples which are irradiated is not completely defined; therefore expected activities of irradiated samples cannot always be estimated with certainty. To control such exposure, a radiation monitor equipped with audible and visual annunciation is located in the vicinity of the pool. All sample removal and handing will be done in accordance with an approved Radiation Nork Procedure which will specify proper radiation monitoring procedures. It is concluded that the probability and consequence of this occurrence is acceptably low. 


\subsubsection{Flooding of External Irradiation Tubes}

Damage from carelessness or accidents in handiing irradiation tubes or sample containers could result in flooding of an external irradiation tube. Flooding of the external tubes cannot cause criticality since the final design of the fuel region was experimentally determined with the external irradiation tubes flooded. The main hazard potential from this accident would be unplanned radiation exposure from a highly radioactive sample being irradiated in a positive buoyancy sample container which floats to the surface. Warning of this hazard is provided by the gama monitor which is equipped with audible and visible annunciation. Radiation Work Procedures and standard NMF operating procedures detail actions to be taken in the event of such annunciation. It is concluded that the probability and consequence of this occurrence is acceptably low.

\subsubsection{Failure to Maintain Proper Water Level}

The water level in the pool gradually drops because of evapozation from the pool surface. A low water level alarm will sound when the level has dropped to a preset level. If water is needed, it may be added by opening a normally closed manual valve in the water make-up line. The person adding the water is required to remain in the room until the proper water level is attained and the manual valve is closed. As a backup, a float control in the pool operates a valve in series with the manual valve to shut off the make-up water when the proper water level is attained. A very liberal calculation of evaporation from the pool under credible conditions indicates that the level would drop less than $4 \mathrm{in.}$ per day. If the condition went undetected for a week the loss of water shielding would increase radiation levels at the top of the pool approximately a factor of 10 to $0.1 \mathrm{mrem} / \mathrm{hr}$. Standard NMF operating procedures require checking the pool water level on a frequency found to detect a drop in water level before it can create a hazard. It is conciuded that the probability and consequence of this misoperation is acceptably low.

The walls of the neutron multiplier pool are designed to withstand the earthquake described in Section 3.2.2. The inside of the pool is coated with several layers of a resin sealant to prevent leaching of materials from the 
concrete into the pool water. If a crack should occur in the wall and the plastic was breached or a pinhole flaw was located in that vicinity, pool water could flow out into the concrete and surrounding soil. Particulate matter (radioactive or nonradioactive) in the water would encounter a high degree of holdup and entrapment in the concrete. Further holdup and entrapment would occur in the soil. The half-life of ${ }^{24} \mathrm{Na}$ is $15 \mathrm{hr}$ and decay to $1 \%$ of the initial value occurs in $100 \mathrm{hr}$. The hazard from ${ }^{24} \mathrm{Na}$ from a possible pool leak is therefore acceptably low because of holdup and decay.

\section{A discussion of the ${ }^{24} \mathrm{Na}$ activity which may be present in trace amounts $\left(10^{-5} \mu \mathrm{Ci} / \ell\right)$ in the pool water is given in Appendix B.}

\subsection{CONTINGENCIES FROM ENVIRONMENTAL CONDITIONS}

Catastrophic events such as fire, flood and tornado will have little effect on safety of the NMA. An earthquake could cause serious damage such as a breach in the pool wall, disarrangement of the fuel rod assembly and a rupture of the fuel pins. A specific fuel disarrangement could result in a criticality incident. During normal operation of the NMA, safety of the system does not depend on continued operation of the support equipment.

\subsubsection{Equipment Failure}

Safety of the NMF is not dependent upon continued operation of supporting equipment. Circulation of water in the pool is not required for cooling purposes; only to provide necessary water quality. If the pump fails, the heat output from the NMA will cause a local temperature increase in the pool water surrounding the assembly; however, natural convection cooling will limit the temperature rise. This is not a critical situation because the temperature coefficient of the NMA is negative above $48^{\circ} \mathrm{C}$.

The ${ }^{252}$ Cf source positioner mechanism serves to turn the NMA "on" or "off". An operational failure would have no effect on the safety of the NMA since the source position does not significantly affect criticality. Manual override operation of the source positioner is available during a motor failure. The stainless steel of the sample containers lowers $\mathrm{k}_{\text {eff }} 0.0017$.

A failure of the air hand 1 ing equipment would not cause a significant hazard. The amount of airborne particulate material in the room will be 
negligible because of the location of the NMA. Particulate materials which may be formed by leaching or corrosion will remain in the water column until they are removed on the filter and ion exchange column section of the water process system. Particulate radioactive materials could be present in certain types of irradiated samples; however, handling these types of samples is in accordance with an approved Radiation Work Procedure designed to reduce the risk of contamination spread to an acceptably low level.

\subsubsection{Fuel and Source Cladding Failure}

The purity of the water (conductivity should be in the range 3-30 $\mu$ mhos) should result in extremely long life (of the order of 10's of years) for the fuel cladding. The ${ }^{252} \mathrm{Cf}$ is contained in a pelletized aluminum powder matrix which is doubly encapsulated in stainless steel. If the cladding should in some way be penetrated, the leak would be of the slow pinhole variety. The filter and ion exchange column in the water process system wiil very efficiently remove any material from the water. Administrative controls require periodic checking of the radiation emanating from the filter and ion exchange column. If fissionable material or fission products are detected, action will be taken to find and eliminate their source.

\subsubsection{Fire}

The neutron multiplier is housed in a mineral fiber-insulated, metal structure constructed on a reinforced concrete foundation and floor. The building is constructed of noncombustible materials in accordance with the Uniform Building Code and is fully protected by a wet sprinkler system. A fire alarm system is provided which is tied into the 300 Area fire station. The building contents are selected to minimize the combustible loading within the NMF. The facility mission requires the presence of only minimal quantities of combustible materials. Fire, or fire fighting, will not result in an environmental hazard. The neutron multiplier is located near the bottom of a 20-ft deep pool of water and its safety does not depend on equipment or facilities which could be affected by fire or fire fighting. 


\subsubsection{Tornado}

The probability of a tornado striking the NMF is extremely small. However, if the building were to be destroyed by a tornado, no nuclear radiation, or radioactive material hazard to personnel or the environment would result. Since the neutron multiplier is located below ground near the bottom of a 20-ft deep pool and its safety does not depend on above ground equipment or facilities, it would be virtually unaffected by complete destruction of the building. Irradiated samples will not be stored in the MMF.

\section{4 .5 Flood}

The NMF is located at an elevation of $398 \mathrm{ft}$ which is higher than the estimated 100-year maximum Columbia River flood stage of $386 \mathrm{ft}$. Flooding from natural Columbia River floods is therefore unlikely during the history of the NMF. If flooding from natural or other causes should occur, the safety of the NMA would not be affected since it operates in a flooded condition and is not dependent on above ground facilities.

\subsubsection{Earthquake}

Although the pool wall is designed to satisfy the Hanford Standard Category II Criteria for Earthquakes, the NMA is not specifically designed to this standard. If ground motion caused a breach in the pool wall with subsequent loss of water, operation of the NMA would be greatly affected. Depending upon the level of water above the NMA, the radiation levels above the pool could increase significantly. If the water is lost completely, the NMA will become far subcritical due to the absence of moderator. In either case, a radiation field would be present above the pool. This field is difficult to estimate because the level of water in the pool has a great influence on the value. If complete water loss occurs, the field is caused by delayed gamma radiation from fission product decay and by gamma radiation and neutron emission from the ${ }^{252}$ cf sources. The gamma radiation from fission product decay depends on the length of operation. The radiation field from the ${ }^{252} \mathrm{Cf}$ sources is estimated at $18 \mathrm{rem} / \mathrm{hr}$ at the top of the pool. If water is lost to the height of the top lattice plate, a leakage of neutrons occurs, 
reactivity decreases and the $N M$ operates at a lower fission rate. The remaining water reduces radiation from ${ }^{252} \mathrm{Cf}$ source to about $6 \mathrm{rem} / \mathrm{hr}$. The radiation field is composed of the source dose rate, neutron leakage and prompt gamma ray dose rate from the NM operation.

If high radiation fields are caused by complete or partial loss of the water column, shielding could be placed over the pool by remote operation of the jio crane located adjacent to the pool. Additional support members could be placed over the pool grates and shielding materials could then be installed. If enough water remained in the pool to sustain the chain reaction, a hose could be lowered into the pool and the remaining water pumped out. The ${ }^{252}$ Cf sources could then be manipulated from the top of the pool using a shadow shield over the sources. The sources could be separated from the source holder and moved to an alternate storage location.

The NMA support structure is rigidly mounted on the floor of the pool by use of anchor bolts into the concrete bottom. The four support legs are 40 in. high and the bottom mounting plate is securely attached with bolts. The top holding plate is bolted to the mounting plate with three $3 / 4-i n$. diameter tie rods. The $60 \mathrm{lb}$ (fuel weight - $47.5 \mathrm{lbs}$ ) fuel-lattice assembly is held in place between the two plates. The center of mass of the fuel-lattice assembly is 252 in. above the pool floor and an earthquake-induced horizontal floor displacement would cause considerable upsetting force on the MMA. Three stabilizing or centering rods, $120^{\circ}$ apart, are attached to the top holding plate and extended out to the pool wall. The holding plate is solidly held at the pool center line by these three rods. Motions induced in the pool floor would therefore have minimal effect on the NMA.

The risk of an earthquake induced criticality should be evaluated. Since the NM assembly is slightly undermoderated, criticality can possibly but not likely occur if the fuel rod configuration is rearranged in a specific manner. In the $0.6 \mathrm{in}$. lattice assembly, criticality can be induced by removal of certain specific fuel rods from the midsection of the annular assembly. Fuel rod removal could not be a random or accidental choice. For example, if two adjacent fuel rods are removed, reactivity would decrease because removal 
of the adjacent fuel rods would result in overmoderation. For an accidental criticality to occur, the following sequence of events would be required:

- The fuel pins are held in place by the cover plate which is locked to the top holding plate. Either the cover plate or the holding plate would need to be separated from the assembly. This action would require shearing the locking bolts or retaining clips which hold the cover in place or the 3/4-in. diameter tie bolts which connect the top holding plate to the bottom mounting plate.

- Specific rods would then require removal from the assembly without disturbing the remaining fuel elements. Since the fuel rods are held in fixed configuration by close tolerance holes in the lattice plate, it is unlikely that single specific rods could be displaced by mechanical motions unrelated specifically to fuel rod removal. For example, if the top lattice plate was bounced off, the fuel rods would fall against each other and reactivity would decrease because of further undermoderation.

- The outer and inner rings of fuel elements would need to be maintained in their respective positions and orientations. If the top plate twisted with respect to the bottom plate, the fuel elements would be forced closer together in the center and the reactivity would decrease because of further undermoderation.

The most likely result of a severe, damaging earthquake event would be a collapse of the assembly which would cause loss in reactivity because of undermoderation. Earthquake caused forces are not likely to reproduce the specific rearrangement of fuel pins which can result in criticality.

\subsection{CONSEQUENCES OF A CRITICALITY ACCIDENT}

If the assumption is made that a specific number of designated fuel elements was incredibly removed from the fuel assembly, criticality would result. The analysis of such a hypothetical event is presented to demonstrate that the consequences are certainly not intolerable.

If criticality occurred, no physical damage to the facility or dangerous direct radiation exposure to personnel would result because the assembly is 
in the pool under $15 \mathrm{ft}$ of water. Loss of ncble gases, iodine, and volatile fission products to the environment could occur after percolation up through the water column. Loss of particulate materials to the environment would be limited by percolation up through the water column and by the HEPA filter exhaust system.

Evaluation of the criticality consequences was based upon the following assumptions:

- The facility was operated continuously for 2 years prior to the event at $1.3 \times 10^{-4} \mathrm{MW}$.

- The event was $10 \mathrm{MW}$ for 1 second followed by steady state $1 \mathrm{~kW}$ for 24 hours.

- Three release periods were used; the first from 0-30 min, the second from $1 / 2-8 \mathrm{hr}$, and the third from 8-24 hr.

- Each release was $100 \%$ of noble gases, $10 \%$ of iodine isotopes and $1 \%$ of the volatile fission products.

- Doses were calculated for Hanford moderately stable and very stable metereological conditions.

Thompson and Beckerley ${ }^{(4)}$ sumarize a number of criticality accidents for heterogeneous assemblies and hydrogeneous solutions. The energy release from several of these events is shown in Table 5-4.

An accidental criticality event ${ }^{(a)}$ at the Oak Ridge Y-12 plant involving an enriched uranium solution in a 55 gal. drum yielded approximately $1.3 \mathrm{x}$ $10^{18}$ total fissions in several bursts. The burst size was estimated to be $10^{17}$ fissions. The Recuplex criticality incident ${ }^{(c)}$ at Hanford in 1962 yielded $8.2 \times 10^{17}$ fissions over a $37-h$ period. Approximately $20 \%$ of the total energy release occurred in the first $1 / 2$ hour of the incident.

Criticality accidents have not been experienced with systems equivalent to the NMA and the initial burst energy release cannot be predicted with accuracy. The $10 \mathrm{MW}-\mathrm{sec}$ assumption is equivalent to $3.12 \times 10^{17}$ fissions 
TABLE 5-4. Energy Release from Prompt Critical

Excursions for Various systems

\section{System}

${ }^{235} \mathrm{U}$ metal - water reflected

235

235

U oxide-plastic-water reflected

$\mathrm{U}$ metal foil - graphite

U-metal $(4000 \mathrm{~kg})-\mathrm{D}_{2} 0$ moderated

Partially enriched $\mathrm{U}-\mathrm{H}_{2} \mathrm{O}$ moderated

${ }^{235} \mathrm{U}$ - paraffin moderator and reflector

$\mathrm{PuO}_{2}\left(\mathrm{NO}_{3}\right)_{2}{ }^{-\mathrm{H}_{2} \mathrm{O}}$

${ }^{235} \mathrm{UO}_{2} \mathrm{~F}_{2}-\mathrm{H}_{2} \mathrm{O}$

${ }^{235} \mathrm{UO}_{2}\left(\mathrm{NO}_{3}\right)_{2}-\mathrm{H}_{2} \mathrm{O}$

${ }^{235} \mathrm{UO}_{2}\left(\mathrm{NO}_{3}\right)_{2}, 34 \mathrm{~kg}$ in $800 \mathrm{l}$ water

$\mathrm{Pu}-\mathrm{H}_{2} \mathrm{O}$

${ }^{235} \mathrm{U}$ metal - beryllium, plastic
Energy Release

(fissions)

$3 \times 10^{16}$

$1.22 \times 10^{17}$

$3.2 \times 10^{16}$

$2.5 \times 10^{18}$

$3 \times 10^{18}$

$10^{15}-10^{16}$

$8 \times 10^{16}, 1.5 \times 10^{17}$

$10^{17}, 1.6 \times 10^{17}$

$26 \times 10^{17}, 1.3 \times 10^{18^{(a)}}$

$4 \times 10^{19(b)}$

$28.2 \times 10^{17(c)}$

$4 \times 10^{17}$

a) several oscillations

b) repeated excursions

c) 37 hr of criticality

which is a factor of three greater than the generally accepted value of $10^{17}$ fissions for a first burst energy release. The assumed equilibrium energy release rate of $1 \mathrm{~kW}$ cannot be justified by experimental data. The equilibrium rate is established by the physical-chemical parameters of the system. The parameters may be greatly influenced by the initial burst event. If the steady state energy release is assumed to be $1 \mathrm{~kW}$-day, the ratio of the initial burst energy to the steady state energy is about the same as for the Recuplex incident.

Calculations were made using ORIGEN and SUBDOSA computer codes.

Dose predictions for the noble gas fraction are shown in Figures 5-3 through 5-6 for stable and moderately stable conditions at 1,000, 2,000, 5,000 and 10,000 meters. Dose predictions from the iodine fraction are shown in 


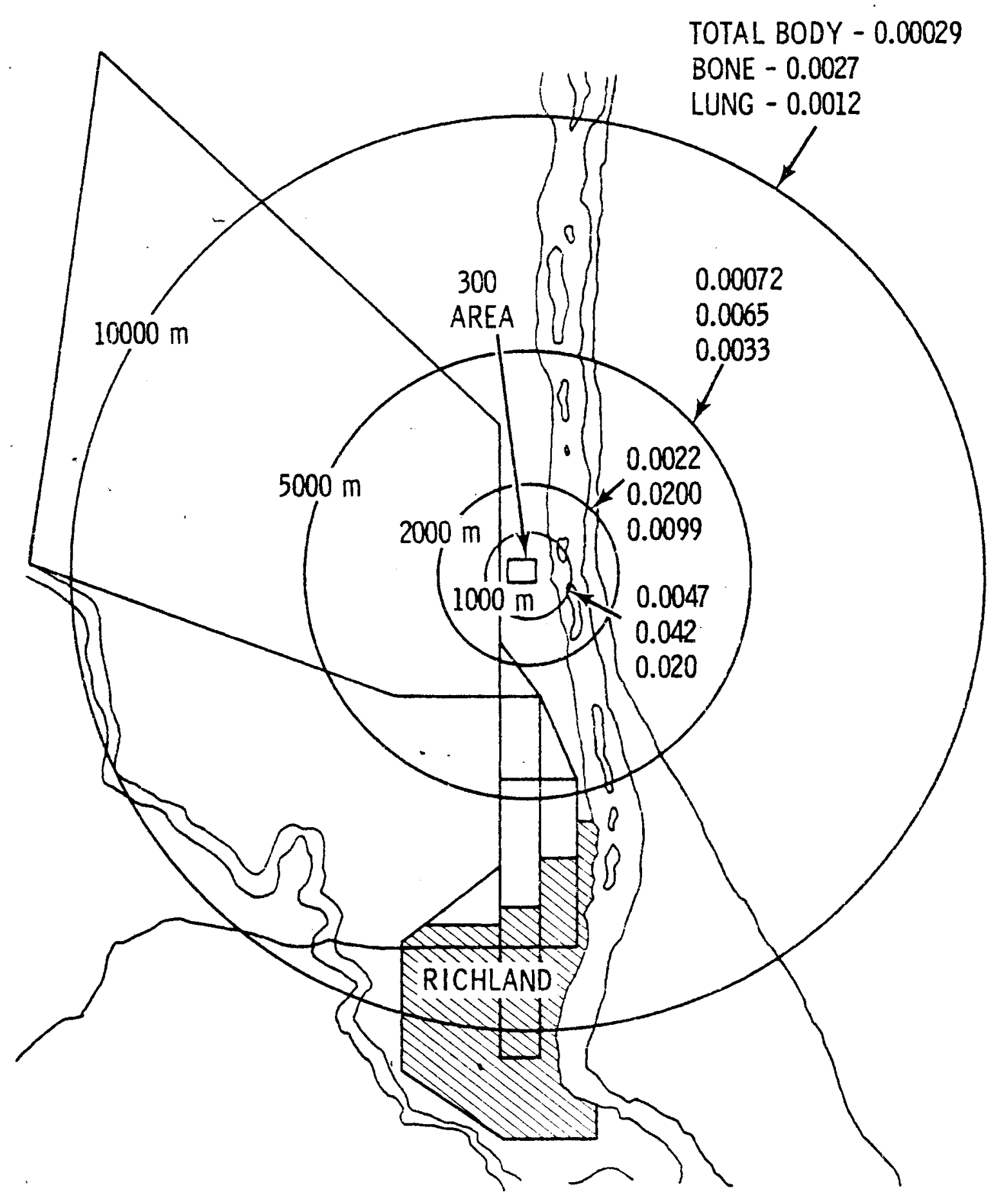

FIGURE 5-3. Inhalation Dose Prediction, Rem-ioble Gases (assumes $100 \%$ release of Noble Gases) Stable Meteorological Conditions 


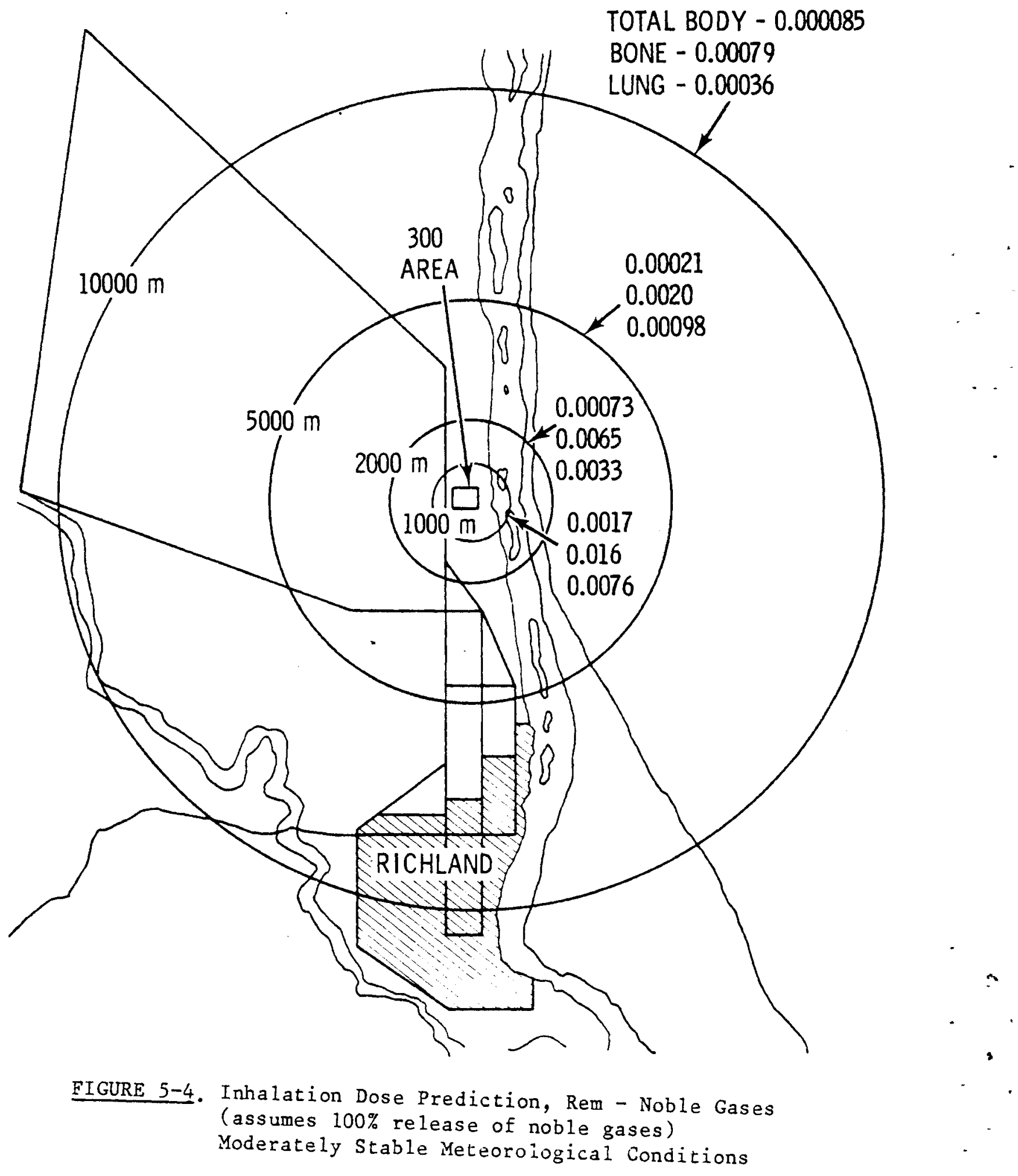




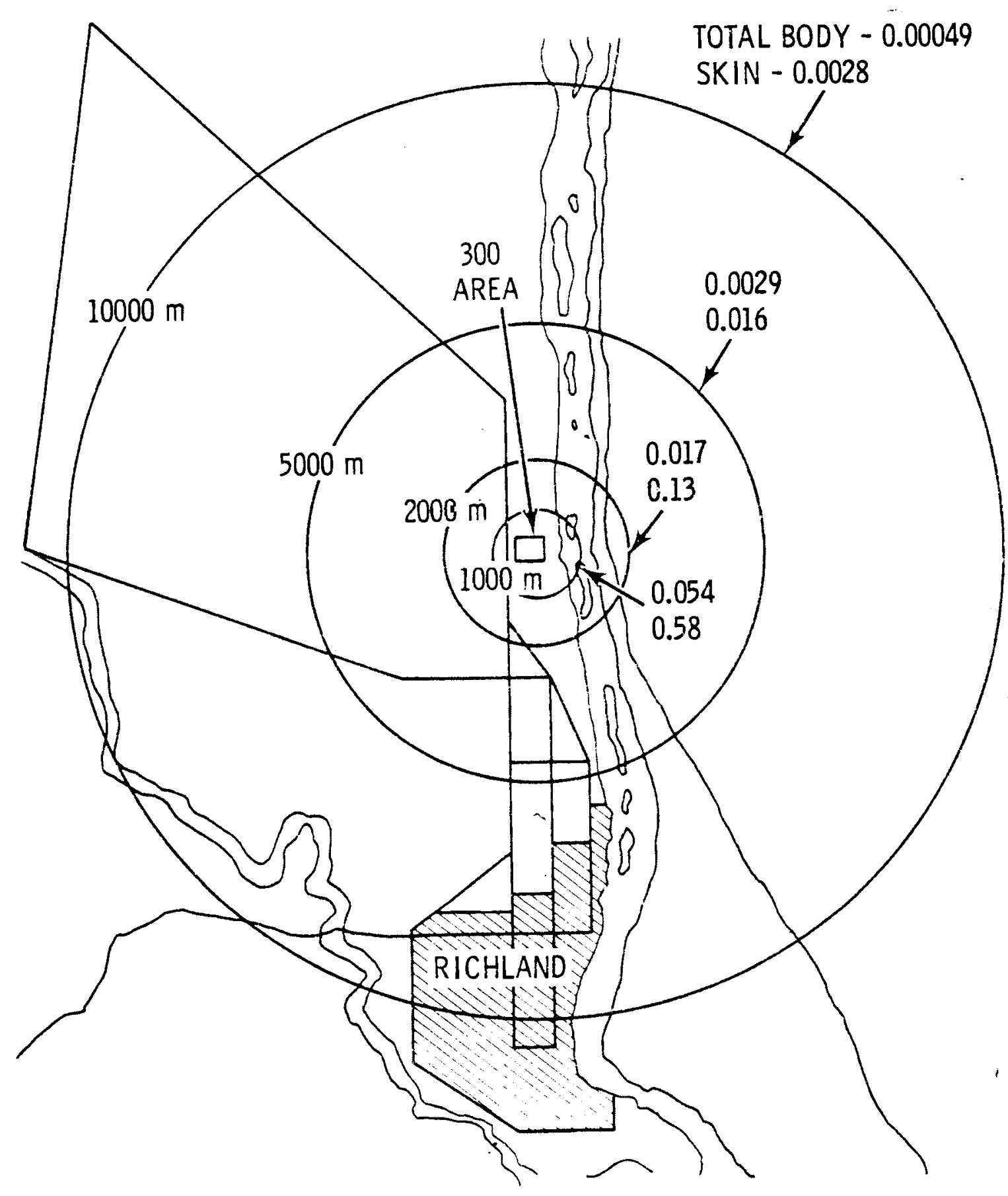

FIGURE 5-5. External Dose Prediction, Rem - Noble Gases (assumes $100 \%$ release of Noble Gases) Stable Meteorological Conditions 


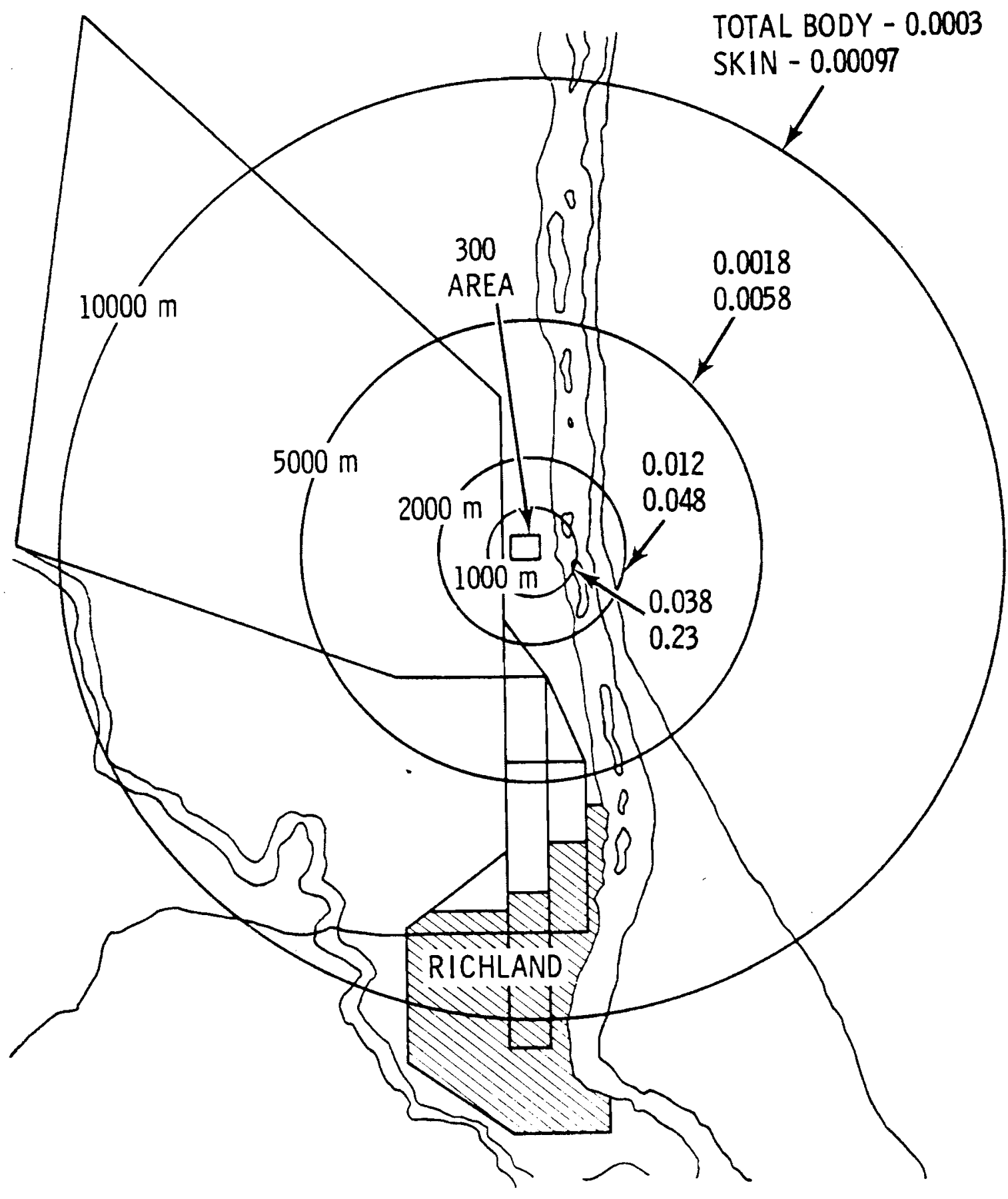

FIGURE 5-6. External Dose Prediction, Rem - Noble Gases (assumes $100 \%$ release of Noble Gases)

Moderately Stable Meteorological Conditions 


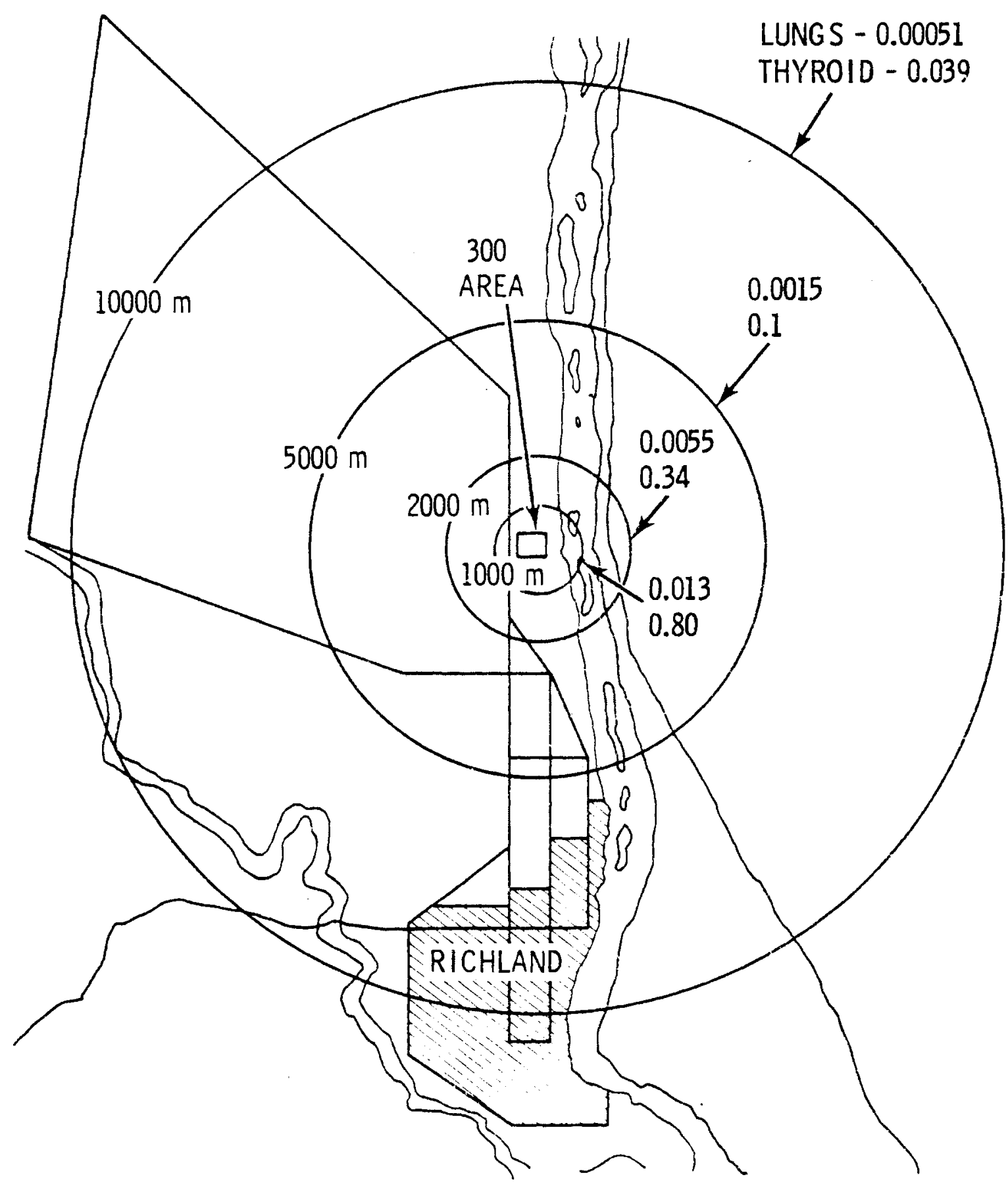

FIGURE 5-7. Inhalation Dose Prediction, Ren - Soluble $I_{2}$ (assumes $10 \%$ release of $I_{2}$ )

Stable Meteorological Conditions 


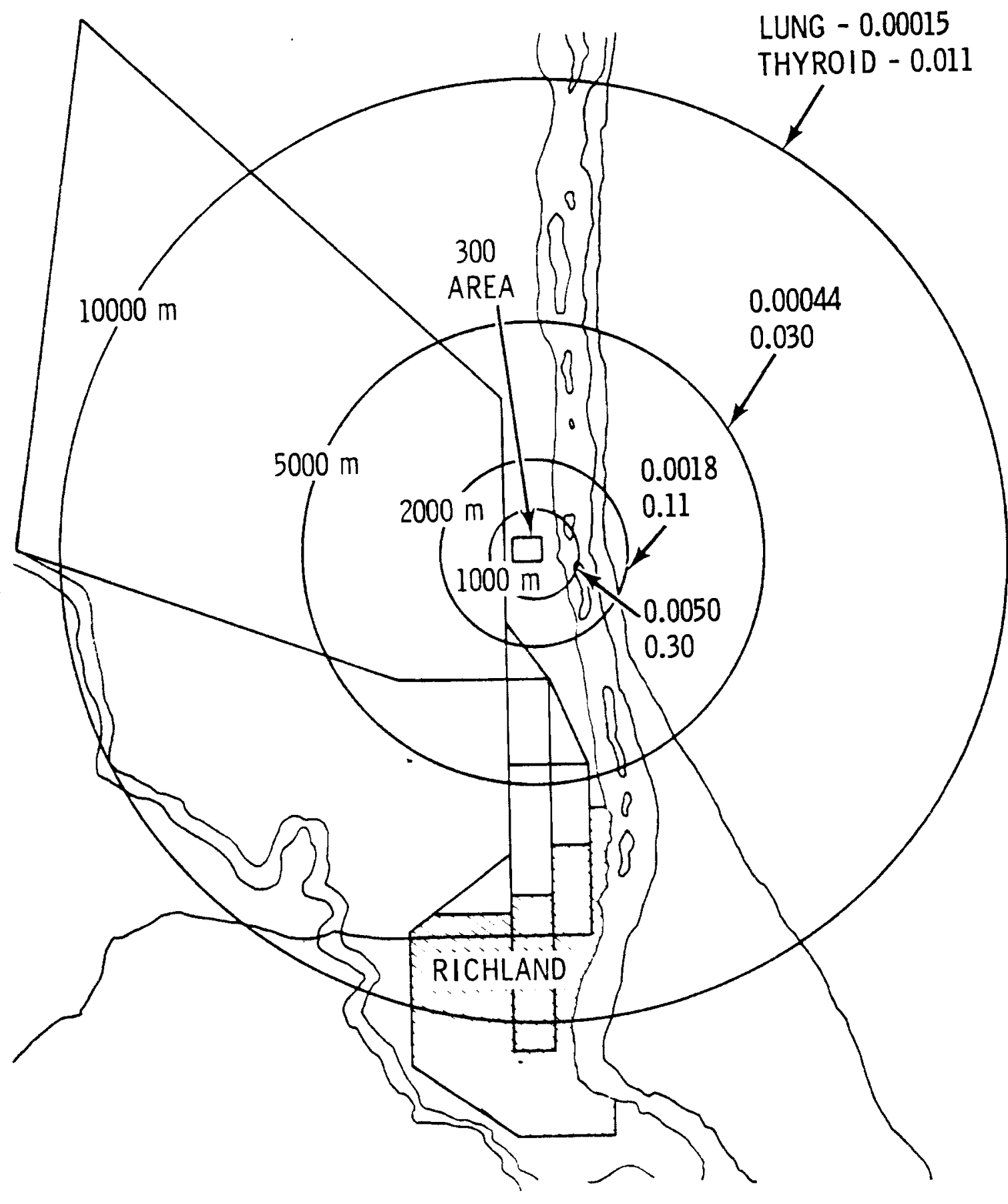

FIGURE 5-8. Inhalation Dose Prediction, Rem - Soluble $I_{2}$ (assumes $10 \%$ release of $\mathrm{I}_{2}$ ) Moderately Stable Meteorological Conditions 


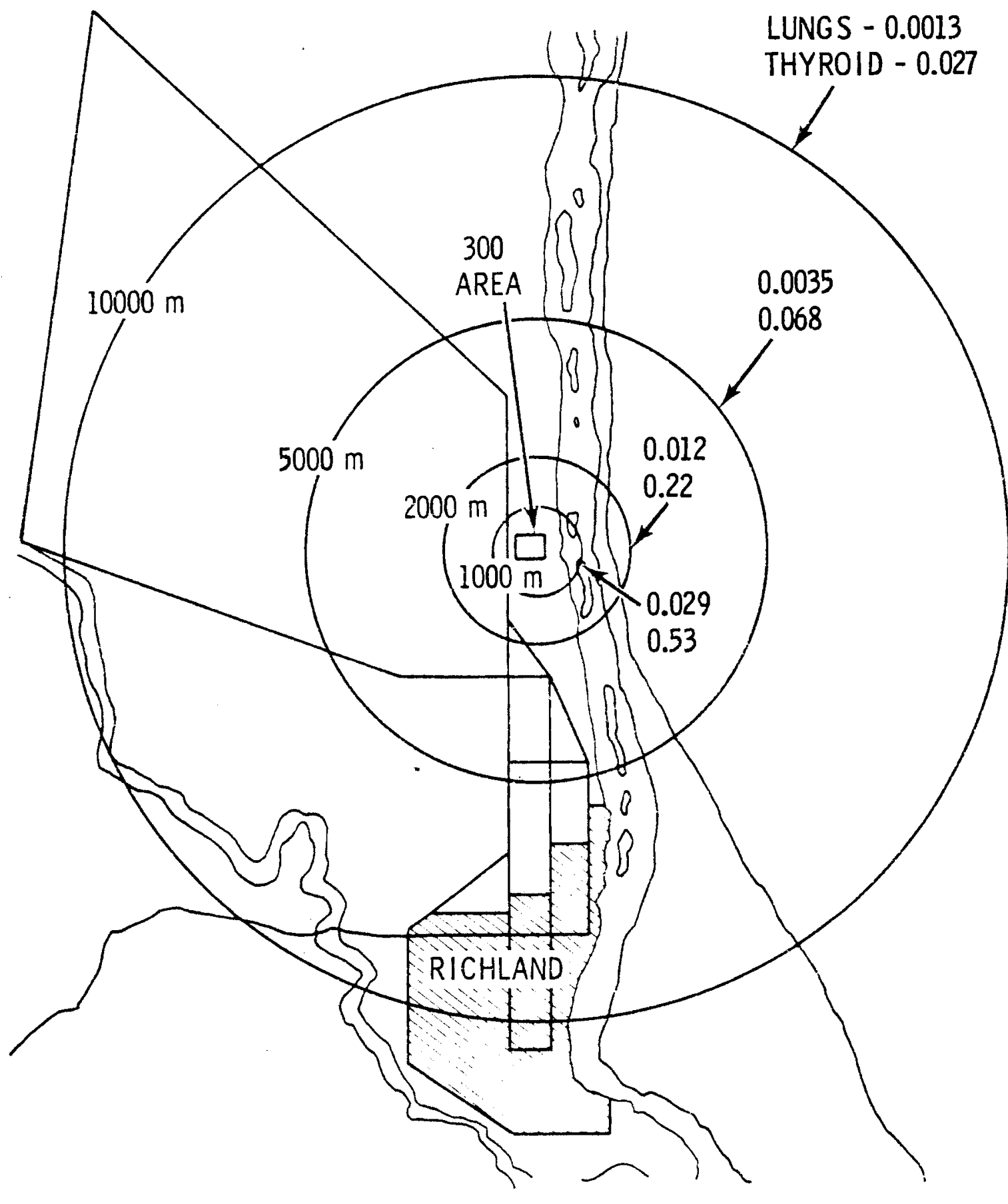

FIGURE 5-9. Irhalation Dose Prediction, Rem - Insoluble $I_{2}$ (assumes $10 \%$ release of $\mathrm{I}_{2}$ )

Stable Meteorological Conditions 


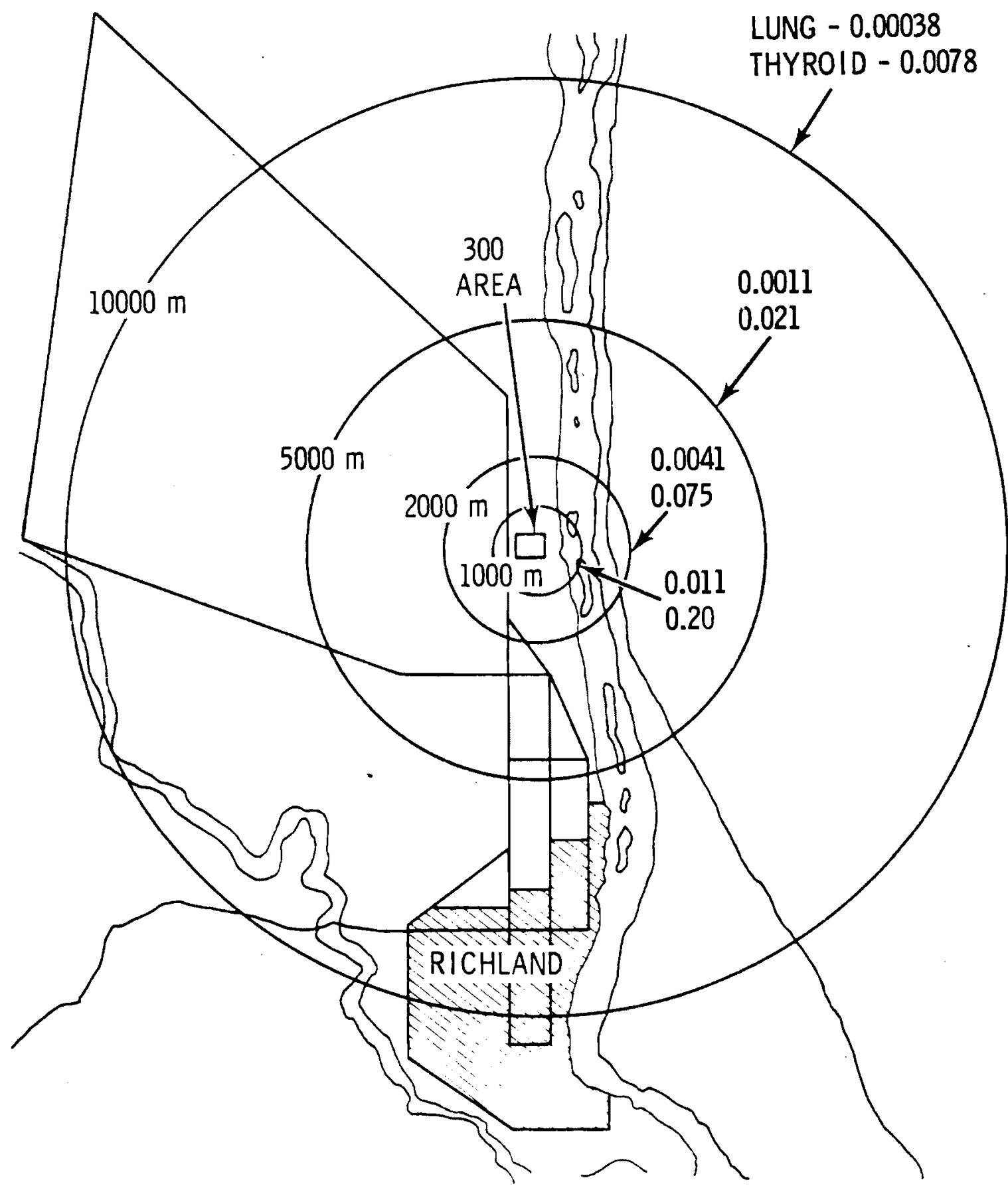

FIGURE 5-10. Inhalation Dose Prediction, Rem - Insoluble $\mathrm{I}_{2}$ (assumes $10 \%$ release of $I_{2}$ )

Moderately Stable Meteorological Conditions 


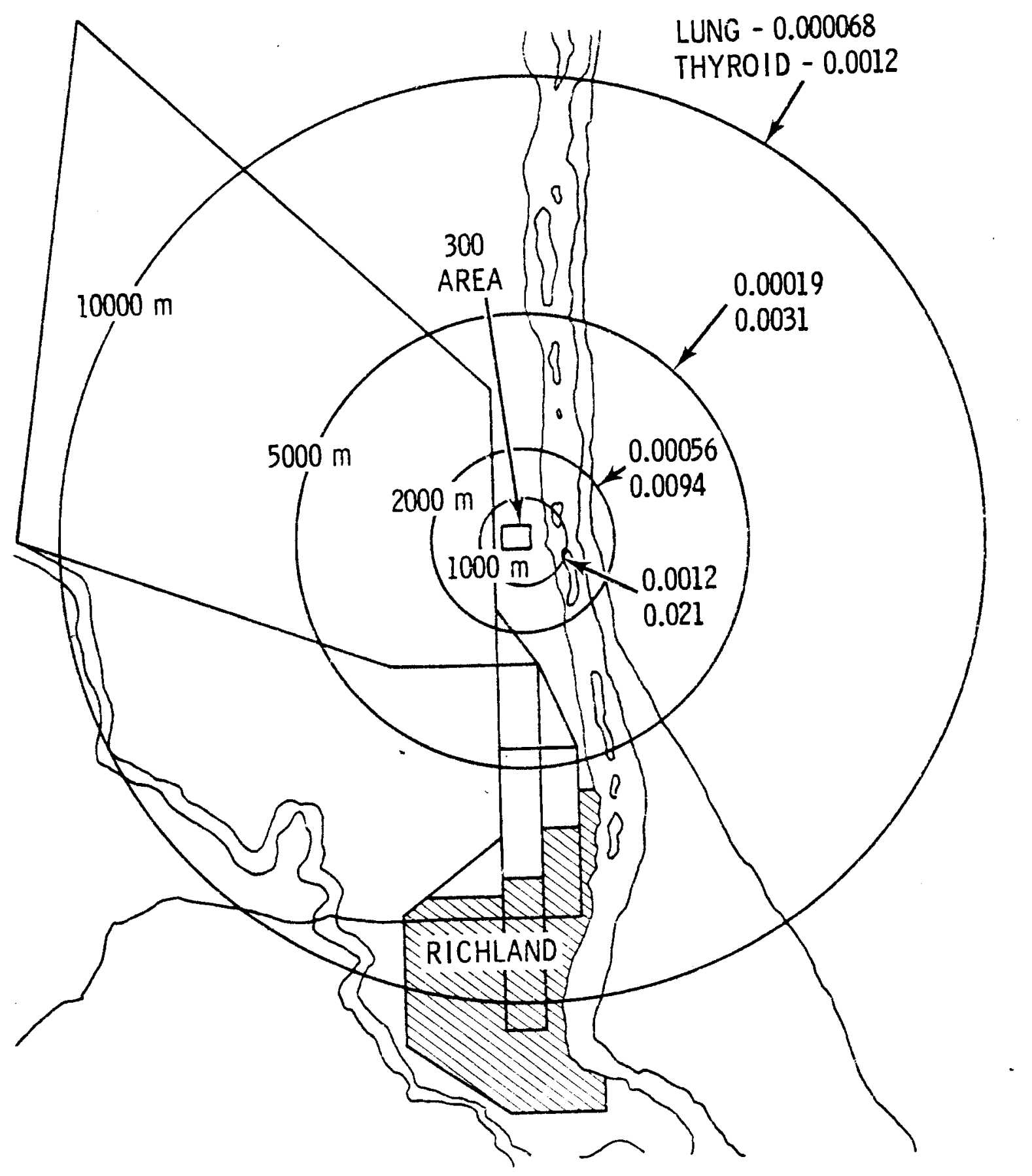

FIGURE 5-11. Inhalation Dose Prediction, Rem Soluble Volatile Fission Products

(assumes $1 \%$ release of Voiatile Fission Froducts) Stable Meteorolngical Conditions 


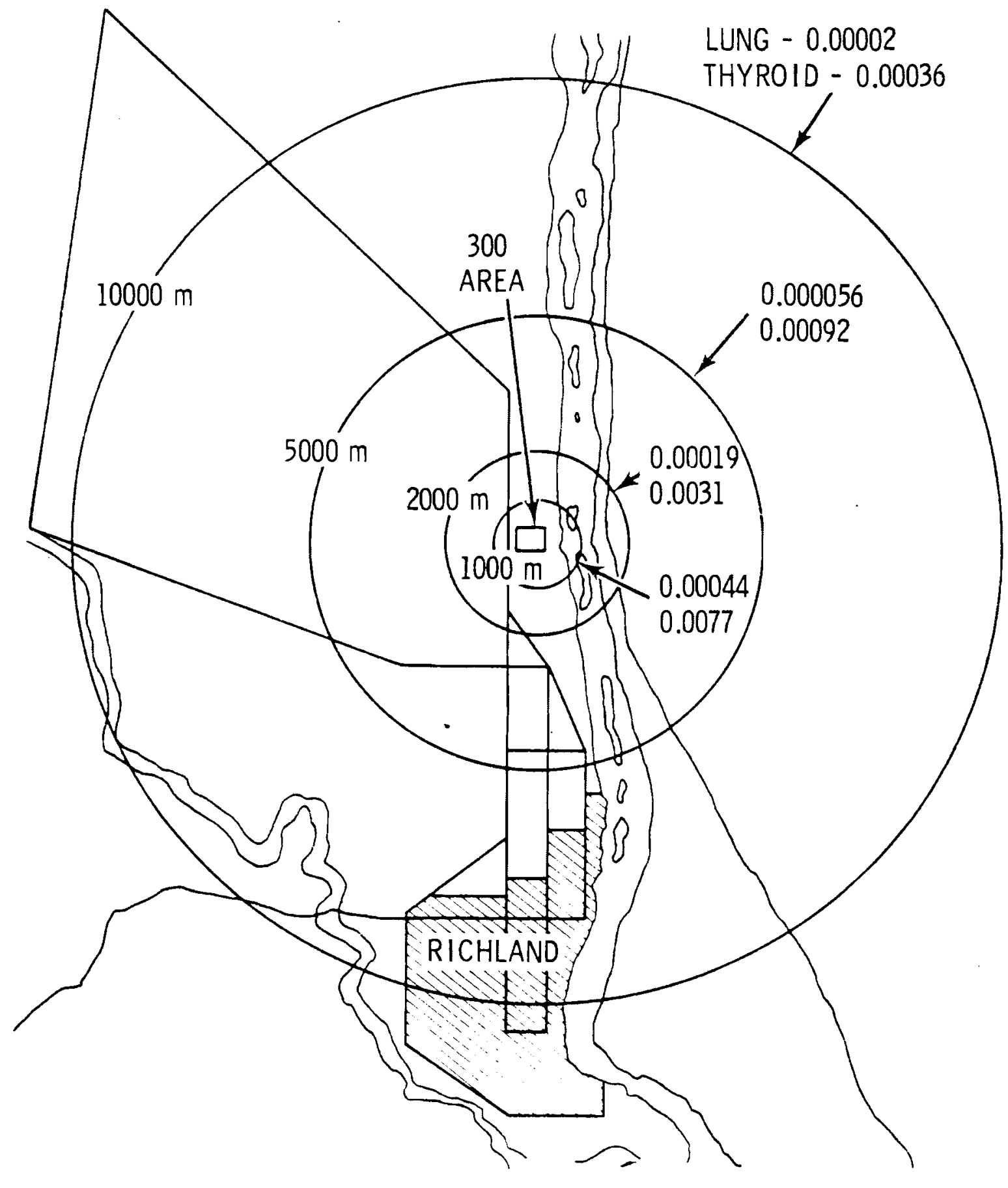

FIGURE 5-12. Inhalation Dose Prediction, Rem Soluble Volatile Fission Products (assumes $1 \%$ release of Volatile Fission Product) Moderately Stable Meteorological Conditions 


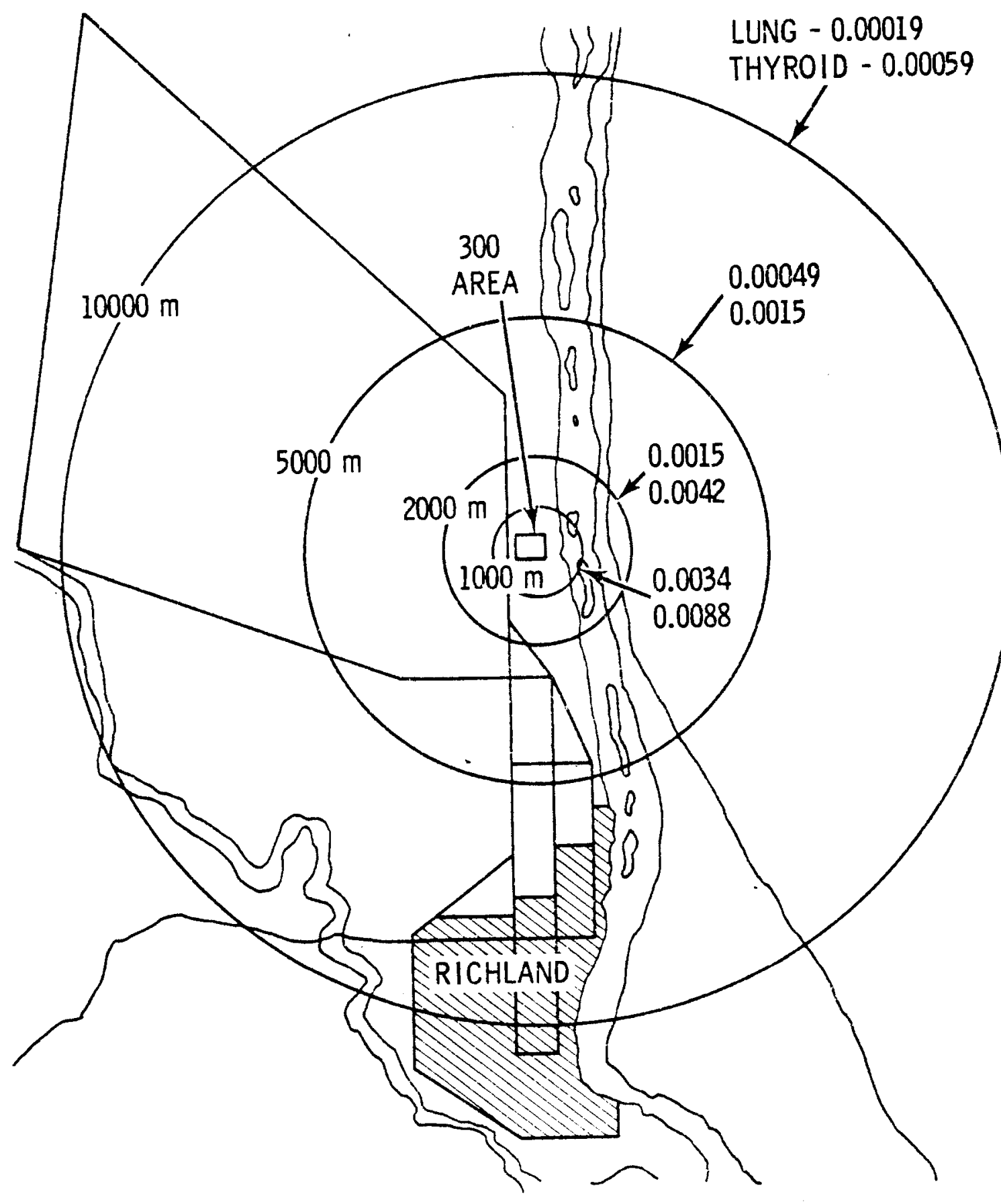

FIGURE 5-13. Inhalation Dose Prediction, Rem Insoluble Volatile Fission Products

(assumes $1 \%$ release of Volatile Fission Products) Stable MeterologicaI Conditions 


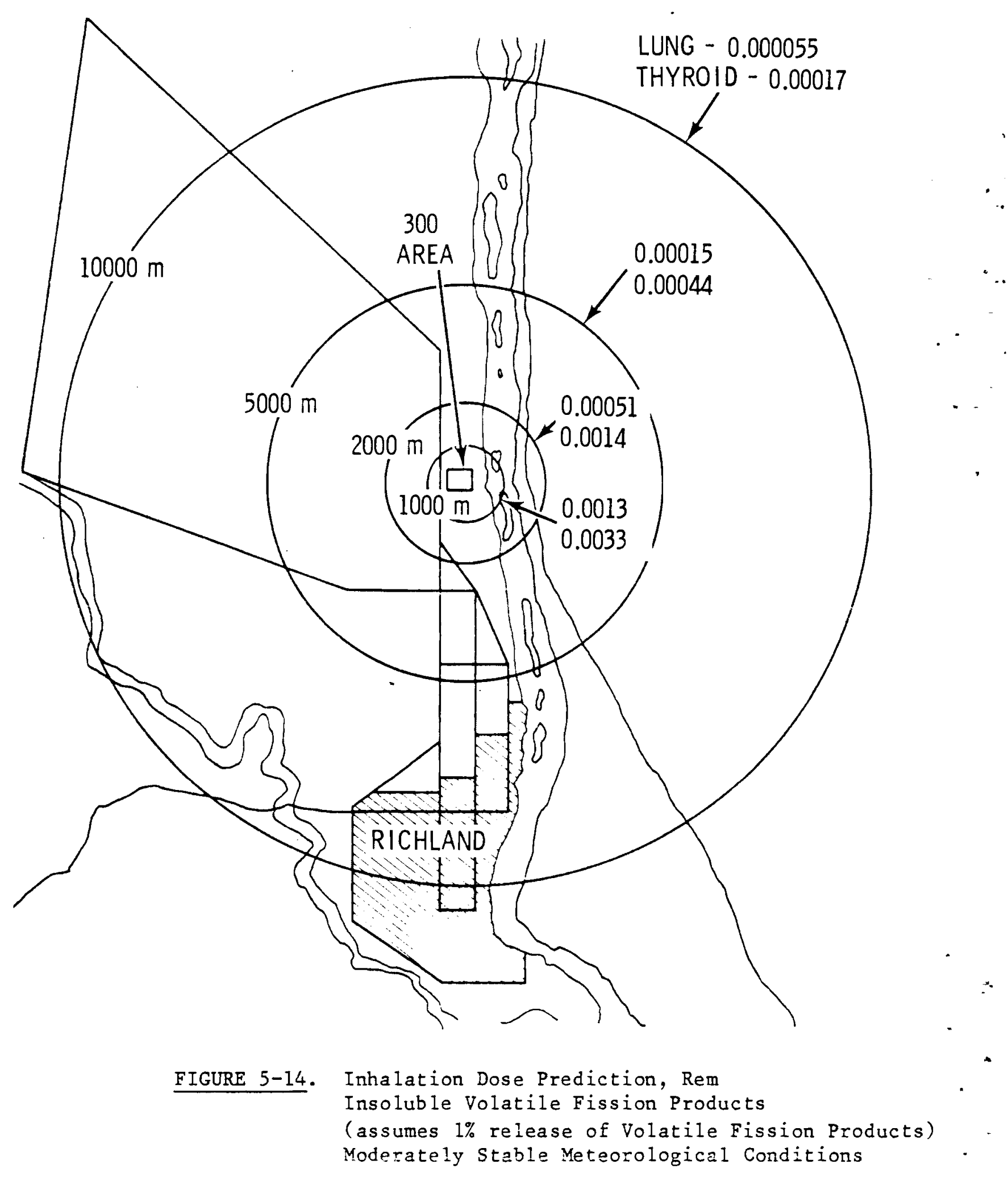




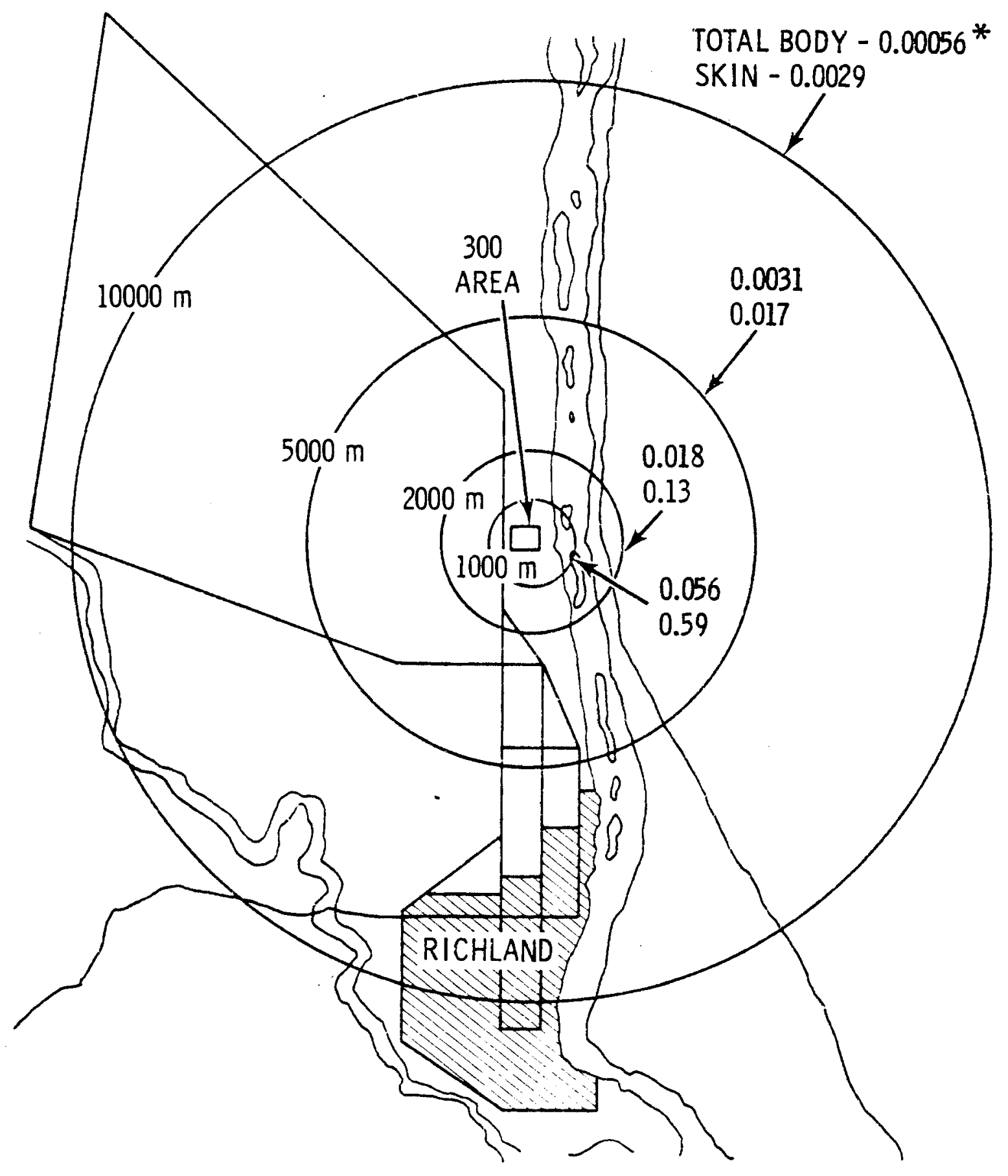

* ASSUMES 100\% RELEA SE OF NOBLE GASES, 10\% RELEA SE OF IODINE ISOTOPES, AND $1 \%$ RELEASE OF VOLATILE FISSION PRODUCTS

FIGURE 5-15. Total External Dose Prediction, Rem Stable Meteorologiaal Conditions 


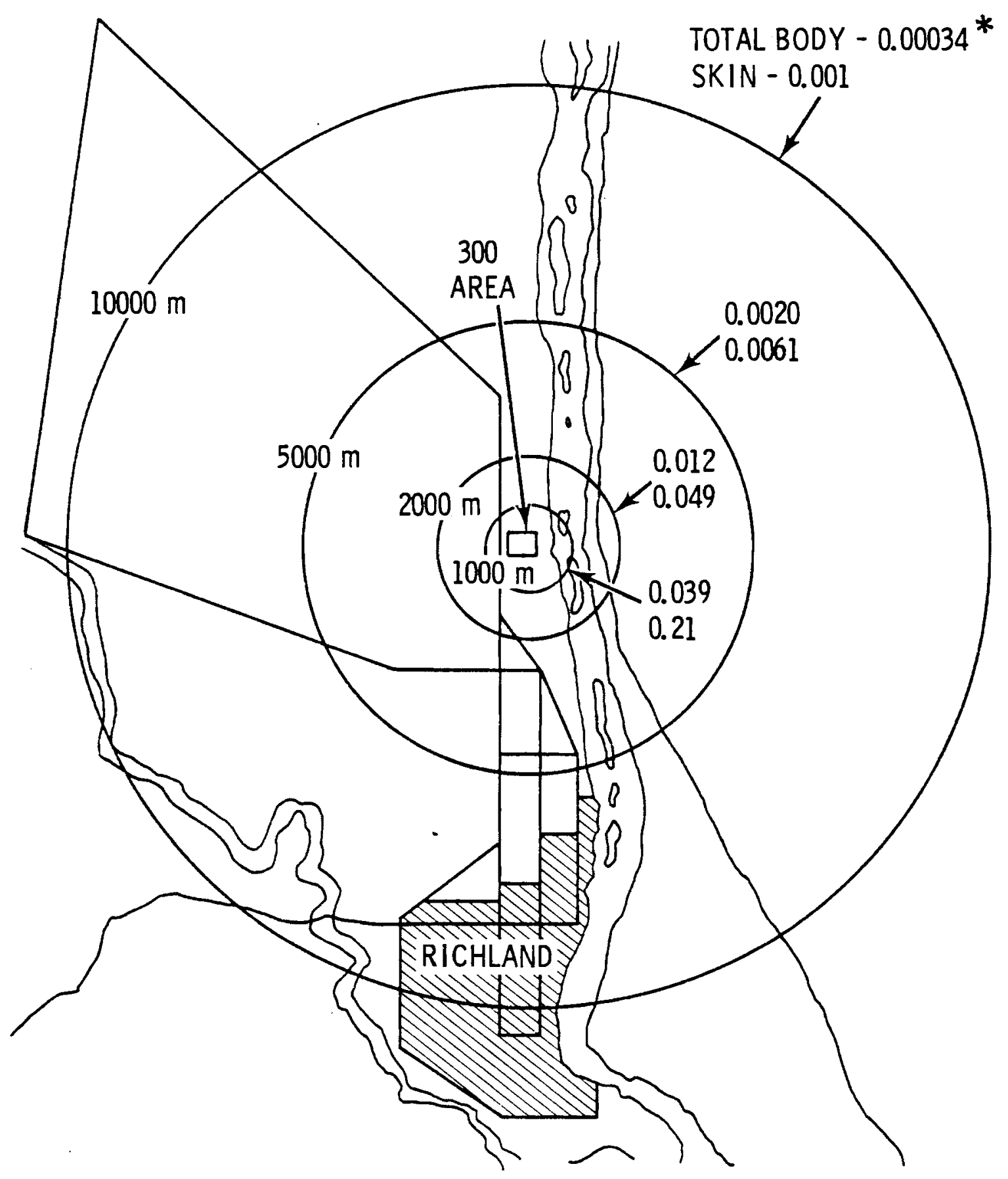
*ASSUMES 100\% RELEASE OF NOBLE GASES, 10\% RELEASE OF IODINE
ISOTOPES AND 1\% RELEA SE OF VOLATILE FISSION PRODUCTS.

FIGURE 5-16. Total External Dose Prediction, Rem Moderacely Stable Meteorological Conditions 
Figures 5-7 through 5-10. Dose predictions for the volatile fission products ( $\mathrm{Cs}, \mathrm{Se}, \mathrm{Te}$ ) are shown in Figure 5-11 through 5-14. Total external dose predictions for body and skin are shown in Figures 5-15 and 5-16.

Visual detection of a criticality night be difficult because visual contact is obscured by the 15-ft water column and the NMA top holding plate and cover. Visual evidence would be limited to bubble formation on the fuel rods and the bluish glow from the Ĉerenkov radiation during the short lived initial burst. The top holding plate and cover would prevent observation of these symptoms. The subsequent stages of criticality would possibly not appear different from routine operation.

A criticality condition would, however, be detected by the neutron calibration monitor located in the pool adjacent to the NMA. Although the detector might saturate during the initial burst, subsequent stages of criticality would indicate abnormally high readings on the calibration monitor. An alarm system signals this condition locally. The calibration montor will be in continuous service with emergency power backup. For those periods in which the calibration monitor is not in service (equipment failure and maintenance service) insertion of samples for irradiation will be prohibited.

In the extremely unlikely situation that an accidental criticality did occur and caused a failure of the fuel cladding, radioactive gases released within the operating area of the NMF would be detected by the gama detector giving both visual and audible alarms. This detector, like the calibration monitor, will be in continuous service with emergency power backup. A significant inhalation dose is not likely to be received from the radioactive gases because the room air is rapidly exchanged by the pass-through ventilation system in the NMF.

An actual or suspect occurrence of a criticality situation will require specific action on procedures designed to protect personnel and equipment from the consequences of such an incident. The severity of the incident will dictate the course of action to be taken. For example, if the pool wall is breached by the action causing the criticality, high radiation fields might be present in the room and the action taken would be different than in the case 
of an intact water column. Minimum accomplishments following an actual or suspected criticality will include the following:

- Establish that a criticality event is in progress. Verification can be made by use of the neutron calibration detector. Evacuate facility until potential hazard from radioactive gases has been evaluated. Access to the room and subsequent actions will be governed by the radiation levels.

- Notify organizations who have a responsibility in this matter. Assess the probable danger involved and evacuate the necessary areas.

- Quench the reaction by introduction of boron materials into appropriate irradiation tubes. Boron materials will be stored in an appropriate location within easy access to the NMA.

- Install appropriate shielding and/or restrict entry if high radiation fields exist.

- Determine cause of criticality and make necessary re-evaluations and revisions of procedures and/or equipment to prevent recurrence.

- A written recovery plan will be used if possible.

\subsection{PLANS FOR EVENTUAL SHUTDOWN AND DISPOSAL OF THE NMF}

If at some future time the need for the neutron multiplier no longer exists, the facility may be shut down and disposed of with minimal expenditure of time or funds. The exact steps required for shutdown and disposal will be developed when the decision is made to shut down the facility. A possible shutdown and disposal plan is given below:

1) Remove the fuel elements and ship them to a processing plant for recovery of the uranium

2) Remove and transier the ${ }^{252} \mathrm{Cf}$ source

3) Process the pool water through the filter and ion exchanger for a sufficient length of time to reduce the amount of dissolved or particulate radioactive material in the water to such a level that the water may be disposed of in the cold process sewer system 
4) Make required modifications to water process system and pump into cold process sewer system

5) Dispose of hardware which was sicuated in or ciose to the neutron mulitplier unit as low level radioactive waste

6) The remainder of the facility should contain only trace amounts of radioactivity. Smear and monitor the remainder of the facility to detect any concentrations of smearable or fixed radioactivity. Any contaminated material or equipment should be selectively disposed of as radioactive waste. Disposal of all other material and equipment should follow the procedures used for non-contaminated materials.

7) Fill in or install a permanent cover over the neutron multiplier pit. 
$\bullet$ - 
1. R. C. Lloyd et al., Criticality Studies of a Neutron Multiplier Lattice, BNWL-2031, Battelle, Pacific Northwest Laboratories, Richland, WA. $99352,1976$.

2. Reactor Handbook, 2nd Edition, Vol. 1 Materials, C. R. Tipton, Jr. Editor, 1960. Interscience Publishers, Inc.

3. Ron Hall and George Rieck, Preliminary Safety Analys is Report for the Battelle Northwest Multiplier Facility, BNWL-B-341, Battelle, Pacific Northwest Laboratories, Richland, WA, 99352, October 1973.

4 T. J. Thompson and J. G. Beckerley (editors), The Technology of Nuclear Reactor Safety - Vol. I, MIT Press, Cambridge, Mass., 1964.

5. W. E. Kennedy, Jr. "Release Exposures from a Neutron Multiplied Facility Criticality Incident," May 10, 1976. Appendix F.

6. R. B. Richmond and C. W. Pollock, Corrosion and Wear Surveillance in Plutonium Recycle Test Reactor Through December, 1967, BNWL-726, Battelle, Pacific Northwest Laboratories, Richland, WA, 99352, July 1968 .

7. Samuel Glasstone and Alexander Sesonske, Nuclear Reactor Engineering, $D$. Van Nostrand Company, Inc. Princeton, New Jersey, 1963.

8. Rules and Regulations of the United States Nuclear Regulatory Commission. Title 10, Chapter 1, Code of Federal Regulation, Part 20, Standards for Protection against Radiation. April 30, 1975 

APPENDIX A

${ }^{41}$ Ar PRODUCTION 
41 Ar PRODUCTION

Air contains approximately $0.93 \%$ (by volume) of the inert gas argon which is $99.6 \%{ }^{40} \mathrm{Ar}$. The $(n, y)$ reaction with ${ }^{40} \mathrm{Ar}$ yields ${ }^{41} \mathrm{Ar}$, a beta emitter with a 1.83 hr half life.

The following assumptions were made in calculating ${ }^{41} \mathrm{Ar}$ production in a capped external irradiation tube:

1) ${ }^{41} \mathrm{Ar}$ is produced during a long term irradiation at an average flux of $3 \times 10^{9}$ neutrons $/ \mathrm{cm}^{2}-\mathrm{sec}$ assumed to exist in the approximateiy $2-\mathrm{ft}$ long portion of a 4-in. diameter irradiation tube which is adjacent to the Iuel region of the neutron multiplier.

2) The ${ }^{41}$ Ar will remain in the capped irradiation tube until physical action by facility personnel disturbs the condition in the tube. The flux of $3 \times 10^{9}$ neutrons $/ \mathrm{cm}^{2}-\mathrm{sec}$ is a conservative estimate of the average flux in the 2-ft long section of a 4-in. diameter external irradiation tube. ${ }^{41}$ Ar production in the irradiation tube outside the $2-\mathrm{ft}$ long section adjacent to the core will be negligible compared to production in this section. There will be no mechanism for ${ }^{41}$ Ar transport except for normal siow diffusion in stagnant uniform temperature air.

\section{$\underline{\text { Data }}$}

40 Ar Target

$$
\begin{array}{ll}
\text { Composition in air } & -0.934 \% \text { (by volume) } \\
\text { Molecular weight } & -39.94 \\
\text { Cross section, } \sigma & -0.64 \times 10^{-24} \mathrm{~cm}^{2} \\
\text { Density, } \mathrm{g} / \ell & -1.784 \\
\hline \mathrm{Ar} & \\
&
\end{array}
$$


For External Irradiation Tubes

Volume

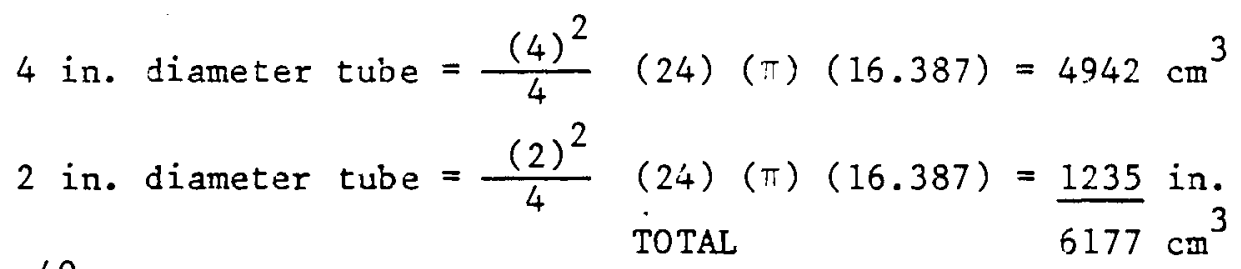

Target $40 \mathrm{Ar}$

Atoms $=\frac{(6.177)(0.00934)(1.784)\left(6.023 \times 10^{23}\right)}{39.94}=1.55 \times 10^{21}$

${ }^{41}$ Ar Production (at saturation)

$$
\frac{d N}{d t}=\text { Production-Decay }=\phi \sigma r_{L}-\lambda n
$$

or $\quad \mathrm{N}=\frac{\phi \sigma n}{\lambda}\left(1-e^{-\lambda t}\right)+N_{0}-\lambda t$

if $\quad N_{0}=0$ and $t=1$ long compared to $t_{1 / 2}$

then $\mathrm{N}_{\text {sat }}=\frac{\phi \sigma \mathrm{n}}{\lambda}$ or Activity sat $=\phi \sigma \mathrm{n}$

or Activity sat $=\left(3 \times 10^{9}\right)\left(0.64 \times 10^{-24}\right)\left(1.55 \times 10^{21}\right)=2.98 \times 10^{6} \mathrm{~d} / \mathrm{s}$.

$$
=31 \mu \mathrm{Ci}{ }^{41} \mathrm{Ar}
$$

For Pneumatic Sample Transfer System in Central Irradiation Tube

Assume that the pneumatic system replaces the center tube so that the active volume is $12 \mathrm{in.}$ long and that air is used to drive the samples.

Volume

$-\frac{(2)^{2}}{4}(\pi)(12)(16.387)=617.28 \mathrm{~cm}^{3}$

Target Ar 40

$-(0.617)(0.00934) \frac{(1.784)}{39.94}\left(6.023 \times 10^{23}\right)=1.55 \times 10^{20}$ atoms 
41 Ar Production at Saturation

$$
\begin{aligned}
\text { Activity }_{\text {sat }} & =\left(3 \times 10^{9}\right)\left(0.64 \times 10^{-24}\right)\left(1.55 \times 10^{20}\right)=2.98 \times 10^{5} \mathrm{~d} / \mathrm{s} \\
& =8.06 \mathrm{HCi}^{4 i} \mathrm{Ar}
\end{aligned}
$$

${ }^{41}$ Ar Production for a 10 Minute Sample Irradiation

$$
\begin{aligned}
A & =A_{\text {sat }}\left(1-e^{-\lambda t}\right) ; \quad \lambda t=\frac{(.693)(10)}{(1.83)(60)}=0.0631 \\
& =(8.06)\left(1-e^{-0.0631}\right)=0.5 \mu \mathrm{Ci}{ }^{41} \mathrm{Ar}
\end{aligned}
$$




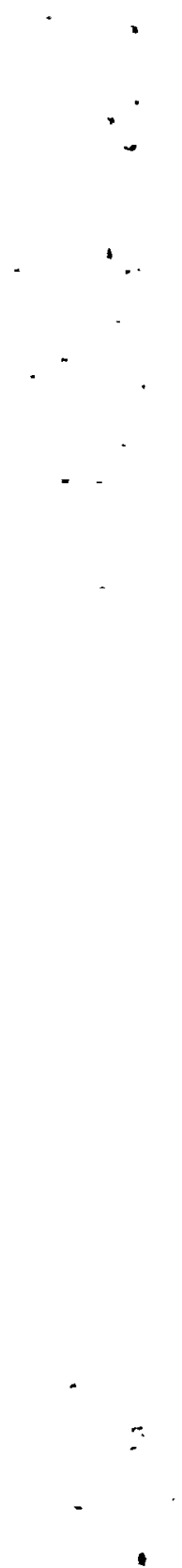


APPENDIX B

CALCULATION OF ${ }^{24} \mathrm{Na}$ ACTIVITY IN POOL WATER ${ }^{(3)}$ 


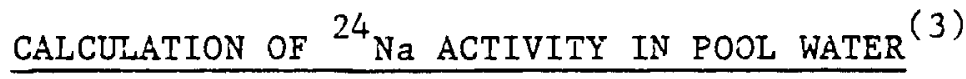

The pool water will contain trace amounts of ${ }^{24} \mathrm{Na}$. A beta emitter with a 15-hr half life, ${ }^{24} \mathrm{Na}$ is produced by the $(\mathrm{n}, \alpha)$ reaction of fast neutrons with ${ }^{27} \mathrm{Al}$. The decay product of ${ }^{24} \mathrm{Na}$ is stable. The ${ }^{24} \mathrm{Na}$ activity will remain in the pool water untii it decays or is retained in the ion exchange column. The maximum concentration of ${ }^{24} \mathrm{Na}$ in the pool water will be less than $10^{-5} \mu \mathrm{Ci} / \mathrm{l}$ (as shown in this appendix). Normally, with proper cleanup of the pool water, the concentration would be significantly lower, since a large portion of the ${ }^{24} \mathrm{Na}$ would be collected on the ion exchange cartridge.

The ${ }^{27} \mathrm{Al}(\mathrm{n}, \alpha){ }^{24} \mathrm{Na}$ reaction is a threshold reaction occurring at approximately $3.25 \mathrm{MeV}$. The cross-section is initially quite small, not reaching 1 millibarn until 5 to $6 \mathrm{MeV}$. From $6 \mathrm{MeV}$ it increases monotonically, reaching a value of approximately 90 millibarns at $10 \mathrm{MeV}$. The maximum thermal neutron flux in the neutron multiplier will be approximately $10^{10}$ neutrons/cm ${ }^{2}-\mathrm{sec}$. The maximum flux above the ${ }^{27} \mathrm{Al}(\mathrm{n}, a)$ threshold is found from diffusion theory calculations to be approximately $2 \times 10^{8}$ neutrons/ $\mathrm{cm}^{2}-\mathrm{sec}$. The average above threshold flux is about $3 / 4$ of this value.

Essentially any collision of a neutron in water will degrade its energy to below the threshold; therefore, the ${ }^{27} \mathrm{AI}(\mathrm{n}, \alpha){ }^{24} \mathrm{Na}$ reaction is only important in the fuel rod cladding. The ${ }^{24} \mathrm{Na}$ formed in the reaction will remain in the aluminum cladding until it decays or is leached into the water. Because of low porosity, there is no leaching from the aluminum metal. The ${ }^{24} \mathrm{Na}$ in the water comes from the thin oxide layer on the external surface of the fuel rod and is leached out at a corrosion rate which permits decay prior to entry into the water. Corrosion rates observed in the PRTR, (6) under conditions which were more favorable for corrosion than those that will exist in the neutron multiplier pool, were less than 0.0001 in. per year. 
The following calculations give an estimate of the ${ }^{24} \mathrm{Na}$ activity in the water:

$$
\mathrm{R}=\text { Reaction Rate } / \mathrm{cm}^{3}={ }^{3} \mathrm{~N}_{\mathrm{A} 1} \bar{\sigma}
$$

The flux above the ${ }^{27} \mathrm{Al}(\mathrm{n}, \alpha)$ threshold is assumed to be $2 \times 10^{8}$ neutrons/ $\mathrm{cm}^{2}-\mathrm{sec}$.

The spectrum weighted average cross section is assumed to be 10 millibarns.

$$
\begin{aligned}
\mathrm{N}_{\mathrm{A} 1} & =\frac{(2.69)\left(6.023 \times 10^{23}\right)}{26.99} \\
& =6.0 \times 10^{22} \text { atoms } / \mathrm{cm}^{3} \\
\mathrm{R} & =\left(2 \times 10^{8}\right)\left(6.0 \times 10^{22}\right)\left(0.01 \times 10^{-24}\right)\left(3.6 \times 10^{3}\right) \\
& =4.32 \times 10^{8} \text { atoms of }{ }^{24} \mathrm{Na} \text { produced } / \mathrm{cm}^{3}-\mathrm{hr}
\end{aligned}
$$

At equilibrium in the aluminum

$$
\begin{aligned}
\frac{\mathrm{d} \mathrm{N}_{24}}{\mathrm{dt}} & =4.32 \times 10^{8}-\lambda \mathrm{N}_{24}=0 \\
\mathrm{~N}_{24} & =\text { atoms of }{ }^{24} \mathrm{Na} / \mathrm{cm}^{3} \\
\lambda & =\frac{0.693}{\text { half } 1 \text { ife of }{ }^{24} \mathrm{Na}}=4.62 \times 10^{-2} \mathrm{hr}^{-1} \\
& =1.283 \times 10^{-5} \mathrm{sec}^{-1} \\
\mathrm{~N}_{24} & =\frac{4.32 \times 10^{8}}{4.62 \times 10^{-2}} \\
& =9.35 \times 10^{9} \text { atoms/ } \mathrm{cm}^{3}=\begin{array}{l}
\text { equilibrium concentration of } \\
24
\end{array}
\end{aligned}
$$


Assume that the corrosion rate of aluminum is $0.1 \mathrm{mils} / \mathrm{yr}=$ $2.9 \times 10^{-8} \mathrm{~cm} / \mathrm{hr}$

$\mathrm{V}=$ Volume of material removed from rodsihr

$$
=\pi(n)(l)\left(r_{1}^{2}-r_{2}^{2}\right)
$$

where

$$
\begin{aligned}
& n=\text { number of rods } \\
& \ell=1 \text { ength of rod } \\
& r_{1}=\text { radius of rod } \\
& r_{2}=r_{1}-\text { corrosion rate in } \mathrm{cm} / \mathrm{hr}
\end{aligned}
$$

Assume that the muliiplier will contain 252 rods each with oD of 0.4 in. and length of $22.75 \mathrm{in}$.

Substituting in these values yields

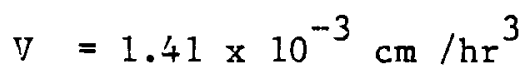

$\mathrm{P}=$ quantity of ${ }^{24} \mathrm{Na}$ entering water/hr $=\mathrm{N}_{24} \mathrm{~V}=(9.35 \times 10)\left(1.41 \times 10^{-3}\right)$ $=1.32 \times 10^{7}$ atoms $/ \mathrm{hr}$

At equilibrium in the water

$$
\frac{\mathrm{dN}_{24}{ }^{1}}{\mathrm{dt}}=\mathrm{P}-\lambda \mathrm{N}_{24}{ }^{1}=0
$$

where

$$
\begin{aligned}
& \mathrm{N}_{24}{ }^{1}=\text { atoms of }{ }^{24} \mathrm{Na} \text { in the water } \\
& \mathrm{N}_{24}{ }^{1}=\frac{\mathrm{P}}{\lambda}=\frac{1.32 \times 10^{7}}{4.62 \times 10^{-2}}=2.85 \times 10^{3} \text { atoms at } \\
& \text { Activity }=\lambda \mathrm{N}_{24}{ }^{1}=\left(1.283 \times 10^{-5}\right)\left(2.85 \times 10^{8}\right) \\
& =3.65 \times 10^{3} \mathrm{dis} / \mathrm{sec} \\
& =0.099 \mathrm{Hi}
\end{aligned}
$$

Volume of water in 5-ft diameter $x$ 20-ft deep pool $=11120$

$$
\text { Na activity }=0.89 \times 10^{-5} \mathrm{LCi} / 2
$$



APPENDIX C

ESTIMATION OF HEAT OUTPUT FROM NMA 
The NMA will be operated with 100 ing of ${ }^{252} \mathrm{Cf}$ at an estimated fission rate of $3.3 \times 10^{12}$ fission/second. This fission rate is based upon the following:

- Source emission $-2.4 \times 10^{11}$ neutrons/second

- Neutron absorption by ${ }^{235} U-40 \%$

- Probability of fission - $85 \%$

- Multiplication factor - 40

$$
\text { Rate }=\left(2.4 \times 10^{11}\right)(0.4)(0.8)(40)=3.3 \times 10^{12} \mathrm{fission} / \mathrm{sec}
$$

Since the energy release per fission is about $195 \mathrm{MeV}^{(7)}$, the total energy released during operation is

$$
\left(3.3 \times 10^{12}\right)(195)=6.44 \times 10^{14} \mathrm{MeV} / \mathrm{sec}
$$

$$
\begin{aligned}
& \text { since } 1 \mathrm{MeV}=1.52 \times 10^{16} \mathrm{Btu} \\
& E=\left(6.44 \times 10^{14} \mathrm{MeV} / \mathrm{sec}\right)\left(1.52 \times 10^{-16} \mathrm{Btu} / \mathrm{MeV}\right) \\
& =0.0978 \mathrm{Btu} / \mathrm{sec} \\
& =(0.0978 \mathrm{Btu} / \mathrm{sec})(3600 \mathrm{sec} / \mathrm{hr}) \\
& =352.12 \mathrm{Btu} / \mathrm{hr} \\
& 1 \mathrm{Btu} / \mathrm{hr}=0.2931 \text { watt } \\
& \begin{aligned}
E & =(352.12 \mathrm{Btu} / \mathrm{hr})\left(0.2931 \frac{\text { watt }}{\mathrm{Btu} / \mathrm{hr}}\right) \\
& =103.2 \text { watts }
\end{aligned}
\end{aligned}
$$


APPENDIX D

CALCULATION OF REACTIVITY CHANGE IN NMA 
If changes are made in the operating conditions of NMA, the reactivity of $k_{\text {eff }}$ is altered. Calculation of these changes in reactivity or $k_{\text {eff }}$ are based upon data taken from "Criticality Studies of a Neutron Multiplier Lattice"(1) Data from Figure 7, p. $18^{(1)}$ is shown in Figure D-1.

Voiding 2-in. Diameter Center Tube

$1 / 2$ full of water filled with water

$$
\begin{aligned}
& \frac{\stackrel{N}{c}}{276.3} \\
& 281.9 \\
& \Delta N_{c}=-5.6 \\
& \text { (p. 5) } \\
& \text { (p. 10) }
\end{aligned}
$$

$$
\begin{aligned}
& \frac{\mathrm{N}_{\mathrm{c}}}{252} \\
& 246.4 \\
& \Delta \mathrm{k}_{\text {eIf }}
\end{aligned}
$$

$1 / 2$ full to void

$$
\begin{aligned}
\frac{N_{c}}{252} & \frac{k_{\text {eff }}}{0.9799} \\
256.9 & \frac{0.9842}{\Delta k_{\text {eff }}} \quad \text { (From D-1) } \\
\text { Total } \Delta k_{\text {eff }} & =0.0043
\end{aligned}
$$

Fue 1 Rod Addition

$1 / 3$ full rod in void of center tube $1 / 2$ full water

$\begin{array}{ll}\frac{\mathrm{N}_{\mathrm{c}}}{252} & \frac{\mathrm{k}_{\text {eff }}}{0.9799} \\ 256.37 & 0.9837 \\ \Delta \mathrm{k}_{\text {eff }} & +0.0038\end{array}$

(Table V, p. 13)

(From D-1) 
1 Fuel Rod

centered vertically

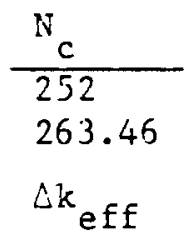

$$
\begin{aligned}
\Delta N_{C}= & +11.40 \\
& \frac{k_{\text {eff }}}{0.9799} \\
& \frac{0.9899}{+0.0100}
\end{aligned}
$$

Graphite (1.75-in. O.D.)

in void in top half

$\frac{\mathrm{N}_{\mathrm{c}}}{252}$
255.3
$\Delta \mathrm{k}_{\text {eff }}$

$$
\begin{aligned}
\Delta \mathrm{N}_{\mathrm{c}}= & +3.29 \\
& \frac{\mathrm{k}_{\text {eff }}}{0.9799} \\
& \frac{0.9827}{} \\
& \div 0.0028
\end{aligned}
$$

(Table V, p. 13)

Source (200g SS)

in water, bottom half

$$
\begin{array}{lll} 
& \Delta \mathrm{N}_{\mathrm{c}} & =-1.86 \\
\frac{\mathrm{N}_{\mathrm{c}}}{252} & \frac{\mathrm{k}_{\text {eff }}}{0.9799} \\
250.14 & \frac{0.9782}{-0.0017} \\
\Delta \mathrm{k}_{\text {eff }} & -0.0017
\end{array}
$$

(Table V, p. 13)

Bismuth ( 1.34 in. D tube) in void in top half

$$
\begin{array}{lll} 
& \Delta \mathrm{N}_{\mathrm{c}}=+0.87 \\
\frac{\mathrm{N}_{\mathrm{c}}}{252} & \frac{\mathrm{k}_{\mathrm{eff}}}{0.9799} \\
252.87 & \frac{0.9806}{\Delta \mathrm{k}_{\text {eff }}} & +0.0007
\end{array}
$$$$
\text { (Table V. P. 13) }
$$

Mineral Oil ( 1.34 in. $D$ tube)

in void in top half

$$
\begin{array}{lrl} 
& \Delta \mathrm{N}_{\mathrm{c}}= & -2.40 \\
\frac{\mathrm{N}_{\mathrm{c}}}{252} & & \frac{\mathrm{k}_{\text {eff }}}{0.9799} \\
249.6 & & \frac{0.9777}{-0.0022} \\
\mathrm{\Delta k}_{\text {eff }} & &
\end{array}
$$$$
\text { (Table V, p. 13) }
$$ 
Boric Acid $(6 \mathrm{~g} / \mathrm{l})$

filled 2 in. center tube

$$
\begin{aligned}
& \Delta \mathrm{N}_{\mathrm{c}}=-29.1 \quad(\mathrm{Table}, \mathrm{V}, \mathrm{p} \cdot 13) \\
& \begin{array}{ll}
\frac{\mathrm{N}_{\mathrm{c}}}{252} & \frac{\mathrm{k}_{\text {eff }}}{0.9799} \\
222.9 & \underline{0.9541} \\
\Delta \mathrm{k}_{\text {eff }} & -0.0258
\end{array}
\end{aligned}
$$

2 in. Void Outside Lattice Plate flush to lattice plate

$$
\Delta N_{c}=-2.39 \text { rods (Table VI, p. 14) }
$$

$\begin{array}{ll}\frac{N_{c}}{252} & \frac{k_{\text {eff }}}{0.9799} \\ 249.6 & 0.9777 \\ \Delta k_{\text {eff }} & -0.0022\end{array}$

5 in. Diameter Void flush to lattice plate

$$
\begin{array}{lll} 
& \Delta \mathrm{N}_{c}= & -5.97 \\
\frac{\mathrm{N}_{c}}{252} & \frac{k_{\text {eff }}}{0.9799} \\
246.03 & \frac{0.9746}{\Delta k_{\text {eff }}} & -0.0053
\end{array}
$$$$
\text { (Table VI, P. 14) }
$$

4 in. Diameter Void (estimate) flush to lattice plate

$$
\begin{aligned}
& 2^{\prime \prime} \\
& 5^{\prime \prime}
\end{aligned}
$$

4-in. D. Void

$$
\begin{aligned}
& \begin{array}{cc}
\frac{N_{c}}{c} & \text { Ratio } \\
\hline-2.39 & -1.195 \\
-5.97 & -1.194
\end{array} \\
& \Delta \mathrm{N}_{\mathrm{c}}=(4)(-1.1945)=-4.78 \operatorname{Rods} \\
& \text { keff } \\
& 0.9799 \\
& 0.9756 \\
& -0.0043
\end{aligned}
$$


2 in. Tube Filled with

1.75 in. D. Graphite Rod

flush to lattice plate

2 in. Tube Filled with

Graphite Compared to Void

$$
\Delta \mathrm{N}_{c}=+1.25
$$

(Table VI, P. 14)

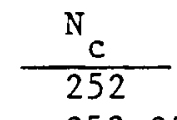

253.25

$\Delta \mathrm{k}_{\text {eff }}$

$$
\begin{aligned}
& \frac{k_{e f f}}{0.9799} \\
& 0.9809 \\
& \hline 0.0010
\end{aligned}
$$

$$
\Delta \mathrm{N}_{c}=+3.63
$$

(Table VI, p. 14)

$\mathrm{k}_{\text {eff }}$

0.9799

0.9831

$+0.0032$

2 in. Void with 1.34 -in. D

Tube Mineral Oil

flush to lattice plate

$$
\begin{aligned}
& \frac{\mathrm{N}_{\mathrm{c}}}{252} \\
& 25 \mathrm{l} . \mathrm{I} \\
& \Delta \mathrm{k}_{\text {eff }}
\end{aligned}
$$

2 in. Void with $1.34-$ in. D

Tube of Bismuth

flush to lattice plate

$$
\frac{\mathrm{N}_{\mathrm{c}}}{252}
$$$$
250.7
$$$$
\Delta \mathrm{k}_{\text {eff }}
$$

$\Delta N_{C}=-0.90$

$\mathrm{k}$ eff

$\overline{0.9799}$

0.9790

$-0.0009$

$$
\Delta N_{c}=-1.31
$$

$\mathrm{k}_{\mathrm{eff}}$

$\overline{0.9799}$

0.9787

$-0.0012$

(Table VI, P. 14)

(Table VI p. 14) 
2-in. Void with

1.25-in. D Wood

flush to lattice plate

$$
\Delta \mathrm{N}_{\mathrm{C}}=-1.37
$$

$$
\begin{array}{ll}
\frac{\mathrm{N}_{\mathrm{c}}}{252} & \frac{\mathrm{k}_{\text {eff }}}{0.9799} \\
250.63 & \underline{0.9787} \\
\mathrm{\Delta k}_{\text {efí }} & -0.0012
\end{array}
$$

2.in. Void with

1.25 in. D Plexiglass

$$
\text { flush to lattice plate }
$$

$$
\Delta \mathrm{N}_{\mathrm{C}}=-0.81
$$

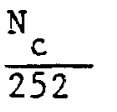

251.2

$$
\frac{k_{\text {eff }}}{0.9799}
$$$$
\underline{0.9790}
$$

$\Delta \mathrm{k}_{\text {eff }}$ $-0.0009$

2-in. Void with 1.34-in. D Minera1 Oil Compared to Water flush to lattice plate

$$
\begin{aligned}
& \frac{\mathrm{N}_{\mathrm{c}}}{252} \\
& 252.06 \\
& \Delta \mathrm{k}_{\text {eff }}
\end{aligned}
$$

$$
\begin{aligned}
\Delta \mathrm{N}_{C}= & +0.06 \\
& \frac{k_{\text {eff }}}{0.9799} \\
& \frac{0.97995}{+0.00005}
\end{aligned}
$$

Temperature Effect

$$
\text { from } 21 \mathrm{C} \text { to } 48 \mathrm{C}
$$

$$
\Delta \mathrm{N}_{\mathrm{c}}=+2.6 \mathrm{I}
$$$$
\text { (Table II, p.6) }
$$

$\begin{array}{ll}\frac{\mathrm{N}_{\mathrm{c}}}{252} & \frac{\mathrm{k}_{\text {eff }}}{0.9799} \\ 254.61 & \underline{0.9820} \\ \Delta \mathrm{k}_{\text {eff }} & +0.0021\end{array}$

(Table VI, p. 14)

(Table VI, P. 14)

(Table VI, P. 14) 
Fissile Material

$$
\begin{aligned}
& \text { For } 1 / 3 \text { rod or } 7.4 \text { grams } \\
& \text { (or } 0.59 \mathrm{rod} / \mathrm{gram} \text { ) } \\
& \text { For } 4 \text { grams } \\
& \begin{array}{l}
\Delta N_{c}=+4.37 \quad(\text { Table } v, p .13) \\
\Delta N_{c}=(4)(0.59)=+2.36
\end{array} \\
& \begin{array}{ll}
\frac{\mathrm{N}_{\mathrm{c}}}{252} & \frac{\mathrm{k}_{\text {eff }}}{0.9799} \\
254.36 & 0.9819 \\
\mathrm{k}_{\text {eff }} & +0.0020
\end{array}
\end{aligned}
$$

Rod Removal

for removal of $12 \operatorname{rods}$

$$
\Delta N_{c}=+6.7 \quad(p .26)
$$

$$
\begin{aligned}
& \frac{\mathrm{N}_{\mathrm{c}}}{252} \quad \frac{\mathrm{k}_{\text {eff }}}{0.9799} \\
& 258.7 \quad 0.9857 \\
& \Delta k_{\text {eff }} \quad 0.0058 \\
& \text { reactivity }=\frac{0.0058}{12}=0.00048 / \mathrm{rod} \\
& k_{\text {eff }} \text { to Criticality }=1-0.9924=0.0076 \\
& \text { rod equivalent }=\frac{0.0076}{0.00048}=15.8 \mathrm{rods}
\end{aligned}
$$




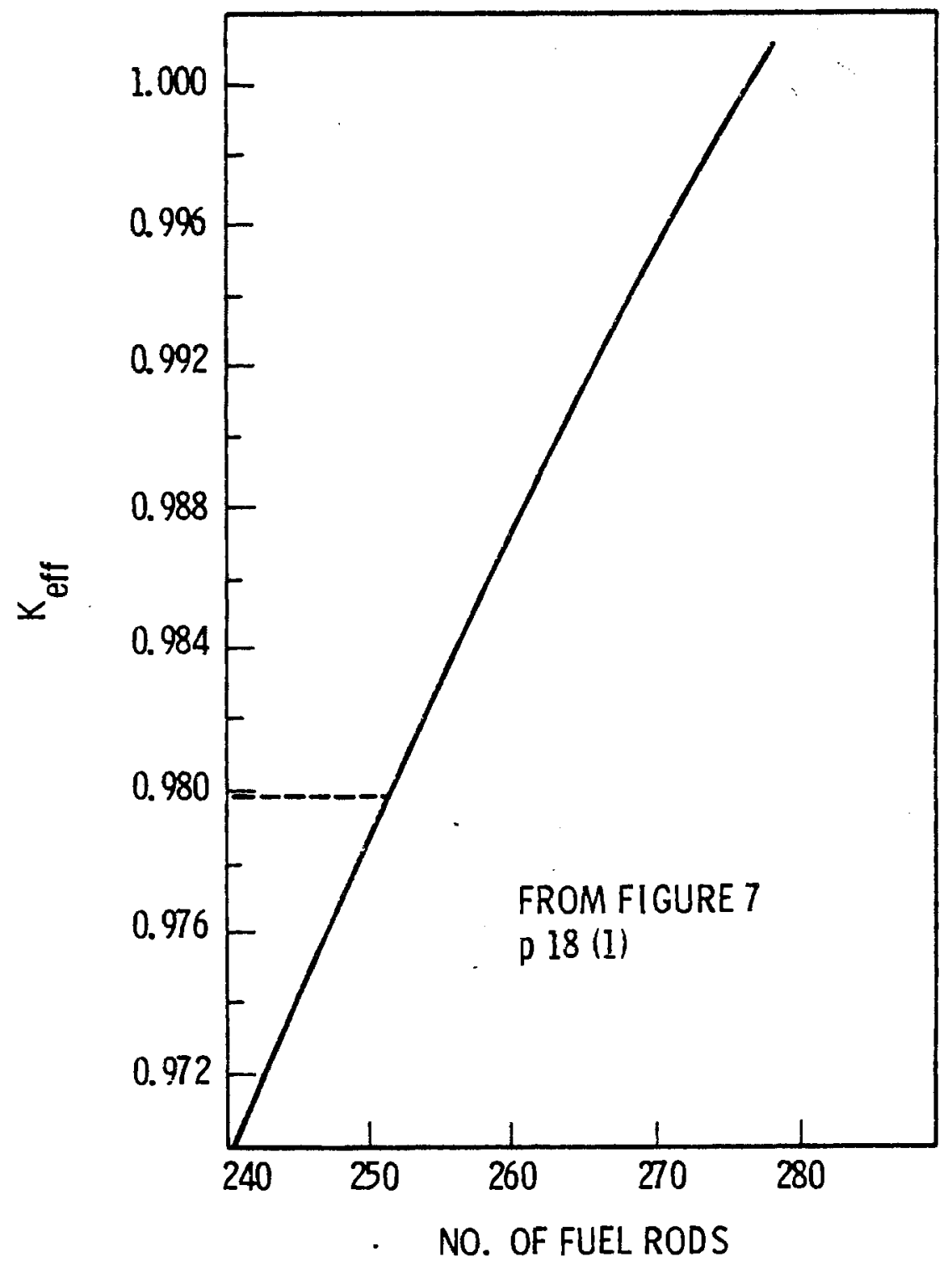

FIGURE D-1. Fuel Rod Loading Effect on Neutron Multiplication Factor, ( $k_{\text {eff }}$ ) 

APPENDIX E

EVALUATION OF ${ }^{252} \mathrm{CE}$ SOURCE TRANSFER METHODS 


\section{APPENDIX E}

\section{Evaluation of ${ }^{252}$ Cf Source Transfer Methods}

Manipulation of the ${ }^{252} \mathrm{Cf}$ sources during unloading from the transport cask will expose personnel to neutron and gama radiation. Six sources ranging from 13.2 to $23.0 \mathrm{mg}$ (at the time of fabrication) will require transfer from the transport cask to the NM pool. The largest source will have decayed to less than $20 \mathrm{mg}$ at the time of delivery.

Exposure rates of various distances have been estimated from exposure data collected during field use of ${ }^{252} \mathrm{Cf}$ sources of different intensities ( 2 mg, $585 \mathrm{\mu g}$ and $194 \mu \mathrm{g}$ ). These estimates are shown in Figure E-1.

In the past, ${ }^{252}$ Cf source transfers during field use have been accomplished with manipulators, long-handled tools equipped with remotely operated jaws which engage the source. A maximum working manipulator length has been $12 \mathrm{ft}$. Radiation levels at this distance ara estimated to be 4.5 rem/hr $(n+\gamma)$. Time required for a source transfer cycle is estimated to be one minute, resulting in an exposure of 0.075 rem $(n+Y)$ per source.

Another system has been devised to make the source cransfer from the transport cask to the NM pool. This system is a 16-ft track mounted about 6 ft above the NMF roof, centered above the roof hatch opening and extending out from the wall so that the transport trailer can be parked directly under the outer end. A remotely operated trolley will be used to position a remctely operated lift line directly over the transport cask opening. A transfer manipulator tool which accompanies the shipment will be attached to the lift line. After the scurce is engaged by the manipulator, personnel will be cleared from the area. The source will be withdrawn from the cask and caused to contact the side of a paper-lined funnel located over the cask entrance. Lateral motion will be caused by a slight movement of the trolley. The source is then lowered into the cask and the paper liner of the funnel is checked for contamination. If contamination is found, the transfer will be terminated at this point. If the liner is free of contamination, the source will be withdrawn fiom the cask and raised vertically to the track with the trolley 
held securely at the outer position. When the source manipulator has been raised to the track, the trolley will then be moved along the track to a point directly above the NM pool. The source will then be lowered into the pool and disengaged from the manipulator under water.

The control lines for the trolley and lift can be located $50 \mathrm{ft}$ from the closest approach to the source. The exposure level is estimated to be 0.175 $\mathrm{rem} / \mathrm{hr}(\mathrm{n}+\boldsymbol{Y})$ at this distance. A complete source transfer cycle will require approximately $3 \mathrm{~min}$ for a total exposure of $0.009 \mathrm{rem}(n+\gamma)$ per source.

An auxiliary transfer cask could be used to move the ${ }^{252}$ Cf sources from the transport cask to the NM pool. From exposure data taken in the field, a 10-in. thick paraffin moderator will reduce radiation levels by about $1 / 3$. A 20-in. diameter $x$ 20-in. high cask would weigh over $2001 \mathrm{~b}$. In use, the transfer cask would be placed adjacent to the transport cask and the source remotely transferred. The transfer cask would then be remotely moved adjacent to the $\mathrm{NM}$ pool and the source transferred into the pool.

This method requires additional manipulation of the sources as we 11 as remote movement of the transfer cask. Positioning the transfer cask close to the transport cask would be difficult because of the size and configuration of the transfer cask and trailer. 


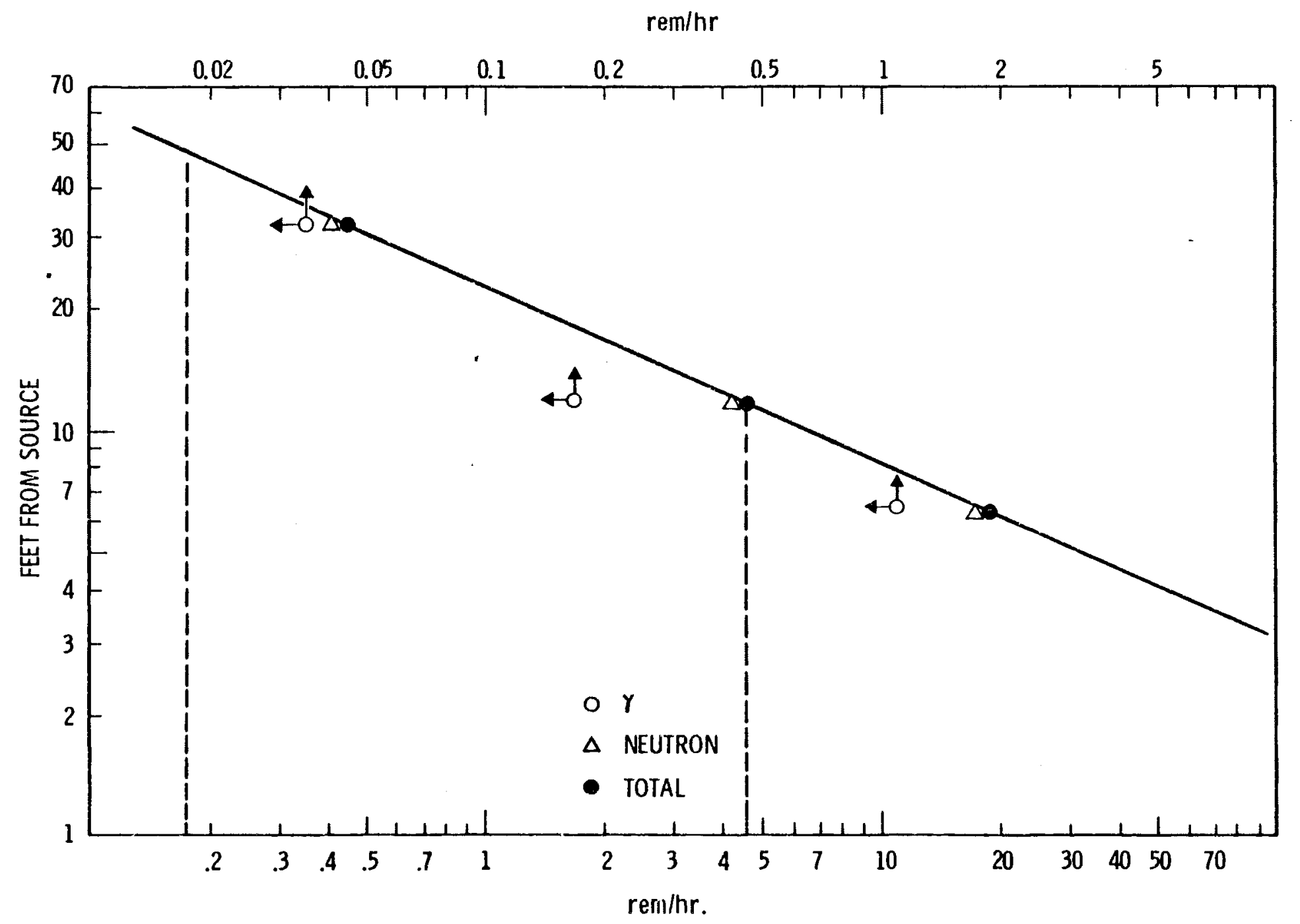

FIGURE E-1. Exposure Rate Estimate from a $20 \mathrm{mg}^{252}$ Cf Source Versus Distance 


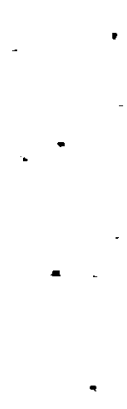


APPENDIX F

RELEASE EXPOSURES FROM A NEUTRON

MUTIPLIER FACILITY CRITICALITY INCIDENT 
Date May 10, 1976

EC Watson

DL Strenge

To George Rieck

File/LB

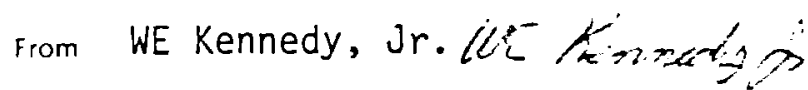

Subject Release Exposures from a Neutron Multiplied Facility Criticality Incident

Calculations of the inhalation and external exposures from radionuclides released from a Neutron Multiplier Facility Criticality accident have been made and are listed in the following tables. The radionuclide quantities were calculated using the ORIGEN computer code, with input values of 23.7 gram-atoms of $235 \mathrm{U}, 1.6$ gram-atoms of $238 \mathrm{U}, 1.6$ gram-atoms of $27 \mathrm{Al}$, and $4.0 \times 10^{-4}$ gram-atoms of $252 \mathrm{Cf}$. The facility was assumed to operate at an effective power of $1.3 \times 10^{-4} \mathrm{MW}$ for a period of two years prior to the accident levels of 1 MW for 1 second and $1 \mathrm{~kW}$ for 24 hours. Three release periods were assumed: the first at thirty minutes after criticaitity, the second at eight hours after criticality, and the third at one day after criticality. Each release assumed that 100\% of the $\mathrm{Kr}$ and $\mathrm{Xe}$ isotopes, $10 \%$ of the icdine isotopes, and $1.0 \%$ of the volatile fission products (the isotopes of $\mathrm{Cs}, \mathrm{Se}$, and $\mathrm{Te}$ ) were released. Dose calculations were performed for these inventories using these standard release fractions to allow for future scaling. The inhalation dose was calculated for Hanford moderately stable and very stable meterological conditions, for both soluble and insoluble radionuclide conditions at the ten downwind distances shown in the tables. The organs of reference for the inhalation exposure were Total Body, Bone, Lungs and Thyroid. The total external exposures for the three release periods were calculated using the SUBDOSA computer code for the two stability cases, and are shown in the fcllowing tables.

WEK:mh 
NELTRION MULTIPI. IER CRJTICALITY ACCIOENT

$05 / 10 / 76$

FIF TY YEAR INHALATION DOSE COMMITMENT. REM. AT OISTANCE SHOWN

OISPERSION IINTER HANG ORT VERY STAALF CONOITIONS

SOLUALE MATFRIAL. I MICRON

NIICLIDE ORGAN OF
GQDUP

KR TOTAL. HOOK

AONE.
LUNG.

LUNGS

XE InTAL anor

BUNE.

LIINGS

I rotal ador

Ling, S

InYROII

CS,SE,TE TOTAL HOBY

RIINE

LIUNGS

THYRTID
INIIVIDUAL DOSE FOR 0 - 24 HRS RELEASE

\begin{tabular}{|c|c|c|c|c|c|c|c|}
\hline $500^{1215}$ & $\begin{array}{l}\text { ANCE FROM } \\
\text { IOON }\end{array}$ & $\begin{array}{l}\text { RELEASE } \\
2000\end{array}$ & $\begin{array}{l}\text { INT, MET } \\
\text { SOOON }\end{array}$ & 10000 & 20000 & 50000 & 100000 \\
\hline $\begin{array}{l}4.3 F=03 \\
2.3 F=n ? \\
3.6 E=02 \\
0 .\end{array}$ & $\begin{array}{l}2 . \Delta F=03 \\
1.3 E=0 ? \\
1.9 E-02 \\
0 .\end{array}$ & $\begin{array}{l}1.2 E=03 \\
6.9 E=03 \\
9.4 E=03 \\
0 .\end{array}$ & $\begin{array}{l}4.1 E=04 \\
? .5 E=03 \\
3.1 E=03 \\
0 .\end{array}$ & $\begin{array}{l}1.6 E=04 \\
1.1 E=03 \\
1.2 E=03 \\
0 .\end{array}$ & $\begin{array}{l}6.4 E=05 \\
5.1 E=04 \\
4.1 E=04 \\
0 .\end{array}$ & $\begin{array}{l}1.9 E-05 \\
2.1 E=04 \\
7.6 E=05 \\
0 .\end{array}$ & $\begin{array}{l}7.4 E=06 \\
1.1 E=04 \\
1.4 E=05 \\
0 .\end{array}$ \\
\hline $\begin{array}{l}5.1 F=n 3 \\
0.5 E=02 \\
2.7 E=03 \\
0 .\end{array}$ & $\begin{array}{l}2.3 F-03 \\
2.0 E-02 \\
1.2 E=03 \\
0 .\end{array}$ & $\begin{array}{l}9.9 E=04 \\
1.3 E-02 \\
3.4 E-04 \\
0 .\end{array}$ & $\begin{array}{l}3.1 E=04 \\
4.0 E=03 \\
1.7 E=04 \\
0 .\end{array}$ & $\begin{array}{l}1.3 F=04 \\
1.0 E=03 \\
7.2 E=05 \\
0 .\end{array}$ & $\begin{array}{l}5,4 E-05 \\
6,9 E=04 \\
3,2 E-05 \\
0 .\end{array}$ & $\begin{array}{l}1.8 E=05 \\
2.3 E=04 \\
1.2 E=05 \\
0 .\end{array}$ & $\begin{array}{l}8,5 E=06 \\
1,1 E=04 \\
6,4 E=06 \\
0,\end{array}$ \\
\hline $\begin{array}{l}3.2 F-03 \\
7.0 E-\cap 5 \\
3.1 E-02 \\
1.4 E+D 0\end{array}$ & $\begin{array}{l}1.4 E-n 3 \\
3.115=05 \\
1.3 E-n 2 \\
6.0 E=n 1\end{array}$ & $\begin{array}{l}6,1 E=04 \\
1.2 E=05 \\
5.5 E=03 \\
3.4 E=01\end{array}$ & $\begin{array}{l}1.8 F-04 \\
2.9 F-06 \\
1.5 E=03 \\
1.0 E=01\end{array}$ & $\begin{array}{l}7.0 F=05 \\
7.9 E=07 \\
5.1 E=04 \\
3.9 E=02\end{array}$ & $\begin{array}{l}2.7 E-05 \\
1.4 E=07 \\
1.7 E=04 \\
1.5 E=0 ?\end{array}$ & $\begin{array}{l}7.4 E-06 \\
4.0 F=09 \\
3.7 E=05 \\
4.3 E-03\end{array}$ & $\begin{array}{l}2,8 E-06 \\
2,8 E-11 \\
9,7 E=06 \\
1.6 E-03\end{array}$ \\
\hline $\begin{array}{l}5.2 E-\cap 4 \\
1.2 E-n 3 \\
2.5 E=n 3 \\
4.5 E-\cap 2\end{array}$ & $\begin{array}{l}2.3 E-00 \\
3.5 E=04 \\
1.2 E-03 \\
2.1 E=02\end{array}$ & $\begin{array}{l}1.0 E-04 \\
2.4 E-04 \\
5.0 E=04 \\
9 . \Delta E=03\end{array}$ & $\begin{array}{l}3.2 E=05 \\
7.5 E=05 \\
1.9 F=04 \\
3.1 E=03\end{array}$ & $\begin{array}{l}1.3 E=05 \\
3.1 E=05 \\
6.8 E=05 \\
1.2 E=03\end{array}$ & $\begin{array}{l}5.4 E=06 \\
1,3 E=05 \\
2.3 E=05 \\
4.9 E=04\end{array}$ & $\begin{array}{l}1,7 E=06 \\
4,3 E=06 \\
5,5 E=06 \\
1.4 E=04\end{array}$ & $\begin{array}{l}7.5 E=07 \\
1.9 E=06 \\
1.9 E=06 \\
5.6 E=05\end{array}$ \\
\hline
\end{tabular}


NEUTRON MULTTPLIER CRITICALITY aCCIDENT

FifiY YeAR INHALATION DOSE COMMITMENT, REM. AT DISTANCE SHOWN

$05 / 10 / 76$

DISPERSION IJNDER HANFORO VERY STABLF CONDITIONS SOLUHLE MATERIAL, I MICRON

INOIVIDUAL DOSE FOR O - 1/2 hR RELEASE

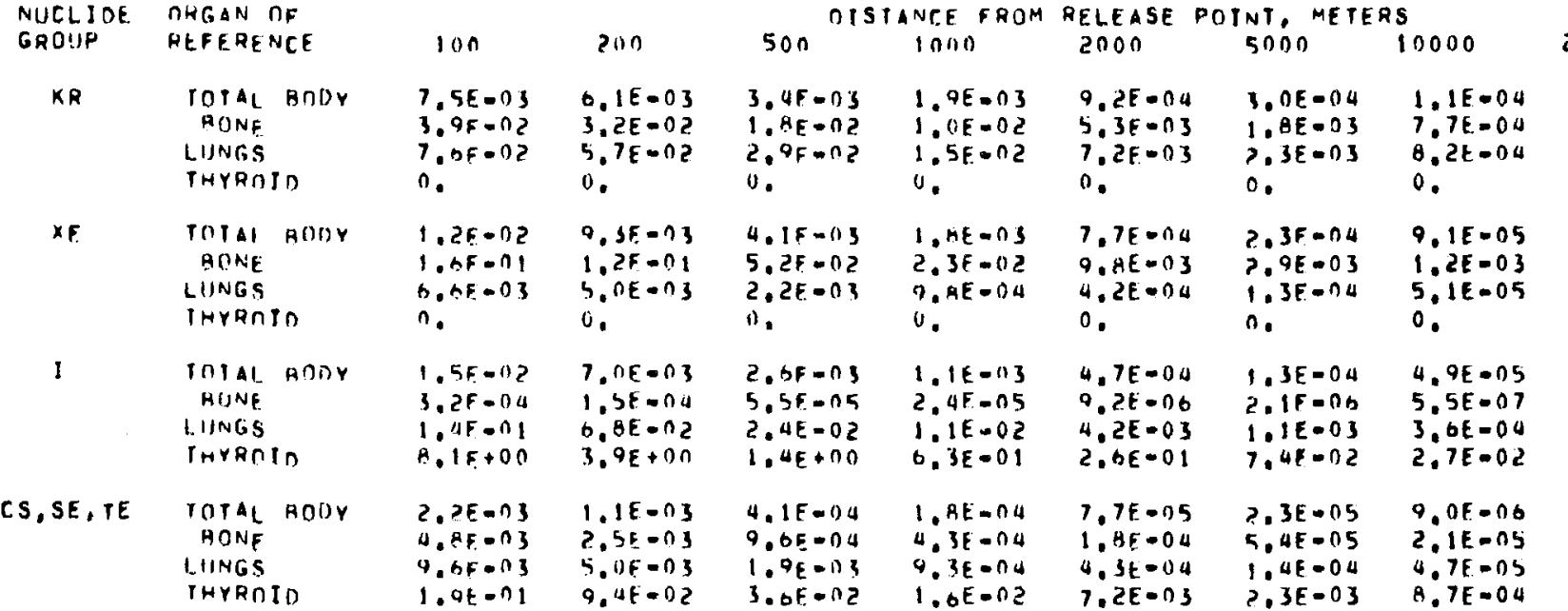

$20000 \quad 50000 \quad 100000$

$4.2 E-05 \quad 1.2 E-05 \quad 4.5 E-n O$ $3,3 E=04 \quad 1.3 E=04 \quad 6,5 E=0$ $2,7 E=04 \quad 4.8 E=05 \quad 8.7 E=06$

.6E-05 $\quad 1.2 E=05 \quad 5.2 E=06$ $4.6 E-04 \quad 1.5 E=04 \quad 6.5 E=05$ $\begin{array}{lll}4.6 E-04 & 1.5 E-04 & 6,5 E-05 \\ 2,1 E-05 & 7.5 E-76 & 3,9 E-06\end{array}$ 0. O. 0. 1.8E-05 $\quad 4,6 E-06 \quad 1,7 E-06$ $9.5 E-08 \quad 2.5 E-09 \quad 1.7 E-11$ IE-nA $2,3 E-05 \quad 5,9 E-00$ $1.0 E-02$ 2.0E-03 9.7E-04

IHYROID

$1.9 t=n 1$

$9.4 f=02$

उ. $O E=02 \quad 1.0 E=02$

.5E- 06

$.5 E-06 \quad 2,7 E=06 \quad 4.5 E-07$

$\begin{array}{lll}1.5 E-05 & 3,4 E=06 & 1.2 E=06 \\ 3.1 E=06\end{array}$

$3,2 E=04 \quad B, 9 E-05 \quad 3,4 E=05$ 
NEUTRON MULTIPLIER CRITICALITY ACCIDENT
FIFTY YFAR INHALATION DOSE COMMITMENT, REM, A DISTANCE SHOWN

$05 / 10 / 76$

DISPEKSION IINOER HANFORD VERY STARLF CONOITIOINS

SOLIIRLE MATERIAL. I MICRON

INIIVIMUIAL DOSF FUR $1 /$ ? - A HR RFLEASE

\begin{tabular}{|c|c|c|c|}
\hline $\begin{array}{l}\text { NIICLIDE } \\
\text { TROUP }\end{array}$ & $\begin{array}{l}\text { ORGAN OF } \\
\text { REFERENCE }\end{array}$ & 100 & 200 \\
\hline$K R$ & $\begin{array}{l}\text { TOTAI HOOY } \\
\text { RONE } \\
\text { LIINGS } \\
\text { THYRTID }\end{array}$ & $\begin{array}{l}1.1 E-03 \\
5.9 E-03 \\
1.2 E=02 \\
0 .\end{array}$ & $\begin{array}{l}0.4 E-04 \\
4.9 E-03 \\
4.9 E-03 \\
0 .\end{array}$ \\
\hline$x \in$ & $\begin{array}{l}\text { TOTAL, FODY } \\
\text { HONF } \\
\text { LIHIGSS } \\
\text { IHYHOIO }\end{array}$ & $\begin{array}{l}1.9 F=03 \\
2 . \Delta F=02 \\
1.0 F=03 \\
0 .\end{array}$ & $\begin{array}{l}1 . \triangle E=03 \\
1 . A E-02 \\
7 . \text { WE }-04 \\
0 .\end{array}$ \\
\hline 1 & $\begin{array}{l}\text { POTAL RODY } \\
\text { RUNE } \\
\text { LUNGS } \\
\text { THYROIO }\end{array}$ & $\begin{array}{l}2.2 E=03 \\
1.9 E=05 \\
2.15=0 ? \\
1.2 E+00\end{array}$ & $\begin{array}{l}1.1 E=03 \\
2 . \Delta F=05 \\
1.0 E=02 \\
6.0 F=01\end{array}$ \\
\hline , SE, TE & $\begin{array}{l}\text { TOYAL HOOY } \\
\text { BONF } \\
\text { LIINGS } \\
\text { IHYROID }\end{array}$ & $\begin{array}{l}3.45=04 \\
7.35=114 \\
1.5 F=013 \\
2.95=07\end{array}$ & $\begin{array}{l}1.9 F-011 \\
3.9 F=04 \\
7 . M F=111 \\
1.5 E-1) 2\end{array}$ \\
\hline
\end{tabular}

500 DISTANCE FHOM PELEASE POINT, METERS

$5.5 E-04 \quad 1,3 E-04 \quad 1.9 E-04 \quad A .0 E-05$

2.9E-n3 1.AE-nS $1.1 E=n 3 \quad 0.9 E-n A$ $4.6 E-n 3 \quad 2.6 E-n 3 \quad 1.5 E-n 3$

0.

0 .

0 .

$6.08=04$

0 .

10000

20000

50040

100000

. OF. 04

$1.0 F=n \Delta$

$4.1 E=03 \quad 2.0 t=03$

h. $2 F-05$

$7.8 F=04$
$3.4 F=05$

$n$.

$3.9 E-05 \quad 1.8 E-05$

. $0 F=04 \quad 1.5 E=04$

2. $H E=\cap 4$

0 .

$1.2 E-04$

0 .

$6.2 E-06 \quad 2,7 E-06$

$6.9 E=05 \quad 3.9 E-05$

$2.0 E-05$

0.2

3.1E-0S 1.0E-05

$3.9 E=04 \quad 2.0 E=04$

1. $7 E-0.5$

0 .

$9,1 E=00$

$0,3 E=06$
$7,9 E=05$

3. $1 E=06$

.

$4.11=06$

0 .

$2,3 E=00$

0.

2.0E-04 $9.4 E=05 \quad 3.5 E=05 \quad 1.7 E=05 \quad 7.6 E-00 \quad 2.5 E=06 \quad 1.0 t=06$

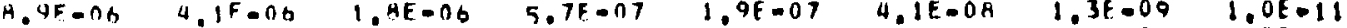

$3.9 E=1) 3 \quad 1.8 E-n 3 \quad A .4 E=04 \quad 2.9 E=04 \quad 1.2 E=04 \quad 4.9 E=05 \quad 1.2 E=05 \quad 3,5 E-06$

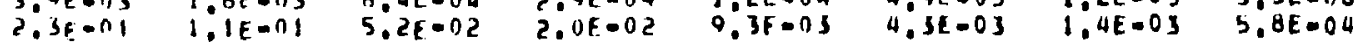

$\begin{array}{ll}5,8 E=07 & 2,7 E-197 \\ 1,5 E=06 & 7,0 E-07\end{array}$

$\begin{array}{llll}0.0 F-15 & 3.2 t-115 & 1.6 F=05 & 6.2 E=00\end{array}$

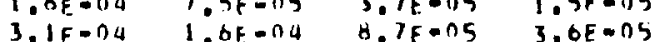

$5.7 E=03 \quad 2.9 E=03 \quad 1.4 E=03 \quad 3.0 E=04$

$\begin{array}{ll}1 E=00 \\ 1.5 E=06\end{array}, 7 E=00$

$1,0 E=05$ O $4 E=06$

$3.0 E=04 \quad 1.4 E-04$

$1,9 E=00 \quad 6.8 E-07$

HE $=05 \quad 2,0 E=05$ 
NEUTRON MULTIPLIEH CRITICALTTY ACCIDENT

$05 / 10 / 76$

FjF TY YEAR INHALATION DOSE COMMITMENT, REM, at DISTANCE SHOWN

DISPERSION UNDER HANFURO VERY STABLE CONDITIONS SOL.URLE MATERIAL, I MICQOBN

INDIVIDIJAL DOSE FIIR 8 - 24 HRS FELEASE

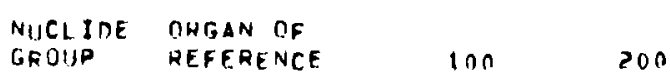

KA IOTAL BORY HONE
LUHGS

THYROIR

xe total anory

$$
\text { AINE }
$$

LINGSS

THYROTI

TOTAL ROOP

BONE

LUNGS

THYROID

CS.SE,TE TOTAL RODY

LIINGS
$B, 1 E=04$ a. $2 E=03$

0.

$1.1 F=03$ $1 . M E-02$ 5. $4 E-C 4$

$1, h F=03$ $3.45-05$ $1.5 E \rightarrow \cap 2$ $8,7 E=01$

$5,4 F-04$ 5. $2 F=04$ $1.0 F-03$ 2. $1 E-\cap 2$
DISTANCE FRUM RELEASE POINT, MEIERS

\begin{tabular}{|c|c|c|c|c|c|c|c|}
\hline 0 & 1000 & 2000 & 5000 & 10000 & 20000 & 50000 & 00000 \\
\hline 3 & $\begin{array}{l}2,0 E=04 \\
1: 1 E=03 \\
1.6 E=03 \\
0 .\end{array}$ & $\begin{array}{l}9.8 E=05 \\
5 . \text {. }=04 \\
7.7 E=0 A \\
0 .\end{array}$ & $\begin{array}{l}3.1 E=05 \\
1.9 E=04 \\
? .3 E=04 \\
0 .\end{array}$ & $\begin{array}{l}1.1 \\
7.5 \\
8.0 \\
0 .\end{array}$ & $\begin{array}{l}3.8 \\
3.0 \\
2.4 \\
0.4\end{array}$ & $\begin{array}{l}8.5 \\
9.2 \\
3.5 \\
0 .\end{array}$ & $\begin{array}{l}E=07 \\
E=06 \\
E=07\end{array}$ \\
\hline $\begin{array}{l}F=04 \\
F=03\end{array}$ & $\begin{array}{l}1.0 E=01 \\
2.0 E=03 \\
B .5 E=05 \\
0 .\end{array}$ & $\begin{array}{l}n .6 E=05 \\
0.4 E=04 \\
3.6 E=05 \\
0 .\end{array}$ & $\begin{array}{l}1.9 E=05 \\
2.5 E-0.4 \\
1.1 E=05 \\
0 .\end{array}$ & $\begin{array}{l}7.2 E-06 \\
9.2 E-115 \\
4.0 E=06 \\
0 .\end{array}$ & $\begin{array}{l}2.6 E=06 \\
3.3 E=05 \\
1.5 E=06 \\
0 .\end{array}$ & $\begin{array}{l}6.7 E=07 \\
6.5 E=06 \\
4.4 E=07 \\
0 .\end{array}$ & $\begin{array}{l}2,4 E=07 \\
2,9 E=06 \\
1,0 E=07 \\
0 .\end{array}$ \\
\hline & $\begin{array}{l}1 . P E=n A \\
2.5 F=0 B \\
1.1 E=03 \\
6.7 E=02\end{array}$ & $\begin{array}{l}4.9 E-\cap 5 \\
9.7 E=07 \\
4.4 E-04 \\
2.8 E-02\end{array}$ & $\begin{array}{l}1.4 F=05 \\
2.2 E=07 \\
1.1 E=04 \\
7.6 E=03\end{array}$ & $\begin{array}{l}4.8 E=n 6 \\
5 . \Delta E=08 \\
3.5 E=05 \\
2.7 E=03\end{array}$ & $\begin{array}{l}1.6 E=06 \\
8.5 E=09 \\
1.0 E=05 \\
8.9 E=04\end{array}$ & $\begin{array}{l}3,3 E=07 \\
1.8 E=10 \\
1.7 E=06 \\
1.9 E=04\end{array}$ & $\begin{array}{l}9,5 E-08 \\
9,7 E-13 \\
3,3 E \cdot 07 \\
5,4 E-05\end{array}$ \\
\hline & $\begin{array}{l}2, O F=05 \\
4, \text { OE }=05 \\
1.0 E=04 \\
1, T E=03\end{array}$ & $\begin{array}{l}3.2 E=06 \\
1.9 E=05 \\
4.0 E=05 \\
7.6 E=04\end{array}$ & $\begin{array}{l}2 . \Delta E=06 \\
5.6 E=06 \\
1.4 E=05 \\
2.3 E=04\end{array}$ & $\begin{array}{l}8.9 E=07 \\
2.1 E=06 \\
4.6 E=06 \\
8.5 E=05\end{array}$ & $\begin{array}{l}3.2 E=07 \\
7.7 E=07 \\
1.3 E=06 \\
2.9 E=05\end{array}$ & $\begin{array}{l}7, T E=08 \\
2.0 E=07 \\
2,5 E=07 \\
6.4 E=06\end{array}$ & $\begin{array}{l}2,5 E=08 \\
6,6 E=08 \\
6,4 E=08 \\
1,9 E=06\end{array}$ \\
\hline
\end{tabular}


VEIITONN MULTIPLIER CHITICALITY ACCTDENT

$05 / 10 / 76$

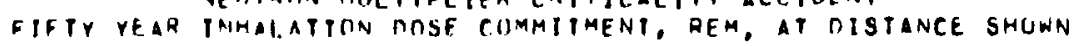

DISPRPSIUN IINGFA HANFBRD MODERATELY STAHLE CONUTIIONS

SULURLE MATEHIAL, 1 MICRDN

\begin{tabular}{|c|c|}
\hline NUICLIDE & ORFAN OF \\
\hline GRCUP & REFERFINEE \\
\hline KR & $\begin{array}{l}\text { TOTAL BOOY } \\
\text { HIINF }\end{array}$ \\
\hline & $\begin{array}{l}\text { LWWGS } \\
\text { THYROID }\end{array}$ \\
\hline
\end{tabular}

$x E$

on

I TOIAL aORY

AONE

Liivisis

THYRIIn

INDIVIOIIAL DOSF FOH O 24 HRS RELEASH

200

$2.5 F-03$
$5,7 F=0 ?$

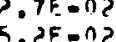

0 . 1. $1 F=01$

0.

CS.SE,TE TIIAL RIIOY

AlINF

LUNGS

THYAOIn

$n$.

$.0,0=05$

Q. hF $=07$
S1) DISTANCE FROM RELEASE DOINT, METERS

$1, H F=n$

$\begin{array}{llll}5 . A E-03 & 2.3 E-03 & 7 . h E=0 A\end{array}$

0 . 0 .

0 .

n.

a. SE-NA

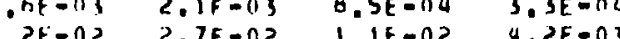

$3,0 t=n 3$

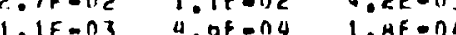

0 .

.45 .05

$1.2 E-03$

$n$.

4. $36-0 \mathrm{~B}$

$\begin{array}{llll}.3 E-03 & 1.4 F-03 & 5.3 E-04 & 2.0 E=04 \\ 0.4 E-115 & 2.4 F-05 & 1.1 E-05 & 4.0 E=0 D\end{array}$

$4.2 F-0) \quad 1,35-0) \quad S, 0 t=03$

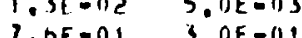

$5,0 E=0 A$

$1, B E-03$
I.

$5.4 F-05$

R. $A E-\cap 7$

A. $A E=\cap 7$

4.
$3,0 F-02$

$1,1 E-01$

$3 ., \mathrm{NF} 02$

$A . O E-O S$

$3.35=n 5$

$7.9 E=05$

$0.6 E=06$

2. $2 E=05$

5. $6 E-\cap 5$
$9.2 F=04$

10000

$1.0 E-n 3 \quad 5.1 F=0$

S.
$3 ., E=0$
.

$4.4 E=04$

$3,1 E=03$
20000

4.7 .0S $1.8 E .05$ $3.2 F=04$

$1.05=04$

0.

7E-0S $\quad 1.5 E-05$

$1.9 E .04$

Q, $9 E=0 h$

2. OE- 05

2. JE-07

1. $5 E-04$

$1.15=0$ ?

$7.5 E-06$

. $1 E=0$ A

$4,9 E=05$

3. $7 E-00$

2. $96-06$

3. $O E=D 4$

$1, S E \bullet C n$

$3,7 E=0 b$

$0.4 E-06$

$1,4 E=04$

50000

100000

$5,1 E-06 \quad 2,0 E=06$

$5,7 E=05 \quad 2,9 E=05$
$2,2 E=05 \quad 4,0 E=06$

0 .

$0,0<-06$

S.JE 06

$2,3 E-06$

. $4 F .05 \quad 2.9 E-05$

$3 E-06$

$1,8 E-00$

2. IE=OG T,IE-07

$1.16-09 \quad 7.8 E-12$

$1,0 E-05 \quad 2,7 E-00$

$1.2 t=03$

पE $\cap$ C 4

$4,8 E=0$ ?

$1.21=06$

$1.5 E=06$
$4.0 E-05$

$2.1 k=0$ ?

$5,4 E-0 ?$

$5.2 E-07$ 
NEUTRIIN MILIIPLIER CAITICALITY ACCIDENT

$05 / 10176$

FifTY YEAR INHALATION DOSE COMMITMENT, REM, AT OISTANCE SHOWN

DISPERSTON INMER haNFORD MODERATELY STAGLE CONDITIONS

SOLUHLE MATEHIAL. I MICRON

INOIVIOUAL DOSE FOH O - 1/2 HR RELEASE

\begin{tabular}{|c|c|}
\hline $\begin{array}{l}\text { NUCL IDE } \\
\text { GRDUP }\end{array}$ & $\begin{array}{l}\text { OHFAN OF } \\
\text { RLFERFNCE }\end{array}$ \\
\hline$K R$ & $\begin{array}{l}\text { TOTAL AOOY } \\
\text { BUNE } \\
\text { LIINGS } \\
\text { THYRIID }\end{array}$ \\
\hline$X_{E}$ & $\begin{array}{l}\text { IOTAL gOBY } \\
\text { OMNE } \\
\text { LIINGS } \\
\text { IHYATID }\end{array}$ \\
\hline$I$ & $\begin{array}{l}\text { IOIAL RODY } \\
\text { RONF } \\
\text { LIINFS } \\
\text { THYROIO }\end{array}$ \\
\hline CS, SE, TE. & $\begin{array}{l}\text { TOTAL MUIDY } \\
\text { HOSNE } \\
\text { LUNGS } \\
\text { THYAOIO }\end{array}$ \\
\hline
\end{tabular}

\begin{tabular}{|c|c|}
\hline 100 & 200 \\
\hline $\begin{array}{l}4.1 F=03 \\
2.1 E=0 ? \\
4.25=0 ? \\
0 .\end{array}$ & $\begin{array}{l}3 . \cup E-\cap 3 \\
1.0 E-1) ? \\
2 . A E-\cap ? \\
0 .\end{array}$ \\
\hline $\begin{array}{l}n, R F=n 3 \\
8.7 E=n 2 \\
3, n E=03 \\
0 .\end{array}$ & $\begin{array}{l}4 ., A E=03 \\
5 ., A E=0 ? \\
2.4 F=03 \\
0 .\end{array}$ \\
\hline $\begin{array}{l}7.9 E-03 \\
1.8 F=0 \Delta \\
7.7 E=02 \\
4 . \Delta E+00\end{array}$ & $\begin{array}{l}1.4 E-05 \\
7.5 E-05 \\
3.3 E-02 \\
1.9 E+00\end{array}$ \\
\hline $\begin{array}{l}1.2 F-113 \\
2.0 F-n 3 \\
5.2 E-113 \\
1.0 E-n 1\end{array}$ & $\begin{array}{l}5.36-14 \\
1.2 E-113 \\
? .1 E-113 \\
4.6 E=02\end{array}$ \\
\hline
\end{tabular}

\begin{tabular}{|c|c|c|c|c|}
\hline 500 & $\begin{array}{l}\text { NCE FHOM } \\
1000\end{array}$ & $\begin{array}{l}\text { RELE ASE } \\
2000\end{array}$ & $\begin{array}{l}\text { INT } \\
5000\end{array}$ & 10000 \\
\hline $\begin{array}{l}1.4 F=03 \\
7.5 E=03 \\
1.2 F=0 ? \\
0 .\end{array}$ & $\begin{array}{l}0.9 E=04 \\
3.9 E=03 \\
5.5 E=13 \\
0 .\end{array}$ & $\begin{array}{l}3.1 E=04 \\
1 . B E=03 \\
2.4 E-03 \\
0 .\end{array}$ & $\begin{array}{l}9.0 E=05 \\
5.5 E=04 \\
6 . B 5=04 \\
O .\end{array}$ & $\begin{array}{l}3,3 E=05 \\
2.2 E=04 \\
2.4 E=04 \\
0 .\end{array}$ \\
\hline $\begin{array}{l}1.7 F=n 3 \\
2.2 E=n 2 \\
9.1 E-115 \\
0 .\end{array}$ & $\begin{array}{l}0 . A E-O A \\
8.0 E=03 \\
3.6 E=04 \\
0 .\end{array}$ & $\begin{array}{l}2.6 E-0.4 \\
3.3 E-03 \\
1.4 E-04 \\
0 .\end{array}$ & $\begin{array}{l}\text { D. } 9 E-0 S \\
A . B E=04 \\
3 . B E=05 \\
n .\end{array}$ & $\begin{array}{l}2,6 t=05 \\
3,3 E=04 \\
1,5 E=05 \\
0 .\end{array}$ \\
\hline $\begin{array}{l}1.1 E=03 \\
2.3 F-05 \\
1.0 E-02 \\
B .0 E=01\end{array}$ & $\begin{array}{l}4.2 E=04 \\
.7 E=06 \\
3.9 E=03 \\
2.3 E=01\end{array}$ & $\begin{array}{l}1.0 E-04 \\
3.0 E-06 \\
1.4 E-03 \\
8.0 E-02\end{array}$ & $\begin{array}{l}4.0 E=05 \\
0.4 E-07 \\
3.2 E=04 \\
2.2 E=02\end{array}$ & $\begin{array}{l}1.4 E=05 \\
1.6 E=07 \\
1.0 E=04 \\
7.0 E=03\end{array}$ \\
\hline $\begin{array}{l}1.7 E=04 \\
4.0 E=01 \\
0.2 F=04 \\
1.5 E=02\end{array}$ & $\begin{array}{l}n .7 F=05 \\
1.6 E=04 \\
3.5 E=04 \\
0.0 E=03\end{array}$ & $\begin{array}{l}2.0 E=05 \\
6.0 E=05 \\
1.4 E-04 \\
2.4 E-03\end{array}$ & $\begin{array}{l}7.0 E=06 \\
1.0 E-05 \\
4.1 E=05 \\
6.8 E-04\end{array}$ & $\begin{array}{l}2.6 F=06 \\
6,2 E=06 \\
1.4 E-05 \\
2.5 E=04\end{array}$ \\
\hline
\end{tabular}

20000

$50000 \quad 100000$ $1.2 E-05 \quad 3,2 E=06 \quad 1.2 E=06$
$9,4 E-05 \quad 3, S E=05 \quad 1.8 E-05$ $7,5 E-05 \quad 1.3 F=05 \quad 2,4 E=06$

0 . 0 . $2,4 E=06$

$1.0 E-05$ $1.3 E-04$ $5,9 E=06$ 0 .

$3,2 E=06 \quad 1,0 E=06$ $4.0 E \cdot 05 \quad 1.8 E-05$ $2,1 E-06 \quad 1,1 E=06$

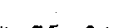
0 .

$4,9 E=0 B$
$2,7 E=O B$ $2,7 E-O B$
$3,2 E-05$ $1,3 E .06$ $1,3 E=06$
$6,9 E=10$ $6,3 E-10 \quad 4,7 E=07$ $3.26=05 \quad 6.35=06 \quad 1.05=06$ THYRTID

$6, D E=03$

9. 9E-07 
NEHTROM MUL TIPLIER CRITICALITY ACCTOEN

$05 / 10 / 76$

fiftr reah inilalation onse commitment, pem, at distance shown

DISPERSTISN IINDFR HANFORO MODERATELY STABLF CUNDITIUNS

SOLIIRI.E HATEHIAL, I MICAOP

GRUUP REFEHENCE

$\ln 2 \quad 2019$

IHATVIDUAL DOSF FUR $1 / 2$ - R HA RELEASE

$x$ R

IOTAL HODY
HOAS
LINGS
IHYHOIS

$0.2 F-194$

$3,2 F=113$

$0.3 F-n 3$

$n$.

$4 . O E=04$

?. $\triangle E-O B$

$4,3 E=03$

0 .

$X F$

intal antir

$1.0 E-O S$

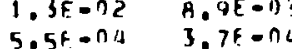

tuncis

THYHCIO

$n$,

$3.76-n 4$

0 .

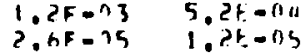

$1.2 F=0 ? \quad 5,1 E=0$

b. $7 E=01$ 2., QEE-OI

OTSTANCE FROM RELEASF POINT, METERS

$3,-n a$

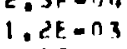

$1.9 F-113$

$1,2 E=\ln 4$

$0,6 E-04$
$9,7 t-014$

a. $7 t=01 /$

2000

$5000 \quad 10000$

20000

50000

100000

$5,9 E=0 A$

$0.2 E-05$

$3.5 E=\cap 4$

$4, A E \cap 04$

0.

2.
$1.5 E=05$
$1.5 E-\cap 4$

1. AE $=04$

n.

$1.1 E-05$
$7.5 E=05$

7. $5 E=05$
$8.0 E=05$

0 .

$5,1 E-106$

1.01 .06 T.U. 07

$3.3 E-05$ I. $3 E=05$ 1.1E-05

0 .

$7.3 E=06$

0.

$1.4 E-06$

$3.5 F=03$

$1.5 E=n 3$

$5.26 \bullet 05$

$1.9 E \cdot 05$

$0,95=00$

$4,4 E=06$

$1,7 \mathrm{E}-\mathrm{Ub}$

0.

o.

i)

2. HE-OS $1.0 E-05 \quad 5,0 E=06$

$5,0 E-06$

$5.0 E-0.5$

$2.2 E .05$

8. $5 E-07$

,

$2.65 \cdot 06$

0 .

$1.1 E-0.5$
$6,4 E=07$

1. IF-0A 7.3F-n5 3.1E=05 1.1E-05 $4.8 E-00$

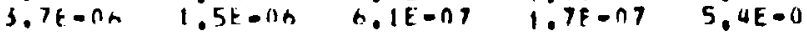

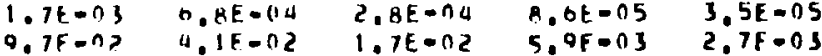

5. $1 E=06$

0 .

0.

IHYROIn
IIINTSES

CS, SE, It. TOTAL AOT:Y

RONE

thyBuIn

1. AF-nA $A .2 E=n S$

$7,9 E=114 \quad 3,7 E=C A$

I. SF $=n 2 \quad 7,1 E=n$

2. $A E=05$

$0.56=05$
$1.36=01$

2. $4 E=0 x$

$2,8 t=07$

$4.0 E=04 \quad 1, E E=04$

$1.2 E-05$

$5.2 E-06 \quad 1.9 F-06 \quad 8.9 E-07$

$1.2 E=05 \quad \square .4 F=06 \quad 2.1 E=06$

$\begin{array}{lll}\text { P. } 9 E=05 & 1.1 E=05 & 4.0 F=06 \\ 4 . R E=04 & 1.8 E=04 & B . S E-O S\end{array}$

$4.3 E-07$

$1.0 E=07$

$1,4 E-O B$

$16=03$

1. $8 E=06$

$3.91=05$

$0.1 E=07 \quad 1.9 E-07$

$5.1 E-07 \quad 1.9 E-07$

1. 3E-OS $5.6 E-00$ 
NEHTHON MULTIPLIER CAITICALITY ACCIDENT

FIFTY YFAL INHALATION DOSE COMMITMENT, REM, AT DISTANCE SHOWN

OISPERSION UNDEK HANFURD MIDOERATELY STABLE CONDITIONS

SOLIJALF MATERIAL, I MICRON

INDIVIDUAL NOSE FDR - 24 HRG RELEASE

\begin{tabular}{|c|c|}
\hline $\begin{array}{l}\text { NUCL. InE } \\
\text { GROUP }\end{array}$ & $\begin{array}{l}\text { OHGAN OF } \\
\text { REFERENCE }\end{array}$ \\
\hline$K R$ & $\begin{array}{l}\text { TOIAL HOOY } \\
\text { HONF } \\
\text { LUNGS } \\
\text { IHYOOIN }\end{array}$ \\
\hline$X E$ & $\begin{array}{l}\text { IOTAL ROUY } \\
\text { HONF } \\
\text { LINRS } \\
\text { THYROIO }\end{array}$ \\
\hline I & $\begin{array}{l}\text { IOIAI RONY } \\
\text { RONE } \\
\text { LHOSES } \\
\text { IHYROTH }\end{array}$ \\
\hline
\end{tabular}

$\ln 2 \quad 200$

DISTANCF FRIM RELEASF POINT, METERS

\begin{tabular}{|c|c|c|c|c|c|c|c|}
\hline 500 & 1000 & 2000 & 5000 & $10 \cap 00$ & 20000 & 50000 & 00000 \\
\hline $\begin{array}{l}1.5 F=0.4 \\
8.1 F=04 \\
1.3 F=03 \\
0 .\end{array}$ & $\begin{array}{l}7.4 E=05 \\
4.0 F=04 \\
5.0 F=04 \\
0 .\end{array}$ & $\begin{array}{l}3.3 E=05 \\
1.9 E=04 \\
2,0 E=04 \\
0 .\end{array}$ & $\begin{array}{l}9,3 E=06 \\
5.7 F=05 \\
7.0 F=05 \\
0 .\end{array}$ & $\begin{array}{l}3.2 E=06 \\
2.2 E=05 \\
2.3 E=05 \\
0 .\end{array}$ & $\begin{array}{l}1.11=06 \\
8.5 F=06 \\
6.8 F=06 \\
0 .\end{array}$ & $\begin{array}{l}2.3 E=07 \\
2.6 E=06 \\
9.7 E=07 \\
0 .\end{array}$ & $\begin{array}{l}1.0 E=08 \\
1.0 E=06 \\
1.0 E=07 \\
0 .\end{array}$ \\
\hline $\begin{array}{l}1.5 F=01 \\
1.9 E=03 \\
7.9 F=05 \\
0 .\end{array}$ & $\begin{array}{l}5 . M E=0 S \\
7.5 F=04 \\
3.1 F=05 \\
0 .\end{array}$ & $\begin{array}{l}2.2 E=05 \\
2.8 E=04 \\
1.21=05 \\
0 .\end{array}$ & $\begin{array}{l}\text { 5. AE }=0 B \\
7 . \text { AF }=05 \\
3.2 E=06 \\
0 .\end{array}$ & $\begin{array}{l}2.1 E=06 \\
2 ., H E=05 \\
1.2 E=06 \\
0 .\end{array}$ & $\begin{array}{l}7.4 E=07 \\
9.4 E=06 \\
4.3 E=07 \\
0 .\end{array}$ & $\begin{array}{l}1.9 E=07 \\
2.4 E=06 \\
1.2 E=07 \\
0 .\end{array}$ & $\begin{array}{l}0,5 E=08 \\
8,2 E=07 \\
4,9 E=08 \\
0 .\end{array}$ \\
\hline $\begin{array}{l}1.2 F=n a \\
2 . S F=n h \\
1.1 E=03 \\
0.4 E-n ?\end{array}$ & $\begin{array}{l}4.5 E-05 \\
4.3 F=07 \\
4.2 E-014 \\
2.5 E-02\end{array}$ & $\begin{array}{l}1.6 E=05 \\
3.2 E=07 \\
1.5 E=04 \\
9.2 E=03\end{array}$ & $\begin{array}{l}a, 1 t=06 \\
b .6 E=0 H \\
3.3 E=05 \\
2.3 E=03\end{array}$ & $\begin{array}{l}1.4 E=06 \\
1.0 E=\cap 8 \\
1.0 E=05 \\
7 ., T E=04\end{array}$ & $\begin{array}{l}4.4 F-07 \\
2.4 E=09 \\
2.9 E=06 \\
2.5 E=04\end{array}$ & $\begin{array}{l}9.2 E-08 \\
5.0 E=11 \\
4.0 E=07 \\
5.3 E-05\end{array}$ & $\begin{array}{l}2.0 E=08 \\
2.7 E=13 \\
9.1 E=08 \\
1.5 E=05\end{array}$ \\
\hline $\begin{array}{l}1 . B F=05 \\
4.3 F=05 \\
8.8 F=05 \\
1.6 F=03\end{array}$ & $\begin{array}{l}7.2 t=06 \\
1.7 E=05 \\
1.7 E=05 \\
6.5 F=04\end{array}$ & $\begin{array}{l}2,7 E-06 \\
6,4 E-06 \\
1.5 E-05 \\
2,5 E-04\end{array}$ & $\begin{array}{l}7.2 E=01 \\
1.7 E=0 B \\
4.2 E=0 B \\
7.0 E=05\end{array}$ & $\begin{array}{l}2 ., 6 E-07 \\
6.1 E=07 \\
1.3 E=0 h \\
2.5 E=05\end{array}$ & $\begin{array}{l}8.9 E=0 B \\
? .2 E=07 \\
3.7 E=07 \\
8.1 E=06\end{array}$ & $\begin{array}{l}2.1 E-0 B \\
5.4 E=U A \\
6.8 E=0 A \\
1.8 E=0 O\end{array}$ & $\begin{array}{l}7.0 E=09 \\
1.8 E=08 \\
1.8 E=08 \\
5.3 E=07\end{array}$ \\
\hline
\end{tabular}


NEUTRON MULTIPLIER CRITICALITY ACCIDENT

$05 / 10 / 76$

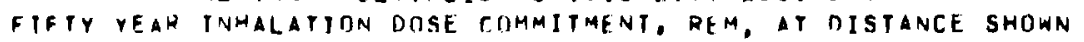

OISPERSITN UNDEH HATHORD VERY STARLF CONIITIONS

TPSCILUALE MATERIAI, I MICRON

INDIVIDUAL OOSE FRIR O - 24 has RELEASE

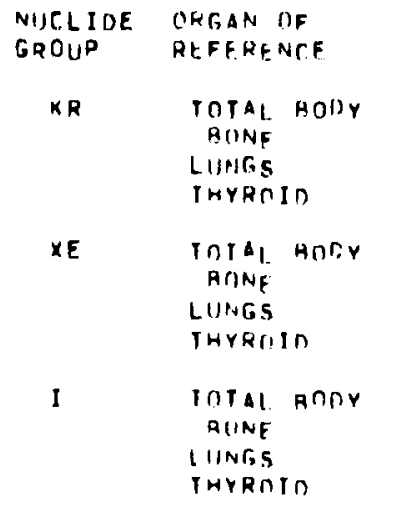

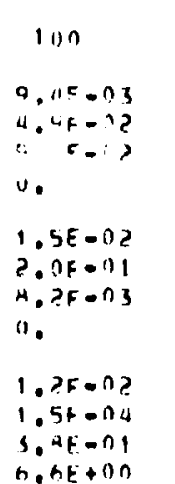

200

$$
\begin{gathered}
\text { DISTANCE FROM RELEASE PITNT, METERS } \\
\text { INOO DOOO TOOO }
\end{gathered}
$$

10000

20000

50000

100000

$\begin{array}{llll}1.1 E-03 & 4.3 E-n 3 & 2.4 E-n 3 & 1.2 E-03\end{array}$

$4.0 E-1) ? \quad 5.3 t-n z$

$1.2[-n)$

$3.0 \mathrm{~B}=\mathrm{n} ?$

0 .

$1.3 E-n s$

$4,15-04$

$1.0 E=04$

0 .

$9.4 E-03 \quad 3.1 F \cdot 03$

0.

$1.1 E=03$
$1.26=03$

$\because$

0. $4 E-05$

$5.1 t=0$.

$a . I E=0$

0.

$1.9 E-05 \quad 7.4 E-06$

$2,1 E=04 \quad 1.1 E=04$

, BE $=0$

$9.9 E+04$

3.1E.04 $1.3 E .04$

$\begin{array}{ll}1.5 E-02 & 5.1 E-03 \\ 1.5 E-01 & 6.5 F-n ?\end{array}$

$\begin{array}{ll}? .3 E=\cap 3 & 9.9 E-n 4 \\ 2.9 E=n 2 & 1.3 E-02\end{array}$

$0 . ? E=03$

$2,7 F=0$

$1.25=113$

5. $\triangle E-014$

$1.7 E=0 A$

0.

$5,4 E=05$
$6.9 E=04$

$1.4 E-05$

$?$.

0 .

$1.6 E=03$
$1.2 E=05$

0 .

$5.7 F-03$

$2.15-113 \quad 0.4 F=04$

$4.0 t-0 j$

3. 2E $=05$

$1.8 E .05$

0 .

$1.110-06$

$\begin{array}{ll}1,8 E-05 & 8.5 E-06 \\ 2,3 E-04 & 1.1 E=04\end{array}$

$6,4 E=06$

$.9 E-05$

0 .

$\begin{array}{lll}0.7 E-n ? & ? .9 E-n E & 1.2 E=02 \\ 1.2 E+0 n & 5.3 E-n 11 & ? .2 E-01\end{array}$

T. $B F=\cap 2$

$1.3 E-03$
$2,1 E=02$

$\begin{array}{lll}5,3 E-0 B & 1.5 E=0 Q & 1.1 E-11 \\ 4, Q E=0 A & 1.2 E=04 & 4.1 E=05\end{array}$

$5.4 E=06$

2.1E-06

. $2 E+n n$

2. $A E=n \square$

$1.5 E-04 \quad 5.0 E-05$

$1,5 F-113$
$3,4 F-n 3$

$3.1 E-n 3 \quad A .1 F=n$

. HE-nQ $1.6 E-04$

3. $\triangle E-03 \quad 1.5 E-03$

$\begin{array}{ll}1.8 E-0 S & 7.3 E-06 \\ 5,0 E-05 & 2.1 F-05\end{array}$

$4.0 E-04$ C. $O E=04$

LIIATS

$Q, 1) E=11 ?$

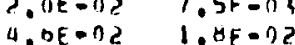

R. $H E=03$ प. $2 E-03$

$1.5 E-03 \quad 5.9 E=04$

$\begin{array}{ll}4,1 E=03 & 1.2 E=03\end{array}$

4. $4 E-01$

$8,8 E=06 \quad 3,0 E=0 B \quad 1.4 E=06$

$7,3 t=05 \quad 2,2 E=05 \quad 8,7 E=06$ 
NEUIRON MULTIDLIER CRITICALITY ACCTDENT

$05 / 10 / 76$

fiftr reah inHalation onse comatTMENT. aEm. at distance shown

DISPERSION UNOER WANFORD VERY STABLE CONDITIONS

INSOLURLE MATERIAL, I MICDON

IHDIVIOUAL DOSE FOR O - I/2 HR RELEASE

\begin{tabular}{|c|c|}
\hline $\begin{array}{l}\text { NUCL IDE } \\
\text { GRQUP }\end{array}$ & $\begin{array}{l}\text { ONGAN OF } \\
\text { QEEFER NCE }\end{array}$ \\
\hline KR & $\begin{array}{l}\text { IOIAL RODY } \\
\text { BONE } \\
\text { LUNGS } \\
\text { THYAOID }\end{array}$ \\
\hline$X E$ & $\begin{array}{l}\text { TOTAL HOOY } \\
\text { RONE } \\
\text { LHNGS } \\
\text { IHYAOIO }\end{array}$ \\
\hline I & $\begin{array}{l}\text { TUTAL ROIV } \\
\text { BONF } \\
\text { LUNGS } \\
\text { IHYROIN }\end{array}$ \\
\hline
\end{tabular}

CS,SE,TE TOTAL AORY

BONF

LUNGS

IHYROID
100

$7.5 E-03$ $3,9 F=02$ 0 .

$1.26-0 ?$

$0.0 F=01$
$1.06-0 ?$ $1.6 F=01$
$0.0 E=03$ 0 .

$9,36-n]$

$1.2 E-0)$

3. OE 01
$5, M E+00$

$1,2 E-1) 3$

3. $n E-\cap B$

$3.25-0 ?$
$7.15=0 ?$
200

$0.1 E-03$

$3.26-0 ?$
$5.7 E-0 ?$

0 .

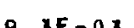

$1.2 E-01$

5.UE-n

1).

4. SE- 03

$5.7 E-05$

1. $4 E-n 1$
?. $5 E+0 D$

$0.0 E-O U$

1 . OE-OB

$1.6 F=02$
$3.7 E=0 ?$
DISTANCE FROM RELEASE POINT, METERS

\begin{tabular}{|c|c|c|c|c|c|c|c|}
\hline 500 & lonn & 2000 & $500 n$ & 10000 & 20000 & 50000 & 00000 \\
\hline $\begin{array}{l}3.4 F-03 \\
1.85-02 \\
2.0 E-02 \\
0 .\end{array}$ & $\begin{array}{l}1.9 E-03 \\
1.0 E-02 \\
1.5 E-02 \\
0 .\end{array}$ & $\begin{array}{l}9.2 E=04 \\
5.3 E=03 \\
7.2 E=03 \\
0 .\end{array}$ & $\begin{array}{l}3.0 E=04 \\
1.8 E=03 \\
? .3 E=03 \\
0 .\end{array}$ & $\begin{array}{l}1.1 E=04 \\
7.7 E=04 \\
8.2 E=04 \\
0 .\end{array}$ & $\begin{array}{l}4.2 E-05 \\
3.3 E=04 \\
2,7 E=04 \\
0 .\end{array}$ & $\begin{array}{l}1.2 E=05 \\
1.3 E=04 \\
4.8 E=05 \\
0 .\end{array}$ & $\begin{array}{l}4.5 E=06 \\
6,5 t=05 \\
0.7 E=06 \\
0 .\end{array}$ \\
\hline $\begin{array}{l}U, 1 E-03 \\
5.2 E-02 \\
2.2 E-03 \\
0 .\end{array}$ & $\begin{array}{l}1 . A E=03 \\
2.3 E=02 \\
9 . \Delta E=04 \\
0 .\end{array}$ & $\begin{array}{l}7.7 E=04 \\
9 . B E=03 \\
4.2 E=04 \\
0 .\end{array}$ & $\begin{array}{l}2.3 E-04 \\
2.95=0.3 \\
1.3 E=04 \\
0 .\end{array}$ & $\begin{array}{l}9.1 E=05 \\
1.2 E=03 \\
5.1 E=05 \\
0 .\end{array}$ & $\begin{array}{l}3,6 E=05 \\
4.0 E=04 \\
2.1 E=05 \\
0 .\end{array}$ & $\begin{array}{l}1.2 E-05 \\
1.5 E-04 \\
1.5 E-00 \\
0.5\end{array}$ & $\begin{array}{l}5,21=06 \\
6,56=05 \\
3,91=06 \\
0 .\end{array}$ \\
\hline $\begin{array}{l}1.7 F=03 \\
2.0 E=05 \\
5.3 E-02 \\
9.3 E=01\end{array}$ & $\begin{array}{l}7.3 E=04 \\
8.7 E=06 \\
2.3 E=02 \\
4.1 E=01\end{array}$ & $\begin{array}{l}3.1 E=04 \\
3.4 F=06 \\
9.4 E=03 \\
1.7 E=01\end{array}$ & $\begin{array}{l}A . R F=05 \\
7.0 F=07 \\
P .0 F=103 \\
5.0 F=12\end{array}$ & $\begin{array}{l}3.3 E=05 \\
2.0 E=07 \\
9.2 E=04 \\
1.9 E=02\end{array}$ & $\begin{array}{l}1.2 E=05 \\
3.5 E=08 \\
3.2 E=04 \\
7.0 E=03\end{array}$ & $\begin{array}{l}3.3 E=06 \\
9.1 E=10 \\
7.6 E=05 \\
1.9 E=03\end{array}$ & $\begin{array}{l}1,3 E=06 \\
6,4 E=12 \\
2,5 E=05 \\
7.26=04\end{array}$ \\
\hline $\begin{array}{l}2 . ? E=04 \\
0.4 E=04 \\
5.9 E=03 \\
1.4 E=02\end{array}$ & $\begin{array}{l}1.0 E-\cap 4 \\
2 ., H E-04 \\
2.7 E-03 \\
0.9 E-03\end{array}$ & $\begin{array}{l}4.3 E-05 \\
1.2 E=03 \\
1.2 E=03 \\
3.2 E=03\end{array}$ & $\begin{array}{l}1.3 F=05 \\
3.0 E=05 \\
3.0 E=04 \\
1.1 E=03\end{array}$ & $\begin{array}{l}5.0 E-00 \\
1.4 E=05 \\
1.3 E=04 \\
4.1 E-04\end{array}$ & $\begin{array}{l}2.0 E=06 \\
5.8 E=06 \\
4.8 E=05 \\
1.4 E=04\end{array}$ & $\begin{array}{l}0.1 E=07 \\
1.9 E=06 \\
1.3 E=05 \\
3.6 E=05\end{array}$ & $\begin{array}{l}2,7 E=07 \\
0,4 E=07 \\
5,3 E=06 \\
1,2 E=05\end{array}$ \\
\hline
\end{tabular}


NEUTRON MULITPLIER CRITICALITY ACCTOENT

$05 / 10 / 76$

fifir year inhalapion dose commitment. rem. at digtance shown DISPFESIOM IINDER HANFORD VFRY SIAGLE CONDITIONS INSOLUALE MATERIAL, I MICRON

\begin{tabular}{|c|c|c|}
\hline $\begin{array}{l}\text { NUCLLIDE } \\
\text { GROUP }\end{array}$ & $\begin{array}{l}\text { ORGAN DF } \\
\text { REFERENCE }\end{array}$ & 100 \\
\hline$K R$ & $\begin{array}{l}\text { IOIAL ROOY } \\
\text { AONE } \\
\text { LUNGS } \\
\text { IHYROID }\end{array}$ & $\begin{array}{l}1.1 F=03 \\
5.9 E=03 \\
1.2 E=02 \\
0 .\end{array}$ \\
\hline$x E$ & $\begin{array}{l}\text { POTAL AODV } \\
\text { HONE } \\
\text { LIINGS } \\
\text { THYROIO }\end{array}$ & $\begin{array}{l}1.9 E=03 \\
2.4 E=0 . \\
1.0 F=03 \\
0 .\end{array}$ \\
\hline I & $\begin{array}{l}\text { IOIAL, aIITY } \\
\text { arinf } \\
\text { LIJNCis } \\
\text { THYROIIO }\end{array}$ & $\begin{array}{l}1.4 E-n 3 \\
1.4 E-05 \\
4.5 E-n ? \\
1.05-01\end{array}$ \\
\hline SS, st, IE & $\begin{array}{l}\text { IOIAL HODY } \\
\text { AONF } \\
\text { LUNGS } \\
\text { IHYROID }\end{array}$ & $\begin{array}{l}1 . A_{F}=04 \\
4.5 F=114 \\
4.8 E=03 \\
1.1 F=02\end{array}$ \\
\hline
\end{tabular}

\begin{tabular}{|c|}
\hline 200 \\
\hline $\begin{array}{l}9.4 E-04 \\
4.98-05 \\
9.4 E-n 3 \\
0 .\end{array}$ \\
\hline $\begin{array}{l}\text { 1. } \triangle E-1) 3 \\
1 . H E-\cap ? \\
7.0 F-\cap 4 \\
0 .\end{array}$ \\
\hline $\begin{array}{l}n .9 E-n U \\
.7 E-06 \\
? .2 E-0 ? \\
3.9 E=01\end{array}$ \\
\hline $\begin{array}{l}9.2 E-n 5 \\
2.5 E=n 4 \\
2.4 E-03 \\
5.7 E-03\end{array}$ \\
\hline
\end{tabular}

individial nOSF FOR I/P - a he RELEASE

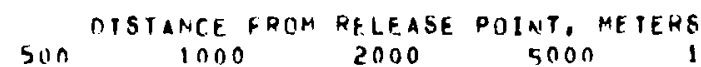

$5.5 E=04 \quad 3.3 E-04 \quad 1.0 E-04 \quad 0.0 E-05$

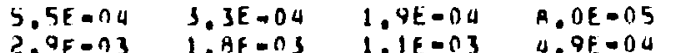

2. $9 E=n 3 \quad 1 . A E=03 \quad 1.1 E-03 \quad \triangle . Q E=0 A$

$4.6 E-103$

$2.0-2=03$

$1.5 E-03$

:

20000

50000

100000

$3.2 E .04$

$3.9 E-05 \quad 1.8 E-05$

$1.8 E=05$
$1.5 E=04$

$0.21006 \quad 2.71006$

$\therefore 0 E-05 \quad 3,9 E-05$

$0.0 E-04 \quad 3.2 E-04$

$1.6 E-0,0.2 E-05$

0.2

0 .

0.

3. SE $=14$

$1: 7 f=n 4$

$2.0 E=03$

G. ZE 0 OS

3.

1. DE $=05$

$6.3 E-06 \quad 3,1 E-00$

$n$.

$3,9 E-04$

$2.0 E=04$

-

$3.4 F=05$

$1.76-05$

$9.1 E=06$

$1.96 .05 \quad 3.9 E-05$

$.1 E=06 \quad 2,3 E=06$

$2.7 E-04 \quad 1.3 E \cdot 04$

$n$.

0 .

0 .

$\begin{array}{llll}1.16-05 \quad 5.3 E-06 & 1.8 E-06 \quad 7.5 E-07\end{array}$

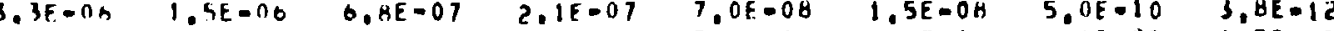

$3.5 E-03 \quad 4.0 E-n 3 \quad 1.9 E-n 3 \quad b .9 E=n a \quad 3.1 E=04 \quad 1.4 E-04 \quad 4.1 E-05 \quad 1.5 E-05$

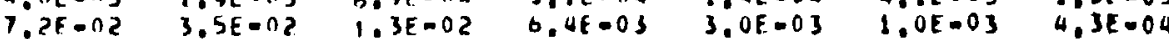

$1,6 E-07$

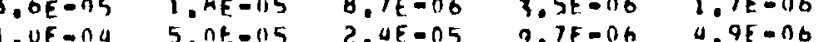

$0.5 E-04 \quad 4.16-04 \quad 2.48-04 \quad 0.5 E-05 \quad 4.5 E=05$

$2,5 E=00 \quad 1.0 E=00 \quad 5,0 E-07$

$2,1 E=05 \quad 7.3+000 \quad 3,2 t=06$

$2.3 E=03 \quad 1.2 E=03 \quad 0.5 E=14 \quad 2.0 E=n 4 \quad 1.4 E=04$

$6.2 E-05$

1. $9 E=05 \quad 7,3 E=06$ 
NEUTRTN MIILTIPLIER CRITICALITY ACCIOENT

$05 / 10 / 76$

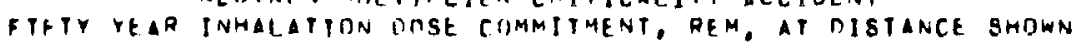

DISPERSITN IINDER HAMFURD VERY STABLF CONDITIOAS

INSOLUHI.E MATEHIAL, I MTCRON

\begin{tabular}{|c|c|}
\hline $\begin{array}{l}\text { NUELI IDE } \\
\text { GA0!PP }\end{array}$ & $\begin{array}{l}\text { RHGAN DF } \\
\text { REFERENCE }\end{array}$ \\
\hline$K R$ & $\begin{array}{l}\text { IOTAL ROOY } \\
\text { AONF } \\
\text { LIINGS } \\
\text { IHYYOID }\end{array}$ \\
\hline$X E$ & $\begin{array}{l}\text { IOTAL HOOY } \\
\text { RIINE } \\
\text { IIINGS } \\
\text { IWYAOIO }\end{array}$ \\
\hline 1 & $\begin{array}{l}\text { OOTAL AOUY } \\
\text { HOANF } \\
\text { LIINISS } \\
\text { THYROII }\end{array}$ \\
\hline
\end{tabular}

CS, St. TE InIAL RODY IHYRIIn

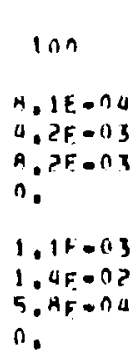

i.

$1, C F=01$ $1.3 F=0.5$ $1.36-192$
$5,7 F=01$

$1,3 E-04$ 3, IF $\rightarrow \cap 4$ $3.4 F-03$
INDIVIDIIAL DOSE FOR 8 - 24 HRS RELEAST

\begin{tabular}{|c|c|c|c|c|c|}
\hline & \multicolumn{2}{|c|}{ OISTANCE FROM } & \\
\hline 200 & $50 n$ & 1000 & 2000 & 5000 & 10000 \\
\hline $\begin{array}{l}0.6 E-04 \\
3,4 E-03 \\
0,2 E=03 \\
0 .\end{array}$ & $\begin{array}{l}3.95=04 \\
1.95=03 \\
3.15=13 \\
0 .\end{array}$ & $\begin{array}{l}2.0 E=0 d \\
1.1 E=03 \\
1 . n t=03 \\
0 .\end{array}$ & $\begin{array}{l}9.8 E-05 \\
5.0 E=04 \\
7.7 t=04 \\
0 .\end{array}$ & $\begin{array}{l}3.1 F=05 \\
1.9 E=04 \\
2.3 E=04 \\
0 .\end{array}$ & $\begin{array}{l}1.1 E-05 \\
7.5 E-05 \\
8.0 E-05 \\
0 .\end{array}$ \\
\hline $\begin{array}{l}A, 1 E=04 \\
1.0 E=0 ? \\
4.3 E=04 \\
n .\end{array}$ & $\begin{array}{l}3.5 F=04 \\
4.5 F=03 \\
1.9 F=04 \\
0 .\end{array}$ & $\begin{array}{l}1.0 t-04 \\
2.0 E-03 \\
8.5 E-05 \\
1 .\end{array}$ & $\begin{array}{l}3.6 E-05 \\
8.4 E=04 \\
3.0 E=05 \\
0 .\end{array}$ & $\begin{array}{l}1.9 E=05 \\
? .5 E=04 \\
1.1 E=05 \\
0 .\end{array}$ & $\begin{array}{l}7.2 E=06 \\
9.2 E=05 \\
0.0 F=06 \\
0 .\end{array}$ \\
\hline $\begin{array}{l}4.9 E=04 \\
n .1 E=n n \\
1.6 F=0 ? \\
2.1 E=01\end{array}$ & $\begin{array}{l}1.8 E=014 \\
2.2 E=06 \\
5.6 E=03 \\
1.0 E=01\end{array}$ & $\begin{array}{l}7 . A E=05 \\
9.3 E=07 \\
2.5 E=03 \\
4.4 E=02\end{array}$ & $\begin{array}{l}3.2 E-05 \\
3.0 E-07 \\
1.0 E-03 \\
1 . B E=02\end{array}$ & $\begin{array}{l}0.1 E=0 B \\
0.1 E=0 B \\
2.7 F=04 \\
5.1 F=03\end{array}$ & $\begin{array}{l}3.2 E=00 \\
2.0 E=0 A \\
9.0 E=05 \\
1.0 F=03\end{array}$ \\
\hline $\begin{array}{l}3.5 t-05 \\
1.4 t-04 \\
1.7 t-03 \\
4.0 F-03\end{array}$ & $\begin{array}{l}2.4 E=05 \\
6.8 F=05 \\
6.3 F=04 \\
1.5 E=03\end{array}$ & $\begin{array}{l}1.1 E=05 \\
3.1 E=05 \\
2.4 E=04 \\
7.4 E=04\end{array}$ & $\begin{array}{l}4.6 E=06 \\
1.3 E=05 \\
1.2 E-04 \\
3.4 E-04\end{array}$ & $\begin{array}{l}1.4 E=00 \\
1.7 F=06 \\
3.7 E=05 \\
1.1 E=04\end{array}$ & $\begin{array}{l}5 . O E-07 \\
1.4 E-06 \\
1.3 E=05 \\
0.0 E=05\end{array}$ \\
\hline
\end{tabular}

$50000 \quad 100000$

\begin{tabular}{|c|c|c|}
\hline $\begin{array}{l}3 E=06 \\
3.0 E=05 \\
2.4 E=05 \\
0 .\end{array}$ & $\begin{array}{l}8,3 E=07 \\
0.2 E=06 \\
3.5 E=06 \\
0 .\end{array}$ & $\begin{array}{l}2.5 E=07 \\
3.6 E=06 \\
4.9 E=07 \\
0 .\end{array}$ \\
\hline $\begin{array}{l}.0 E=06 \\
.3 E=05 \\
.5 E=06 \\
.\end{array}$ & $\begin{array}{l}6.7 E=07 \\
6 . S E=06 \\
4.4 E=07 \\
0 .\end{array}$ & $\begin{array}{l}2 . U E=0 Y \\
2.9 E=00 \\
1 . A E=07 \\
0 .\end{array}$ \\
\hline $\begin{array}{l}1 E-06 \\
2 E-09 \\
9 E-05\end{array}$ & $\begin{array}{l}2.4 E-07 \\
6.0 E=11 \\
5.5 E-00 \\
1.4 E=04\end{array}$ & $\begin{array}{l}7.0 E=0 B \\
3,0 E=13 \\
1.4 E=06 \\
4.0 E=O S\end{array}$ \\
\hline & $\begin{array}{l}4.4 E=08 \\
1,4 E=07 \\
9.7 E=07\end{array}$ & $\begin{array}{l}1 ., 5 E-08 \\
4.7 E=08 \\
3.0 E=07\end{array}$ \\
\hline
\end{tabular}


NEUYRON MUL TIPLIEH CRITICALITY ICCIDENT

$05 / 10176$

firit year inHalation DOSE COMMITMENT, REM. at DISTANCE SHOWN

DISPERSPON UNDFR HANFIPD MUOFRAPELY STAGLE CONDITIONS

$$
\text { TNSOLLINIE MATERIAL, I MICRON }
$$

INIIVIDUAL DOSE FOH 0 - 24 HRS RELEASE

$\begin{array}{lll}\text { NUCLIDE } & \text { OHGAN OF } \\ \text { GROUP } & \text { GEFERFNCE } & 100 \\ \text { KR } & \text { TOTAL AONY } & 5.2 F=03 \\ \text { HONF } & ? .7 E=0 ? \\ & \text { LINGS } & 5.2 F=0 ?\end{array}$

XF TOTAL RODY

RIINE:

PHYROI

TIITAL anOYY

BIINF

Luivis

THYPIID

CS,SF, IE TUTAL AOUYY

I.IINTS
200

$3 . B E-03$

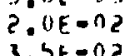

$3, S E=0$ ?

A. $4 F-\cap 5$

5. $\mathrm{HE}-\mathrm{OC}$

$.1 E-n 1 \quad 7,2 E-\cap 2$

a. SE - I) 3

$5.0 E=03$

h. $14=-1) 3 \quad P, A E=03$

A. 150.05 उ. $5 E-0,5$

5. $1 E-11 \quad H .9 E-0$ ?

$.65+00$

$1, O E+O D$

A. $1 E=\cap A$

$5,1 F=03$

S. $5 F=0,0$

$4.9 F \cdot 1) ?$

$7 F=0$,

$1 ., 0 F-n 3$

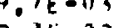

?. $3 t-\pi$ ?

\section{DISTANCE FRIM RELEASE POINT, METER}

$$
1000
$$

2000

5000

10000

20000

50000

100000

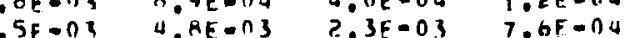

$.5 F=02 \quad 7.1 F=n 3$

0.

).

$5.1 E-n 3$

$3.2 F=04$
$3,4 E=04$

0.

$1.8 E-05$

$1.4 E=04$

0.

$1.7 E-1 F=112$

$1.1 F-n 3$

0.

3. $3 E=04$

$3.7 E \cdot 05$

$\begin{array}{ll}5,1 E-06 & 2,0 E-06 \\ 5.7 E=05 & 2,9 E-15\end{array}$ $2,2 E-05 \quad 4,0 E=06$ $0.52=0$

$5.1 E=06 \quad 2,3 E-0 h$ $\begin{array}{llllll}.2 E-03 & 1.2 E-03 & 4.7 E-04 & 1.9 E-04 & 6.4 E-05 & 2.9 E-05 \\ .8 E-04 & 5.1 E-05 & 2.1 E-05 & 8.9 E-00 & 3.3 E-06 & 1.0 E-06\end{array}$

0 .

0 .

0 .

H.AF-04 S.GE-04 $\quad 1,3 E-04 \quad 3.6 F=05 \quad 1.4 E-05$

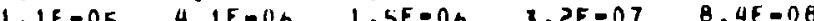

2.8E-n? $\quad 1.1 F-02 \quad 4.1 E-03 \quad 1.1 E-n 3 \quad 3 . B E=04$

$5.2 E-06$

$.5 E-0 B$
$1.1 E=10$

$\begin{array}{lll}1.4 E=04 & 3,4 E=05 & 1,1 E=05 \\ 3,0 E=03 & B, 3 E=04 & 3,3 E=04\end{array}$

T. HF $=03$

$8,5 E-07$
$2,5 E=06$

$5.45-06$

$2,1 E=00$

a. $\partial E=0 S$

$1.9 E-05$

$3.4 F-n A \quad 1.3 E-n 4 \quad 5.2 E-05$

, IF $=03$ 1. SE -03

$1.5 F=115$

$0.0 E-06$

i.

$1.5 F=0$

$1,7 E=04$

, $1 E=05$

$2,7 E-07$

3. $B E=07$

$0,0 E-0) \quad 2,4 E=06$

$.0 E-0 S \quad 5,6 E=06$
. 
NEUTTON MUITIPI.TER CRITICALITY ACCIUENT

$05 / 10 / 76$ fiftr rear INHALATION OOSE COMMITMEMT, RFM. AT DisTANCE SHINN

DISPEFSION IINDER HANFORO MOOERATELY STARLE CONDITIONS INSIILUALE MATERIAL, I MICQUIN

NIICLIDE
GRUUP

ORTAN TRE

PEFERENCE

$K R$

TOTAL RODY
BIINE
LIINGS
IMYRIIIO

IMYROIOH

TOTAL BOOY

BUNE.

LIINGS

1 TOTAL aONY

RUINE

LINRTS

ThYATIO

$\frac{T}{G}$
CS, SE, TE TOIAL KODY

HOAN

LHYREIT
INDIVIDHAL nOSF FUR D - I/? Ha hFLEASE

500 DISTARCE FROM RELEASF DOINT, METERS
1000

1000

2000

50 ino

10000

20000

50000

100000

\section{$4,1 F=03 \quad 3,0 E-C 3$} $4,1 F=0 ?$
$4, T E=0 ?$

0 .

$n$.

$\begin{aligned} ., 5 E-03 & , 9 E=04\end{aligned}$

3.1E-04 $9.0 E-15$

$\begin{array}{ll}1.4 E-03 & 5.5 F-04 \\ 2,4 E=03 & 0.8 E-04\end{array}$

0 .

$3.3 E-05$

$1.2 E=05$ $0.4 E-05$
$0.5 t=05$

0 .

$3.2 E=0$ 3. $5 E=05 \quad 1.86=05$

AF-n3 $4.0 E=02$

TE-n? $5, A F=1)$

$3,6 F=03$

D. $A F=014$

$2.6 E-04$

A. $9 E-05$

3E-O3 R. $A E-04$

$9,1 F-04 \quad 3,6 F=04$

$1.4 E-O A$

3. AF $=05$

3. AF

$2.6 F-05$

$3,3 E+04$

$1.5 E-0.5$

$2.1 E-n 3 \quad$ ?. $E=-n 3$

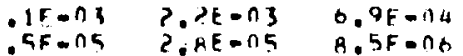

2. $7 E \rightarrow C 4$

$1 . n E-\cap 4$

$1.0 E-05$

$1.3 E-04$

$5.9 E=n h$

$1.0 E=n 4 \quad ? .7 F+05$

T. $25=06$

$.5 E=03$
$1.5 E=01$

$3,1 E=03$ TDE-04

$3.4 E .06$
9.96 .09

$\therefore 0 E=05$

2. $0 E=03$

$3 E=05$
$1,1 E=11$ is

$5.7 E-02$

$1.5 \mathrm{E}=\mathrm{n2}$

$5.4 E=n s$

9. $45=05$

$1,4 E=05$

$.305-00$

$1.5 E \cdot 00$

$5.0 E-07$

$1.6 E=03 \quad 8.0 E=04$

1.7F-n T.TE-n

, $5 F=n 3$

$.0 E=0 S \quad 1,1 F=05$

$1.1 E-04$

$1 . N E=n a$
$2 . D E=03$
$4.2 E=06$
$3, B E=05$

I. $2 E=04$
0.

$3.2 E-06$ $1.8 E=05$ $0,1 E=0 B \quad 1,1 E=06$

$2 F-07 \quad 3,5 E-07$

$2.5 F-10 \quad 1,7 E-12$

2. $1 E=05 \quad$ H. $9 E-C O$

$1.7 E-07 \quad 7,3 E=08$
$1.5 E-00 \quad 5,2 E=07 \quad 2,3 E-07$

1. $3 E=05=06 \quad 1.5 E=06$ 
NEUTOON MILLTIPLIER CRITICALITY ACCIOENT

$05 / 10 / 76$

fifir veap inhalation OISE CoMmitment, Rem. at distance shown

DISPERSTONA IINDER HANFOOD MODOERTELY STIBLE CONOITIONS

INSOLUALE. MATERIAL, I MTCQON

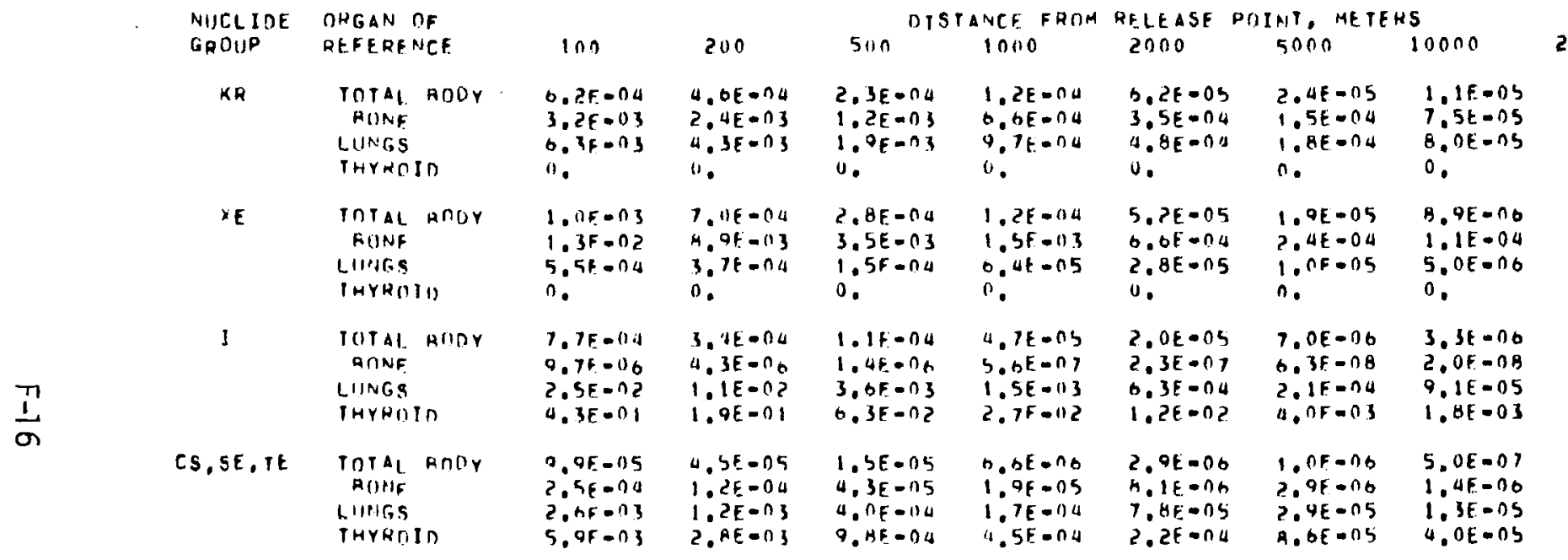

INDIVIDUAL DOSE FOR $1 / 2$ - B hR RELEASE

$50000 \quad 50000 \quad 100000$

$5.1 E .06 \quad 1.7 E-06 \quad 7.4 E-07$

$4.1 E-05$ 1.9E-05 $1.1 E=05$

T.3E=0 $1.4 E=0$

0 .

0.

4. $4 E-06 \quad 1.7 E-00 \quad 8,5 E-07$

$5.6 E=05 \quad 2.2 E=05 \quad 1,1 E=05$

$\begin{array}{lll}2.2 E-06 & 1.1 F=06 & 0,4 F-07 \\ 0 . & 0 . & 0.1\end{array}$

$1.5 E-00 \quad 5.0 E-07 \quad 2,1 E=07$

$4,3 E=09 \quad 1.4 E-10 \quad 1.1 E-12$

$3.9 E-05 \quad 1.2 E=05 \quad 4,1 E=00$

B. $5 E-04 \quad 2,9 \mathrm{E}-04 \quad 1,2 \mathrm{E}-04$

$2.4 E-07 \quad 9.2 E-0 \mathrm{~A} \quad 4,4 E-08$

$7.1 E=07 \quad 2 . H F-07 \quad 1.4 E-07$

$5.9 E-06 \quad 2.0 E-U_{0} \quad 8,7 E-07$

$1.8 E-05 \quad 5,4 E \rightarrow 06 \quad 2,0 E=06$ 
NEIITAON MILLTIPLIFA CRITICALITY ACCIOENT

fiftr rear inhalation ONSE COMMITMENT. Rem. at DISTANCE SHOWN

$05 / 10 / 76$

DISPERSTON HNOER HANFOHD MONEHATELY STABLE CONDITIONS

INSILLIIALE MATERIAL, I MICPON

INDIVIDIIAL DOSF FIR B $=24$ HES RFLEASE

\begin{tabular}{|c|c|}
\hline $\begin{array}{l}\text { NUCLIOE } \\
\text { GROUP }\end{array}$ & $\begin{array}{l}\text { RRGAN OF } \\
\text { REFERFNCE }\end{array}$ \\
\hline$K R$ & $\begin{array}{l}\text { IOTAL PODY } \\
\text { RIINE } \\
\text { LUNGS } \\
\text { IHYAOIO }\end{array}$ \\
\hline$X E$ & $\begin{array}{l}\text { InYAI. ROAY } \\
\text { RUNF } \\
\text { LUNGS } \\
\text { IHYROIN }\end{array}$ \\
\hline 1 & $\begin{array}{l}\text { TOIAL HOOY } \\
\text { RONF } \\
\text { LIINGS } \\
\text { THYAOID }\end{array}$ \\
\hline
\end{tabular}

$\ln 0 \quad 200$

A. $\triangle E-D A \quad 3.2 E-0 \mathrm{~B}$

?. $3 E-133 \quad 1.7 E-O 3$

$4,5 F=03$

1).

$3,0 E=03$

$n$.

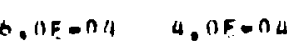

$7 ., \mathrm{BF}=03$

$3, \quad 2 F=04$

$5.1 E \cdot 03$

5. $15=0$ i

2. $4 E=\cap A$

9.55 .04

$7,0 F=06$

1.AE-05 $T, O F=03$

$1 ., 3 E=01$
$1.0 E-03$

3. IEDI

CS,SE,TE TOTAL BODY

THYROIO

$7,1 E-05$

1.0.

$1.9 E=03 \quad H .3 E=04$

$4.2 F=03$

1. $2 \mathrm{E}-0 \mathrm{O}$

$0,3 E-01$ 2.7E-0. $1.1 E-04 \quad 3.3 E=05$
500

DISTANCE FrOM RELfaSE POINT, METERS

\section{$9,3 E-10$}

$5,7 E=05$

T.OF-n5

$n$.

$3.2 E \cdot 06$

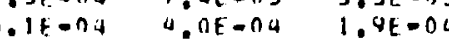

1. Jf $=13$

ก.

$5.6 E-0$

$n$.

$2,2 E=05$
$2,3 E=05$

0 .

20000

50000

100000

$.56-04$

$\begin{array}{ll}1.9 E-03 & 7.5 t-04 \\ 0.9 F=05 & 3.1 E-05\end{array}$

0 .

2. $2 E=05$

$5 . A t=06$
$7.4 E=05$

3. $2 E=n_{0}$

0.

$2,1 E=06$

$2.6 F .05$

0 .

$7.5 E=05 \quad 2.9 E=05$

.

1. 16.06

$8.5 E-00 \quad$ T.OE-OB $\begin{array}{lll}0.8 E-06 & 9,1,007 & 1,0 E=06\end{array}$ 0 .

0 . 0 .

7. $4 F-07$ 9. $4 E-06$ 4. SE-OT

1.96 .07 $\begin{array}{ll}2.4 F-06 & 0,2 E .07 \\ 1.2 F-07 & 4,9 E-0.9\end{array}$ 0 .

0.750 .06 Q.3EN07 3.1E-07

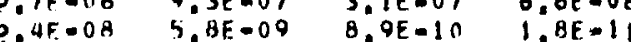
Q.0E-0S 2.6E-05 Q.1E-06 1.5E-10 3,9E-0?

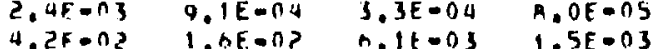

$5,3 E=04$

$1,8 E-04$

$1.5 E-106$
$3 ., B E=05$

$3,9 E=07$
$1,16=05$

$1.0 E=05 \quad \square .0 E=00 \quad 1.5 E=0 B \quad \square .1 E=07$

$2,7 E-04 \quad 1.1 E-04 \quad \triangle 1 E=05 \quad 1.1 E=05$

$1,4 E-07$

$4.1 E-07$

$5,0 E-08$

$1.2 E=O B$

$4.1 E-109$

$1,2 E-0 S \quad 3,0 E-D h \quad T, 1 E=07 \quad 1,9 E=07$ 
NFIITRON MULTIPLIER CPITICALITY ACCTOENT

05110170

EXIERMAL DOSE (REM) AT DISTANCF SHOWN DISPERSIONA IINIJER HANFORD VERY SIAHLE CONDITIONS

\begin{tabular}{|c|c|c|c|c|c|c|c|c|c|c|c|c|}
\hline \multirow{2}{*}{\multicolumn{2}{|c|}{$\begin{array}{l}\text { NIJTLIDE } \\
\text { GRUIJP }\end{array}$}} & \multirow{2}{*}{$\begin{array}{l}\text { OHGON OF } \\
\text { REPFHENCE }\end{array}$} & \multicolumn{8}{|c|}{ DISTANCE FROM SOUACE, METERS } & \multirow[b]{2}{*}{50000} & \multirow[b]{2}{*}{100000} \\
\hline & & & 100 & 200 & $50 n$ & 1000 & $200 n$ & 5000 & 10000 & 20000 & & \\
\hline \multirow{5}{*}{$\frac{1}{\infty}$} & KH & $\begin{array}{c}\text { TOTAL. RONY } \\
\text { SKIN }\end{array}$ & $\begin{array}{l}1 . O E+00 \\
6 . A E+\cap 1\end{array}$ & $\begin{array}{l}2,6 F-n 1 \\
1,4 E+01\end{array}$ & $\begin{array}{l}3.0 E=0 ? \\
1.0 E+00\end{array}$ & $\begin{array}{l}2.7 E-02 \\
3.9 k-01\end{array}$ & $\begin{array}{l}1,1 E=0 ? \\
8, B F=02\end{array}$ & $\begin{array}{l}1.95-03 \\
9.8 E=03\end{array}$ & $\begin{array}{l}2.0 F=04 \\
1.1 E=03\end{array}$ & $\begin{array}{l}1.4 E=05 \\
9.6 E=05\end{array}$ & $\begin{array}{l}3.1 E=06 \\
9.8 E=06\end{array}$ & $\begin{array}{l}9,9 E=07 \\
2,7 E=06\end{array}$ \\
\hline & $X E$ & $\begin{array}{c}\text { TOTAL BOINY } \\
\text { SKIN }\end{array}$ & $\begin{array}{l}1.1 E+0 n \\
3.6 E+01\end{array}$ & $\begin{array}{l}0.7 E-01 \\
9.7 E+00\end{array}$ & $\begin{array}{l}1.4 E-01 \\
1.2 F+C 0\end{array}$ & $\begin{array}{l}2,7 E=02 \\
1.9 E=01\end{array}$ & $\begin{array}{l}6.4 E=03 \\
4 . U E=02\end{array}$ & $\begin{array}{l}9 . A E=04 \\
0.3 E=03\end{array}$ & $\begin{array}{l}2,9 E=04 \\
1.7 E=03\end{array}$ & $\begin{array}{l}7.9 E=05 \\
3.6 E=04\end{array}$ & $\begin{array}{l}5.1 E=06 \\
2.6 E=04\end{array}$ & $\begin{array}{l}1,1 E=06 \\
2,8 E=06\end{array}$ \\
\hline & I & $\begin{array}{c}\text { TOTAL AODY } \\
\text { SKIN }\end{array}$ & $\begin{array}{l}6.6 E=01 \\
4.7 E=02\end{array}$ & $\begin{array}{l}4.4 E-03 \\
? .3 E=02\end{array}$ & $\begin{array}{l}2.24-03 \\
9.0 F=03\end{array}$ & $\begin{array}{l}1,2 F=03 \\
a, 0 E=03\end{array}$ & $\begin{array}{l}5.8 E=04 \\
1.6 E=03\end{array}$ & $\begin{array}{l}1.7 E-04 \\
3 . A E-O A\end{array}$ & $\begin{array}{l}5.1 E=n 5 \\
1.0 E=n 4\end{array}$ & $\begin{array}{l}1.5 E-05 \\
2.96=05\end{array}$ & $\begin{array}{l}3,2 E=06 \\
6,3 E=06\end{array}$ & $\begin{array}{l}7.7 E-07 \\
1.6 E-06\end{array}$ \\
\hline & CS.SE, IE & $\begin{array}{c}\text { THTLL AOONV } \\
\text { SKIN }\end{array}$ & $\begin{array}{l}1.7 E-0 ? \\
7.0 E=01\end{array}$ & $\begin{array}{l}4.3 E=03 \\
1,1 E=01\end{array}$ & $\begin{array}{l}n .1 F=04 \\
9.1 E=03\end{array}$ & $\begin{array}{l}3,0 E=04 \\
2.0 F=03\end{array}$ & $\begin{array}{l}1.4 E=04 \\
9.0 E=04\end{array}$ & $\begin{array}{l}4.2 E=0 S \\
1.5 E=04\end{array}$ & $\begin{array}{l}1.1 E=05 \\
3.2 E-05\end{array}$ & $\begin{array}{l}2,0 E=06 \\
4,7 E=06\end{array}$ & $\begin{array}{l}4,5 t=07 \\
7.0 t=07\end{array}$ & $\begin{array}{l}1,8 E-07 \\
2,7 E-07\end{array}$ \\
\hline & TOTAL & $\begin{array}{l}\text { TIIAL ROAY } \\
\text { SKIN }\end{array}$ & $\begin{array}{l}2.7 F+00 \\
1.1 E+02\end{array}$ & $\begin{array}{l}9.4 E-01 \\
2.4 E+01\end{array}$ & $\begin{array}{l}2.0 E-01 \\
2.8 E+00\end{array}$ & $\begin{array}{l}5.0 t=02 \\
5.9 E-01\end{array}$ & $\begin{array}{l}1.8 E=02 \\
1.3 E=01\end{array}$ & $\begin{array}{l}3.1 E=0.3 \\
1.7 F=02\end{array}$ & $\begin{array}{l}5.6 E=04 \\
2.9 E=03\end{array}$ & $\begin{array}{l}1.1 E=04 \\
4.9 E=04\end{array}$ & $\begin{array}{l}1,5 E-05 \\
2,8 E-04\end{array}$ & $\begin{array}{l}3,0 E=06 \\
7,3 E=06\end{array}$ \\
\hline
\end{tabular}


NEUTRON MULTIPLIER CAITICALITY ACCIDENT

$05 / 10 / 76$

EXTERINAL DOSE (REM) AT DISTANCF SHOWN

OISPERSION UNDFR HANF DHO MUDERAIELY STABLE CONDIIIONS

\begin{tabular}{|c|c|c|c|c|c|c|c|c|c|c|c|}
\hline NUCLTOE & ORGAN OF & & & & NCE FROM & DHRCE, ME & 25 & & & & \\
\hline GROUP & REFE PENCE & 100 & 200 & 500 & 1000 & 2000 & 5000 & 10000 & 20000 & 50000 & 100000 \\
\hline$K R$ & $\begin{array}{l}\text { TOTAL HOOY } \\
\text { SKI }\end{array}$ & $\begin{array}{l}1.3 E+00 \\
2.0 E+01\end{array}$ & $\begin{array}{l}4,9 E=01 \\
4,9 E+00\end{array}$ & $\begin{array}{l}9,6 F=02 \\
5, \triangle E=01\end{array}$ & $\begin{array}{l}1.9 E-02 \\
7.9 F=02\end{array}$ & $\begin{array}{l}4.5 E=n 3 \\
1.5 E=02\end{array}$ & $\begin{array}{l}6,3 F=04 \\
2,2 k=03\end{array}$ & $\begin{array}{l}1,8 E=04 \\
5.8 E=04\end{array}$ & $\begin{array}{l}4.6 E=05 \\
1.3 E=0.4\end{array}$ & $\begin{array}{l}4,2 E=00 \\
9,3 E=00\end{array}$ & $\begin{array}{l}5,1 E=01 \\
9,9 E=07\end{array}$ \\
\hline$X E$ & $\begin{array}{l}\text { rotal HOOY } \\
\text { SKTH }\end{array}$ & $\begin{array}{l}7.5 E-01 \\
3.7 E+01\end{array}$ & $\begin{array}{l}1,4 E-01 \\
6,9 E+06\end{array}$ & $\begin{array}{l}4.35=02 \\
0.9 E=01\end{array}$ & $\begin{array}{l}1.9 F-02 \\
1.5 F=01\end{array}$ & $\begin{array}{l}7,3 E=03 \\
3,3 E=02\end{array}$ & $\begin{array}{l}1.2 E=03 \\
3.6 E=03\end{array}$ & $\begin{array}{l}1,2 E-04 \\
3.9 E=104\end{array}$ & $\begin{array}{l}7,7 E=06 \\
3,1 E=05\end{array}$ & $\begin{array}{l}1,5 E=06 \\
3,5 E=06\end{array}$ & $\begin{array}{l}4,2 E=07 \\
9,0 E=07\end{array}$ \\
\hline 1 & $\begin{array}{c}\text { rOTAL HOAR } \\
\text { SKIN }\end{array}$ & $\begin{array}{l}5.0 E=03 \\
2.7 F=02\end{array}$ & $\begin{array}{l}3,2 E=03 \\
1,3 E=0 ?\end{array}$ & $\begin{array}{l}1.0 E-03 \\
4.4 E=03\end{array}$ & $\begin{array}{l}R, 2 E=04 \\
1,0 E=03\end{array}$ & $\begin{array}{l}3 ., 8 E=04 \\
7.3 E=n 4\end{array}$ & $\begin{array}{l}1.1 F=04 \\
1.7 E=04\end{array}$ & $\begin{array}{l}3, I E=05 \\
4, T E=05\end{array}$ & $\begin{array}{l}B .6 E=06 \\
1,3 E=05\end{array}$ & $\begin{array}{l}1.6 E=06 \\
2.5 E=06\end{array}$ & $\begin{array}{l}3,5 E=07 \\
5,9 E=07\end{array}$ \\
\hline CS,SE, TE & $\begin{array}{l}\text { TOTAL POBY } \\
\text { SKIN }\end{array}$ & $\begin{array}{l}1.3 E-1) 2 \\
4.3 E=119\end{array}$ & $\begin{array}{l}3.1 E-133 \\
5,3 E-112\end{array}$ & $\begin{array}{l}0.3 E=00 \\
4.0 E=03\end{array}$ & $\begin{array}{l}2.1 F-n 11 \\
1,2 F-03\end{array}$ & $\begin{array}{l}9.5 F-05 \\
3.5 E-04\end{array}$ & $\begin{array}{l}2.7 F=05 \\
0.1 E=05\end{array}$ & $\begin{array}{l}0.4 E-n B \\
1,3 E=05\end{array}$ & $\begin{array}{l}1.25 .06 \\
1,9 E-06\end{array}$ & $\begin{array}{l}2, J E-07 \\
3,2 E=07\end{array}$ & $\begin{array}{l}0,4 E=06 \\
l, 1 E=07\end{array}$ \\
\hline TOTAL & $\begin{array}{l}\text { THAL AUMY } \\
\text { SKIN }\end{array}$ & $\begin{array}{l}2.0 E+100 \\
5.8 E+01\end{array}$ & $\begin{array}{l}0 . N E-01 \\
1.2 E+n !\end{array}$ & $\begin{array}{l}1.4 F \cdot n 1 \\
1 . ? F+00\end{array}$ & $\begin{array}{l}3,9 F-02 \\
2,4 E=01\end{array}$ & $\begin{array}{l}1.2 E-02 \\
4.9 E-02\end{array}$ & $\begin{array}{l}2.0 E-03 \\
6.1 E=03\end{array}$ & $\begin{array}{l}3,4 E=04 \\
1.0 E=03\end{array}$ & $\begin{array}{l}6,3 E=05 \\
1.7 E=04\end{array}$ & $\begin{array}{l}7.6 E .06 \\
1.66 .05\end{array}$ & $\begin{array}{l}1.4 E=00 \\
2.6 E=00\end{array}$ \\
\hline
\end{tabular}




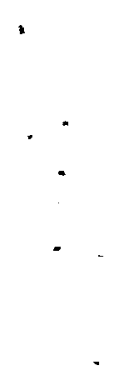




\section{DISTRIBUTION}

No. of

Copies

OFFSITE

A. A. Churm

DOE Patent Division

9300 S. Cass Avenue

Argonne, IL 60439

DOE Div. Pollutant Charac-

terization and Safety Rsearch

Robert Wood

27 DOE Technical Information

Center

ONSITE

DOE Richland Operations Office
No. of

Copies

Pacific Northwest Laboratory

39 N. E. Ballou

S. R. Bierman

E. D. Clayton

W. D. Felix

D. E. Friar

G. R. Gallagher

R. J. $\mathrm{Ha} 11$

H. L. Henry

J. J. Jeck

L. J. Kirby

H. V. Larson

R. C. Lloyd

J. M. Nielsen

R. W. Perkins

C. R. Richey (4)

H. G. Rieck (10)

P. I. Reeder

W. D. Richmond

E. I. Nandling

N. A. Wogman

Technical Information (5)

Publishing Coordination (2) 


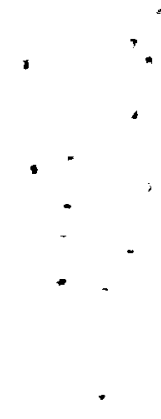

- 